\title{
The Integration of a Coal Mine Emergency Communication Network into Pre-Mine Planning and Development
}

\author{
Mark F. Sindelar \\ West Virginia University
}

Follow this and additional works at: https://researchrepository.wvu.edu/etd

\section{Recommended Citation}

Sindelar, Mark F., "The Integration of a Coal Mine Emergency Communication Network into Pre-Mine Planning and Development" (2013). Graduate Theses, Dissertations, and Problem Reports. 174. https://researchrepository.wvu.edu/etd/174

This Thesis is protected by copyright and/or related rights. It has been brought to you by the The Research Repository @ WVU with permission from the rights-holder(s). You are free to use this Thesis in any way that is permitted by the copyright and related rights legislation that applies to your use. For other uses you must obtain permission from the rights-holder(s) directly, unless additional rights are indicated by a Creative Commons license in the record and/ or on the work itself. This Thesis has been accepted for inclusion in WVU Graduate Theses, Dissertations, and Problem Reports collection by an authorized administrator of The Research Repository @ WVU. For more information, please contact researchrepository@mail.wvu.edu. 


\title{
The Integration of a Coal Mine Emergency Communication Network into Pre-Mine Planning and Development
}

\author{
Mark F. Sindelar \\ Thesis submitted to the \\ Benjamin M. Statler College of Engineering and Mineral Resources \\ at West Virginia University \\ in partial fulfillment of the requirements \\ for the degree of \\ Master of Science \\ in \\ Mining Engineering
}

\author{
Christopher J. Bise, Ph.D., Chair \\ Keith A. Heasley, Ph.D. \\ Brijes Mishra, Ph.D. \\ Department of Mining Engineering
}

\section{Joe Andrews}

Senior Geologist, Ark Land Company

Morgantown, West Virginia

2013

Keywords: Communication; Exploration; Borehole

Copyright 2013 Mark F. Sindelar 


\begin{abstract}
The Integration of a Coal Mine Emergency Communication Network into Pre-Mine Planning and Development
\end{abstract}

Mark F. Sindelar

Regulations, such as the MINER Act of 2006, require the installation of redundant and secondary communication systems to assure that contact can be established with coal miners who may become trapped underground as a result of an event such as a fire, explosion, or inundation. For half a century, the orientation towards underground communications has been that more complex systems better serve the coal miner. However, if the goal is to provide for a reliable means of establishing communication between the surface and trapped miners underground, then the technology employed should be simple, reliable, and cost-effective. Coal mines spend hundreds of thousands of dollars on exploratory drillholes to characterize reserves, sometimes decades ahead of mine development. During the pre-planning phases, certain exploratory drillholes could be located and then outfitted with a simple communication link which would remain compatible even with the continuing evolution of communication systems. These links, whose locations would be accurately recorded, would be exposed by continuous miners during mine development thereby allowing an underground phone to be connected to a surface station in the event of an emergency. A latent network of these communication links could be installed for less than $\$ 500$ each, without affecting drilling and grouting operations, and could be designed to be compatible with several communication systems as well as meeting MSHA and State requirements. This thesis examines appropriate methods and materials for incorporating an embedded communication link during pre-mine exploration drilling and addresses significant factors affecting its implementation. A design based on the research is presented. 


\section{Acknowledgements}

I would like to thank my advisor, Dr. Christopher J. Bise, not only for suggesting this topic but also for his guidance as I made the transition to mining after 20 years in the metals industry, and the West Virginia Coal and Energy Research Bureau for their financial support on this project. Additional support and advice has been, and continues to be, provided by my committee members, Dr. Keith Heasley, Dr. Brijes Mishra, and Mr. Joe Andrews. Throughout this research, Dr. Heasley provided good feedback on the feasibility of various materials and assemblies. Dr. Mishra was instrumental in assisting with the laboratory tests and extremely patient with the dust it created. Mr. Andrews, Senior Geologist at Ark Land Company, provided access to field drilling procedures and provided essential information from his industry experience.

In addition to my committee, I also thank Karen Centofanti and Karla Vaughn in the Department of Mining Engineering for their assistance with materials procurement and for their encouragement. The Interlibrary Loan Department at West Virginia University, including Beth Royall and David Bell, assisted with obtaining sometimes rather obscure sources that contributed to the research.

I also thank a very select group of electricians (who wished to remain anonymous) with whom I worked in a coal mine in Pennsylvania. These electricians, understanding the objectives of my research, provided pertinent anecdotal information from their experiences and also spent much time searching the mine with me for evidence of exploration boreholes.

Finally, I thank my wife, Dr. Jennifer E. Sindelar, for her encouragement and support, especially during the tumultuous period when I walked out of the steel mill and into the coal mine. 


\section{Table of Contents}

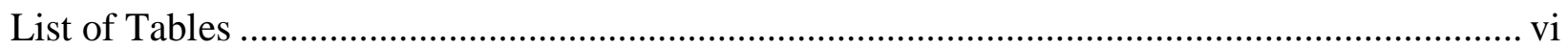

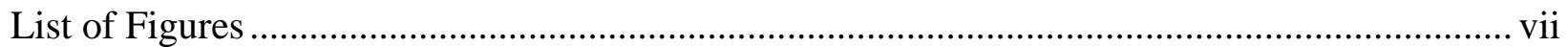

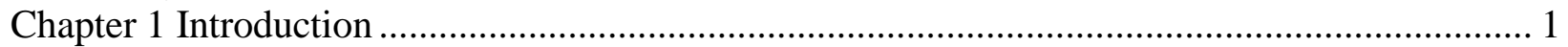

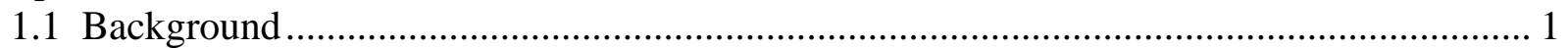

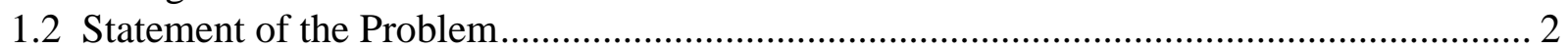

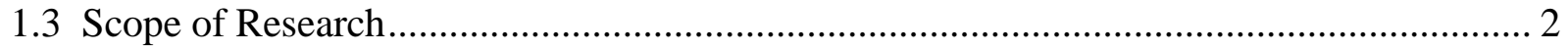

1.4 Organization of this Thesis ...................................................................................... 5

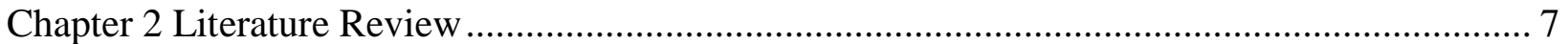

2.1 Concepts for Similar Communication Networks ………................................................ 7

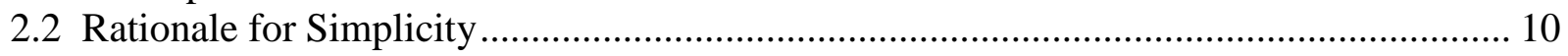

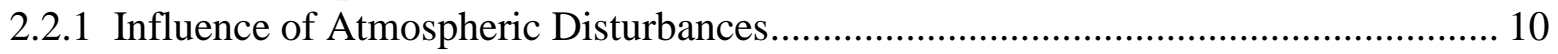

2.2.2 Human Behavior and Communication Systems .................................................... 11

2.2.3 Statistics on the Failure of System Components....................................................... 12

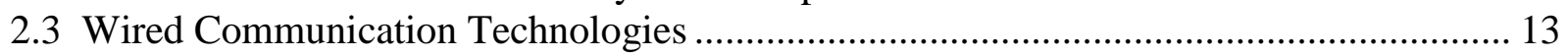

2.3.1 Traditional Mine Telephones ................................................................................... 14

2.3.2 Sound-powered Phones....................................................................................... 15

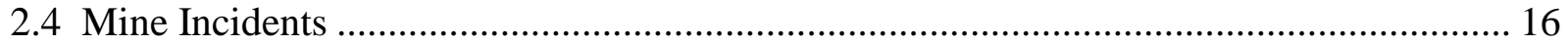

2.4.1 Quecreek Mine................................................................................................... 16

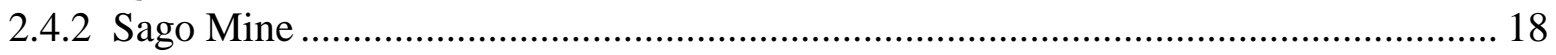

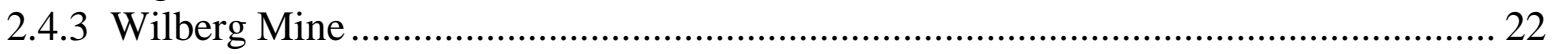

2.4.4 Mountaineer Alma A Mine ………………….............................................. 25

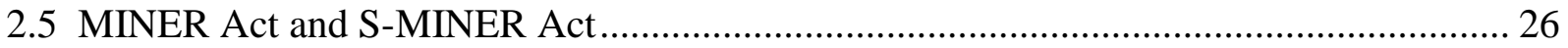

Chapter 3 Design for Mine Pre-Planning and Development ……………………..................... 29

3.1 Concept of Establishing a Surface to Underground Link ................................................ 29

3.2 Location of Drillholes During Mine Pre-Planning .......................................................... 34

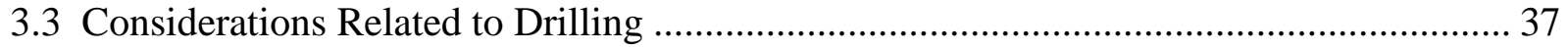

3.3.2 Accuracy of the Drilling, from Aboveground............................................................. 37

3.3.2 Derivation of Drilling Equation .................................................................................. 43

3.3.3 Location of the Device, Underground ………........................................................ 53

3.4 Considerations Related to Grouting .............................................................................. 54

3.4.1 Field Observations of Contemporary Grouting Procedure ......................................... 54

3.4.2 Identification of the Hole, from Underground ........................................................ 55

3.5 Recommended Process for Installing Drillhole Communication Link ………………....... 57

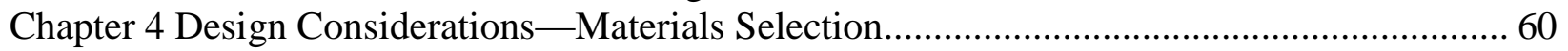

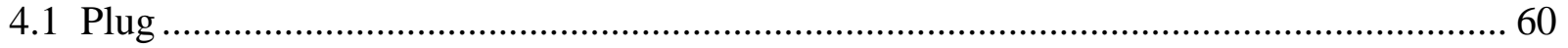

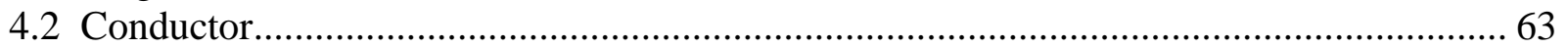

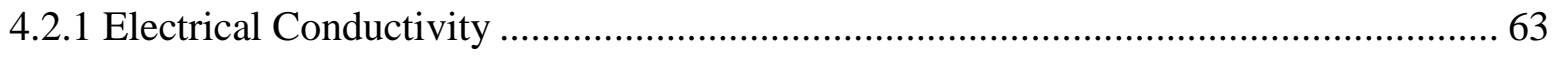

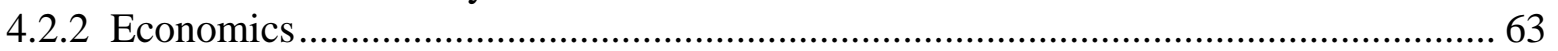

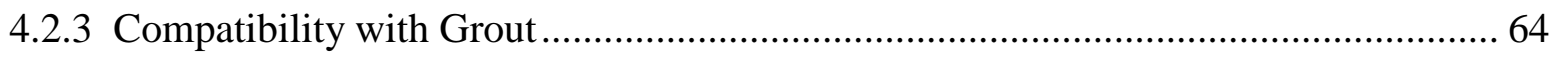

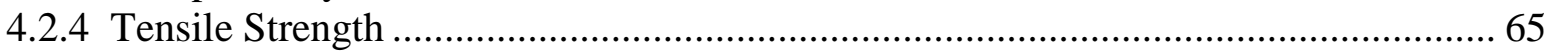

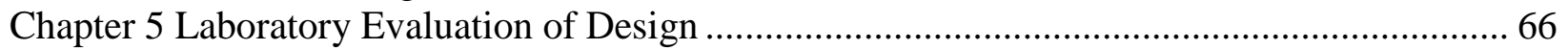

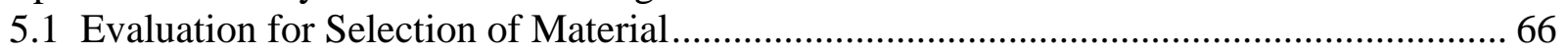

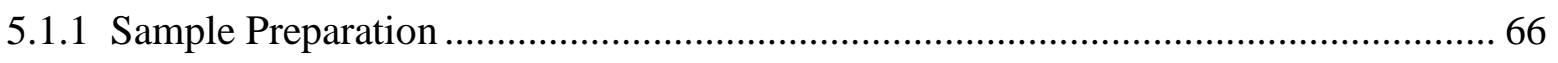




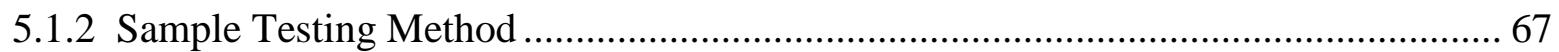

5.2 Evaluation of Conductor Configuration ................................................................. 77

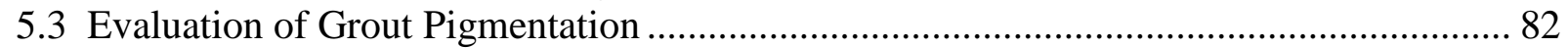

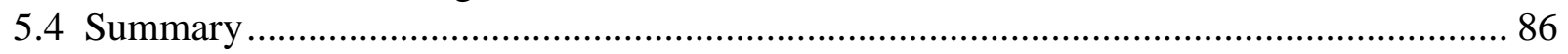

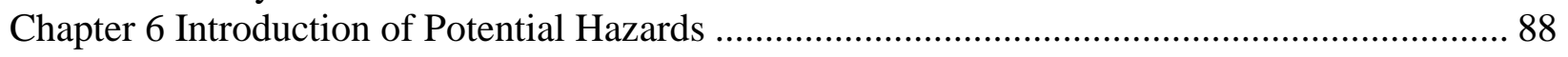

6.1 Lightning and Underground Workings ............................................................... 88

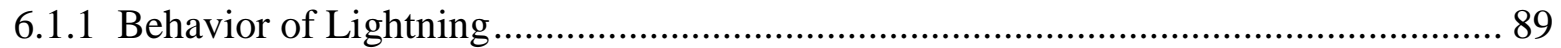

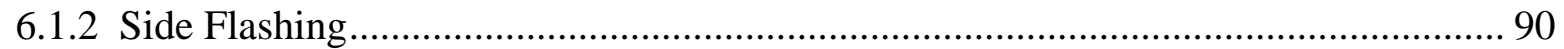

6.1.3 Examples of Lightning Effects on Underground Workings ................................. 91

6.1.4 Lightning Protection Considerations for Mine Electrical Systems .......................... 94

6.2 Evaluation of Drillhole Communication Link for Lightning Hazards .......................... 96

6.2.1 Probability of Lightning Directly Striking Drillhole ............................................ 97

6.2.2 Electrical Properties of Grout .......................................................................... 102

6.3 Mining Regulations...................................................................................... 103

Chapter 7 Summary, Conclusions, and Areas of Future Research ...................................... 105

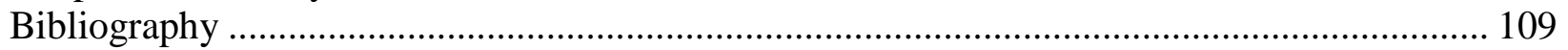

Appendix A: Data Tables from Shear Load Tests ............................................................ 116

Appendix B: Instructions for Borehole Grout Pigment Experiment ..................................... 118

Appendix C: Grout Pigment Experiment Data ............................................................... 119 


\section{List of Tables}

Table 3.1: Maximum angular deflection as a function of overburden depth, 400-1300 feet, based on the intersections formed by entries of nominal 20 -foot width.......................... 40

Table 3.2: Input values for calculation of Ratio indicating expected value of drillhole intersecting an open area of an entry, depending on deviation of drill rig, overburden, and entry width.

Table 4.1: Comparison between steel and copper wires (data from Fink \& Beaty).................. 63

Table 4.2: Rated breaking strengths for copper wire compared with 3/32" wire rope (Fink \&

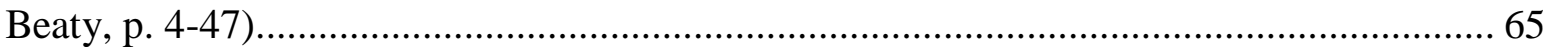

Table 5.1: Count data for borehole grout pigment experiment............................................... 85

Table 5.2: Transition probabilities between categorical variables.......................................... 87

Table A-1: Experimental Data from Shear Testing for Material Selection...................115

Table A-2: Experimental Data from Shear Testing for Configuration Evaluation..............116

Table C-1: Raw Data Collected for Borehole Grout Pigment Experiment...................118 


\section{List of Figures}

Figure 1.1: Exploration boreholes for an underground coal seam........................................... 3

Figure 2.1: Corehole phone system (from Parkinson, 1972, p. 7) ........................................... 9

Figure 2.2: Looped Phone System (from Parkinson, 1972, p. 4)............................................. 13

Figure 2.3: Plan view of Quecreek Mine (Brady et al., 2003).............................................. 17

Figure 2.4: Elevation view Quecreek Mine (Brady et al., 2003)........................................... 18

Figure 2.5: Overall mine map of Sago Mine (Gates et al., 2007) .......................................... 20

Figure 2.6: Areas of Sago Mine where miners barricaded (Gates et al., 2007)......................... 21

Figure 2.7: Wilberg Mine, Location of Victims (Huntley et al., 1985)..................................... 23

Figure 2.8: Wilberg Mine map with three possible locations of exploration boreholes along the

intake (illustration modified, from Huntley et al., 1985)................................................ 24

Figure 2.9: Flooded area of Mountaineer Alma A Mine (Bentley et al., 2009)....................... 25

Figure 3.1: Basic concept of underground to surface communication using a drillhole, with

primary communication system damaged by roof fall or similar event. ........................... 30

Figure 3.2: Depiction of continuous miner in coal seam prior to intersecting drillhole communication link. Drawing is to scale and represents an 8-foot coal seam with a 3-inch diameter drillhole extending approximately 7 feet below the bottom of the coal seam...... 31

Figure 3.3: Suggested method of protection for surface elevation wires of communication link

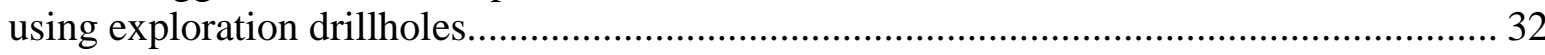

Figure 3.4: Alternate suggestion for top termination of drillhole communication link when top elevation of device must be placed significantly below grade. ....................................... 33

Figure 3.5: Exploration boreholes over a coal reserve. ......................................................... 34

Figure 3.6: Proposed entries along paths that intersect exploration boreholes......................... 35

Figure 3.7: Drillhole communication link wires connected to mine telephone system and refuge

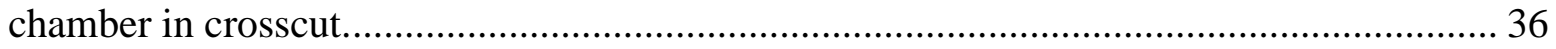

Figure 3.8: For calculation of maximum allowable angular deflection from vertical................ 39 Figure 3.9: Maximum deviation from vertical for an exploration drillhole rig to be able to intersect a 20-ft. x 20-ft. intersection, as a function of overburden depth. ....................... 41

Figure 3.10: Drilling deviation radius with relation to underground intersection..................... 43

Figure 3.11: Three areas used for calculation of open workings........................................ 44

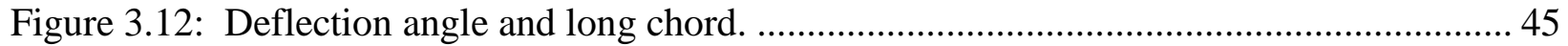

Figure 3.13: Likelihood of intersecting open area vs. overburden, 0.5-8.5 degrees deviation, 16

ft. entry.

Figure 3.14: Likelihood of intersecting open area vs. overburden, 0.5-8.5 degrees deviation, 18 ft. entry.

Figure 3.15: Likelihood of intersecting open area vs. overburden, 0.5-8.5 degrees deviation, 20 ft. entry.

Figure 3.16: Likelihood of intersecting open area vs. overburden, 0.5-8.5 degrees deviation, 22

ft. entry.

Figure 3.17: Original concept sketch depicting a "plug" delivered to the bottom of the drillhole

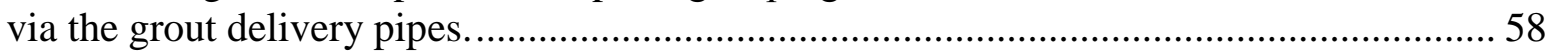

Figure 3.18: Original concept sketch for feeding of communication conductors..................... 59

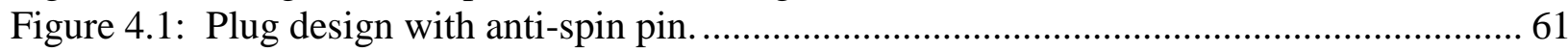

Figure 4.2: Plug with anti-spin pin on end of grout delivery pipe inside drillhole.................... 62 
Figure 5.1: Direct shear testing device. Hydraulic press for normal load on top right (white) and

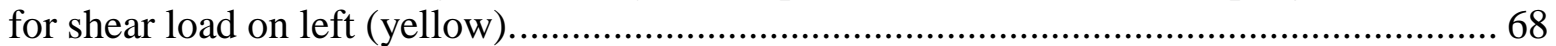

Figure 5.2: Sample A05 Post-Test. Lean grout without embedments. ..................................... 70

Figure 5.3: Sample B05 Post-Test. Fractures propagating along embedments....................... 71

Figure 5.4: Sample B01 Post-Test. Fractures propagating along embedments....................... 71

Figure 5.5: Sample C03 Post-Test. Embedments solid with fracture confined to plane of shear

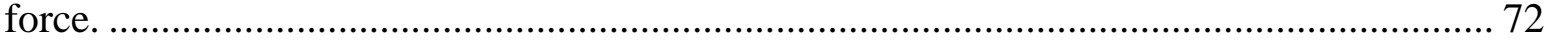

Figure 5.6: Sample C05 Post-Test. Shattering around embedments. ..................................... 72

Figure 5.7: Sample D05 Post-Test. Top of sample to right. ............................................... 73

Figure 5.8: Sample E05 Post-Test. Before removal from platen. Shows structure of fracture. 74

Figure 5.9: Sample E01 Post-Test. Fracture along plane of direct shear load........................ 74

Figure 5.10: Sample E05 Post-Test, after displacement pull ............................................ 75

Figure 5.11: Sample F04 Post-Test. Angular cracks from plane of direct shear load. .............. 76

Figure 5.12: Sample F06 Post-Test. On displacement pull, exposed copper wires can make

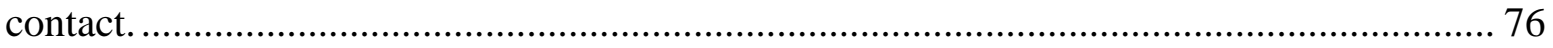

Figure 5.13: Two-, three-, and four-wire configurations. ................................................ 77

Figure 5.14: Two-, Three-, and Four-Wire configurations with stabilizers to maintain separation

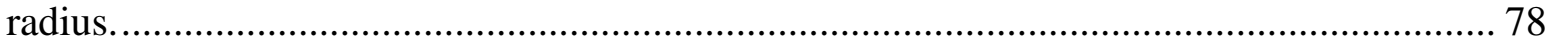

Figure 5.15: Sample G04 Post-test. Wires stripped but are not in contact on displacement..... 79

Figure 5.16: Sample J03 Post-test. Note also breakout wedge on left (top of sample). ............ 80

Figure 5.17: Sample H02 Post-test. Typical result for the square configuration...................... 81

Figure 5.18: Sample H04 Post-test. Two wires were found to be in contact (note that some separation resulted on removing samples from platens) ........................................ 81

Figure 5.19: Pigmented grout samples in simulated coal face ......................................... 83

Figure 5.20: Model with dark background to simulate coal. ............................................... 83

Figure 5.21: Pigmented grout samples in simulated coal face with rock dust or light-colored rock.

Figure 5.22: Model with light background to simulate coal with rock dust or light-colored rock.

Figure 6.1: Basic Positive and Negative Lightning Waveforms (Higgins and Morris, 2006, p. 49).

Figure 6.2: Example of side flashing to residential structure (scale approximate). Adapted from illustration in Golde (1975) illustrating phenomenon documented by Müller-Hillebrand (1957). Lightning current follows the path marked by large arrows.

Figure 6.3: Example of ground currents surrounding a mine entry. Adapted from Golde (1975).

Figure 6.4: "Protective zone" for vertical lightning rod (left) adapted from Golde (1973) and "attraction zone" for high voltage utility lines (right) adapted from IEEE Standard 14102004.

Figure 6.5: "Attractive Radius" for lightning rod when analysis is performed underground.... 100 Figure 7.1: 36" Model of Borehole Communication Link with pigmented grout and four conductors. 


\section{Chapter 1 Introduction}

\subsection{Background}

The improvement of communication in underground coal mines has always been an important objective. Despite the fact that fatalities are at record low levels, serious incidents have occurred, such as those at Crandall Canyon, Sago, and Upper Big Branch. A common denominator in all instances is the post-incident ability to locate and track the movement of miners that are underground. Roof falls, explosions, fires, and inundation frequently compromise the traditional communication systems that exist between the working face and the surface (Dobroski and Durkin, 1980). Four incidents, contrasted and compared, highlight these issues.

The incident at the Quecreek Mine in 2002 provides proof of the ability to rescue coal miners via a drillhole and rescue capsule when their location was accurately determined. This could not be accomplished through the use of the mine's communication network, which was damaged by the event. The breach into the adjacent, abandoned Harrison Mine and subsequent inundation occurred at the bottom of the section being mined. Since this section had a slightly inclined seam, there was only one probable location where the miners could have sought refuge - the highest elevation in that section. That the miners could be accurately located at the Quecreek mine resulted directly from the configuration of the mine providing a single location where the miners could have survived.

When an inundation of storm water occurred at the Mountaineer Alma A Mine in 2009, miners were entrapped for 24 hours. However, unlike Quecreek, an intact mine phone system allowed communication with the surface and they remained in a safe location until the water was pumped down and all were able to walk out.

Conversely, other incidents have had unfavorable outcomes and illustrate the difficulties associated with identifying the location of miners post-incident. When an emergency renders traditional communication lines inoperative, communicating with trapped miners becomes difficult, if not impossible. This difficulty can be exacerbated when the miners are moving about the mine, whether unaware of the situation or actively attempting to escape.

At Sago Mine in 2006, after an initial explosion, some coal miners moved inby and barricaded. There was no communication with the surface as to their whereabouts. However, unlike Quecreek, the physical characteristics of the mine provided multiple options for the miners seeking refuge. A drillhole bored as part of the rescue attempt did not enter the mine in the location where the entrapped miners had barricaded. Inability to quickly and positively locate the miners resulted in all but one succumbing to carbon monoxide poisoning.

Earlier, in 1984 at the Wilberg Mine, an even more complicated scenario transpired after a fire disabled the traditional mine communication systems. Attempting to escape the fire, 
personnel travelled in various directions based on their initial location, perception of the situation, and physical fortitude. Victims were distributed over a wide area, including both the headgate and tailgate entries and in the bleeder. Their locations were not known until after the mine was re-entered following the initial sealing to extinguish the fire.

Catastrophic events bring renewed interest in the improvement of underground-to-surface communications in the event of an emergency. In the wake of the events at Sago, several broad recommendations were made, including improvements to communication systems to increase the ability to locate trapped miners and the establishment of underground refuge shelters (McAteer et al., 2009). Many of these were incorporated in the Mine Improvement and New Emergency Response Act of 2006, also known as the MINER Act, which amends the Federal Mine Safety and Health Act of 1977. Some of the these recommendations, unfortunately, were not realistic given the existing state of the technology, such as the requirement to install wireless two-way communications between the surface and underground - a technology that, despite half a century of research, was still not available four years after the Sago incident (Ward, 2010a). Furthermore, there are no requirements or guarantees that such systems would be functional following an explosion, a fire, an inundation, or a roof fall.

\subsection{Statement of the Problem}

That the communication focus of the MINER Act is myopically restricted to redundancy of communication systems within the mine and/or underdeveloped wireless technologies presents the opportunity to provide a practical standalone approach towards low-cost communication with trapped miners. The elements of this standalone back-up system must be relatively impervious to damage by explosion and integrated into a strategy that is developed during the mine pre-planning phases. Such a back-up system must be able to provide the option of future communication with underground miners in the event of an emergency situation that compromises the traditional and redundant systems. Furthermore, the philosophy underlying the development of such communications must incorporate the idea that miners may not be stationary underground but may be moving, whether in a group or individually.

\subsection{Scope of Research}

Mining companies invest hundreds of thousands of dollars on exploratory drilling which is a fundamental element of mine pre-planning. Often using a grid pattern with approximate half-mile centers, drillholes are made through the depth of the reserves to determine roof conditions, seam thickness, floor conditions, and coal characteristics. These point observations

are then analyzed using a variety of methods. The drillholes are then fully grouted and sealed to prevent water and/or methane from gathering in the hole and, subsequently, the developed mine. Figure 1.1 illustrates this concept. 


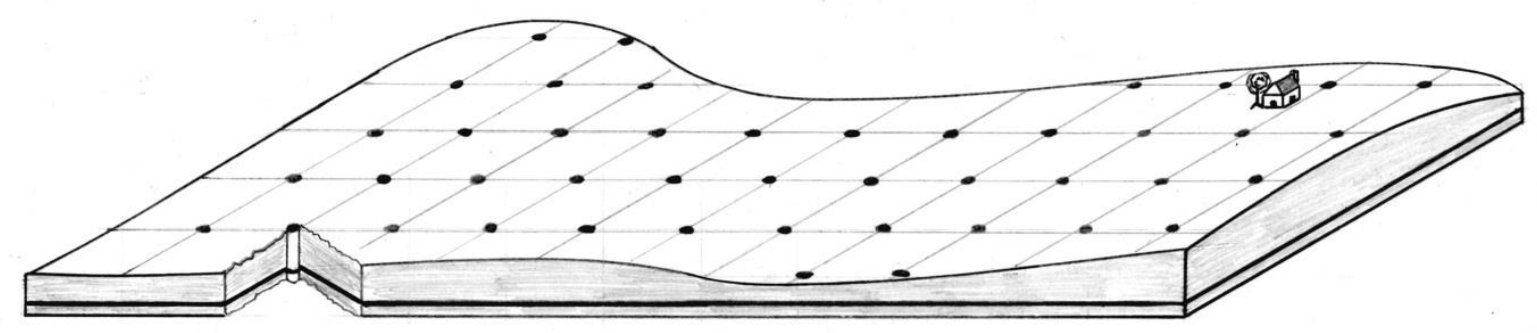

Figure 1.1: Exploration boreholes for an underground coal seam.

This project investigates a secondary, beneficial use of these drillholes by exploiting them as a communication conduit between the developed mine and the surface. While sealing the drillholes, consider if conductors are embedded within the grout. Later, when a continuous miner intersects such a drillhole during mine development, the communication link is exposed. This link to the surface could either be connected into the existing mine phone system, could be left unconnected for future use, or could be established as a standalone line dedicated at that location.

On the surface, the exploratory drillholes clearly marked on survey maps would have the communication links recessed below grade to protect the embedded conductors until they were needed. Then, the top of this assembly would be exposed when it is desired to establish the communication underground. In the event that the primary underground communication system is compromised during an emergency situation this link would provide a method to contact miners trapped inby an event either via a one-to-one dedicated communication link or via connection to the undamaged portion of the mine phone system. Similar to the emergency phones located along a highway, miners in transit could "check-in" with the surface as they make egress, providing critical information about their locations and gaining valuable information about mine-wide emergency conditions.

To be cost effective, a latent network of drillholes outfitted with drillhole communication links should require minimal investment in materials and be implemented without making any major changes to the existing methods of drilling and grouting of the hole. Such a network of drillhole communication links must not increase underground hazards. Surface lightning strikes and associated electrical phenomena should not jeopardize the safety of the underground coal mine. The design should be, except for very simple adaptations, compliant with MSHA and state mining regulations.

This research investigates the concept of a secondary, beneficial use of selected exploration boreholes as emergency communication links. Several new concepts are introduced. First, while the implementation of surface to underground links via boreholes is not new, the exploitation of exploration boreholes to create a latent network of communication links-as opposed to making attempts to connect one or two to a larger system — seeks an economic 
advantage by using holes that are already planned. By developing the drilling scheme with an orientation to outfitting the boreholes with low-cost communication links (which may or may not be utilized in the future), the mine operator would create a dependable communication option to contact coal miners who may become trapped inby due to a rock fall, inundation, or fire, each of which has different implications and effects. Second, the prevailing perspective for use of boreholes for communication links has been that the boreholes would be usually be larger, open, and encased. The research presented herein suggests that an embedded conductor could be selected such that there is compatibility with contemporary grouting practice and that the conductors themselves can be designed to be resilient to overburden movement while still being capable of being cut in shear as a continuous miner develops the entries through them. Furthermore, elimination of a metallic casing is believed to greatly reduce the potential hazards associated with lightning or similar electrical events.

In addition, this research takes the position that exploration boreholes, properly surveyed, drilled, and mapped, are at known locations that can be immediately accessed in the event of an incident versus the more time-consuming procedure of determining where boreholes might be drilled to establish communications and then doing so. Finding the established surface locations of previously mapped boreholes can employ more traditional surveying methods that do not depend on technologies such as global positioning systems (GPS) which may be compromised by certain weather events. This reduces uncertainty, which is already significant during an incident.

Underground, the final location of the borehole with respect to the workings is explored. The question of the effect of drill rig deviation on the ability to effectively intersect (planned) open workings is analyzed as a design element which must be considered during the mine planning phase. The diamond drill rigs used to retrieve core samples are notorious for deviation. A deviation analysis suggests the recommendation for a down-the-hole sensor to accurately map the exploration hole location.

During mine development, the identification of previously placed communication links formed by embedments in exploration boreholes can be aided by the introduction of pigment to the grout. This concept looks at reflected light against coal and rock dust backgrounds, versus more traditional research into projected and emitted light recognition in open, underground workings.

Possible interaction effects between a surface-to-underground conductor and lightning flashes are addressed and the probability of a direct lightning strike to such an installation is shown to be no more frequent than once every 10,000 years which is commensurate with the possibility of lightning hazards that may be introduced by any surface-to-mine path capable of conducting energy.

A design has been developed for an exploration borehole communication link using embedded conductors, with pigmented grout at the elevation where workings are expected, following the recommendations suggested by the research. This includes the method of installation and appropriate materials for the design itself. 


\subsection{Organization of this Thesis}

The Literature Review, Chapter 2, starts with more detailed information about the incidents at Quecreek, Sago, Wilberg, and Mountaineer Alma A. These summaries not only illustrate the complexities of post-incident communication with underground miners, but also provide additional information about factors germane to the secondary use of exploration boreholes as a possible communication link between the surface and underground. One of these factors, the influence of lightning on any link between underground workings and the surface, is explored more in Chapter 6. Requirements of the MINER Act and S-MINER Act are reviewed, showing that the secondary use of exploration boreholes for emergency communication links could provide a cost effective communication option that was not considered by the legislation.

Previous research, or mention, of communication links incorporating boreholes is then presented, with some background as to why this concept has received only marginal interest in the past. This is followed by rationale for installing simple, standalone, links to form a latent network instead of immediately incorporating them into the larger, general mine communication network. Typical components which would interface with a simple link through an exploration borehole are then described, with the caveat that developing technologies would also be compatible.

Chapter 3 addresses this endeavor by defining a specification for the secondary use of exploration boreholes to establish a surface-to-underground link that can be activated in the event of an emergency. During the mine pre-planning phase, the drillholes must be located so as to be usable for this secondary purpose. However, it is known that core drills typically do not drill perfectly vertical holes, so mitigation factors are considered. An analysis is presented that relates the probability of intersecting planned workings as a function of overburden depth, entry width, and drill rig deviation. The grouting procedure is reviewed with the objective of minimizing interference with the contemporary process when outfitting an exploration borehole for communication purposes.

Possible materials and designs for outfitting an exploration borehole for secondary communication use are then considered in Chapter 4, with laboratory evaluation indicated. The design and materials are considered based on cost-effectiveness combined with the desire to not introduce additional hazards_-primarily those associated with lightning events — while meeting mechanical resiliency for the installation.

Elements of the design are then subjected to a laboratory evaluation in Chapter 5. Three phases of laboratory tests were performed. The first round considered the type and general configuration of conductor to be embedded in grout in the exploration borehole. The second round, based on the results of the first, considers the effects of placing additional conductors into the grout assembly. The third round is a color diagnosticity experiment to determine if the addition of pigment to the grout would improve its recognition underground.

Chapter 6 reviews lightning phenomena and considers the likelihood of a direct lightning strike to a borehole communication link. Mine-related lightning incidents are presented and the applicability of conventional surface lightning protection methods is called into question as it 
relates to attempts to protect a subgrade communication link in a borehole. Despite these concerns, how this design may still comply with existing regulatory requirements is then described.

Chapter 7 then presents the initial design suggested for a proof-of-concept field investigation with the caveat that an extensive study of the interaction effects of such a device with lightning strikes be performed prior to any such field test at an active coal mine site. 


\section{Chapter 2 Literature Review}

The motivation for this research is presented twice within the Literature Review. Initially, in Section 2.1, this motivation arises from previous studies, suggestions, and regulations proposing the concept of using an exploration borehole, or variants thereof, for a communication link. Often, these ideas were not conceived to be solely for emergency communication. Later, in Section 2.4, four cases of actual mine emergencies are presented which illustrate the critical nature of establishing voice communication with coal miners who may become trapped underground.

Prior to evaluating the four case studies, however, Sections 2.2 and 2.3 provide information on parsimonious system design and contemporary wired communication options that are relevant to the case studies and, therefore, provide a foundation on which the case studies can be better analyzed. The information presented in the case studies will then be revisited in later chapters where certain elements therefrom are applicable.

The first case study is the rescue of nine miners from the Quecreek Mine (2002) where they were trapped inby due to inundation. Although communication was lost, the location of the miners could be deduced from the physical characteristics of the mine. This is contrasted with the second case study, Sago Mine (2006), in which communication was lost and the location of the trapped miners was not known. The Wilberg Mine fire (1984) where 29 lost their lives scattered throughout a wide area around a longwall panel, illustrates a scenario in which miners were mobile during the event and communication about their locations was not available. The fourth case study, the Mountaineer Alma A Mine (2009) describes entrapment by inundation but differs from Quecreek inasmuch as communication was not lost and the miners stayed in a known location until the water was pumped down and they could safely walk out 24 hours later.

While all the scenarios illustrate entrapment conditions where communication could possibly have been aided by the installation of a secondary communication device using exploratory drillholes, the Sago case also contains information regarding lightning events that were thought to have contributed to a methane-air ignition and are the motivation for the discussions of Chapter 6.

The Literature Review concludes with the MINER Act and proposed S-MINER Act to demonstrate that the establishment of a network of readily available communication links via exploratory drillholes provides a cost-effective method of providing contact with trapped miners, post-incident, that was not explicitly considered by the Acts themselves.

\subsection{Concepts for Similar Communication Networks}

The idea to use any type of borehole as a part of a communication system has been explored in the past. However, scope creep often occurred thereby pushing the concept well beyond the development of a scheme that is cost-effective for emergency use. Conversely, it was often mentioned in publications as an option but subsequently never developed. The 
objective was generally that described in a NIOSH report titled "Communication Systems Research at Bruceton Safety Research Mine." This report states, "To maintain safe operating practices, general mine communications must encompass post-disaster rescuing, environment monitoring, and day-to-day operating communications as an integrated whole" (Parkinson, 1972, p. 2). The suggested implementation method was to create a loop communication system whereby the phone line formed a loop by entering the shaft, extending down the entries, and finally returning overland to the dispatcher phone located atop the shaft. Then, in the event of an emergency, the underground line would be "switched to the overland line." A selective pathing variant was also suggested, whereby the aforementioned loop communication system could be coupled to the trolley line in mines so equipped. The possibility of such an arrangement introducing potential hazards to the mining environment was not mentioned. After these two suggestions, which would employ boreholes, albeit not necessarily exploration drillholes, it was stated, "Looping and selective pathing are things that can be done. However, other experimental activities also have immediate promise" (italics from original, Parkinson, p. 5). Most of the focus then turns towards a variety of significantly more complicated types of communication systems, many using radio frequency transmissions of various configurations for which the technology is still not mature.

Interestingly, the exploitation of an exploration drillhole for an emergency telephone connection is explicitly mentioned on page seven of the same NIOSH report. In its entirety, it says:

Many mines have exploration core holes. A telephone cable has been inserted in the core hole, and a quick-open enclosure located in the mine houses a standard sound-powered telephone. A junction box with a plug-in receptacle for a sound-powered handset is located on the surface. An explosion evaluation must be made in the Experimental Mine and the system checked for functioning after the explosion.

This is illustrated in Figure 2.1. It is assumed that this concept was not explored much further due to the aforementioned stated objective of creating a comprehensive communication system. In addition, this report and the Foster-Wilson (1983) report assume open boreholes for the communication link which differs from the perspective taken with using exploration boreholes that are backfilled with grout. Also, possible hazards associated with the use of boreholes were not addressed by these reports, although they were occasionally mentioned. The research herein provides a communication link where some of the perceived hazards are eliminated, others can be shown to be no more likely than a random event, and still others must be addressed by significant additional research.

A similar concept to Foster-Wilson was explored earlier by Murphy and Parkinson (1978) which envisioned using boreholes, although their perspective was oriented more towards ventilation shafts or larger openings. Again, the idea was to create a comprehensive system with an overland loop - in this case using a transmitted radio signal. Selective path coupling would tie the radio systems, pager phone systems, and trolley phone systems together to create a massive communication network which, in a roundabout way, they hinted may create complexities that would expose the system to too many vulnerabilities and render it less reliable (p. 47). 


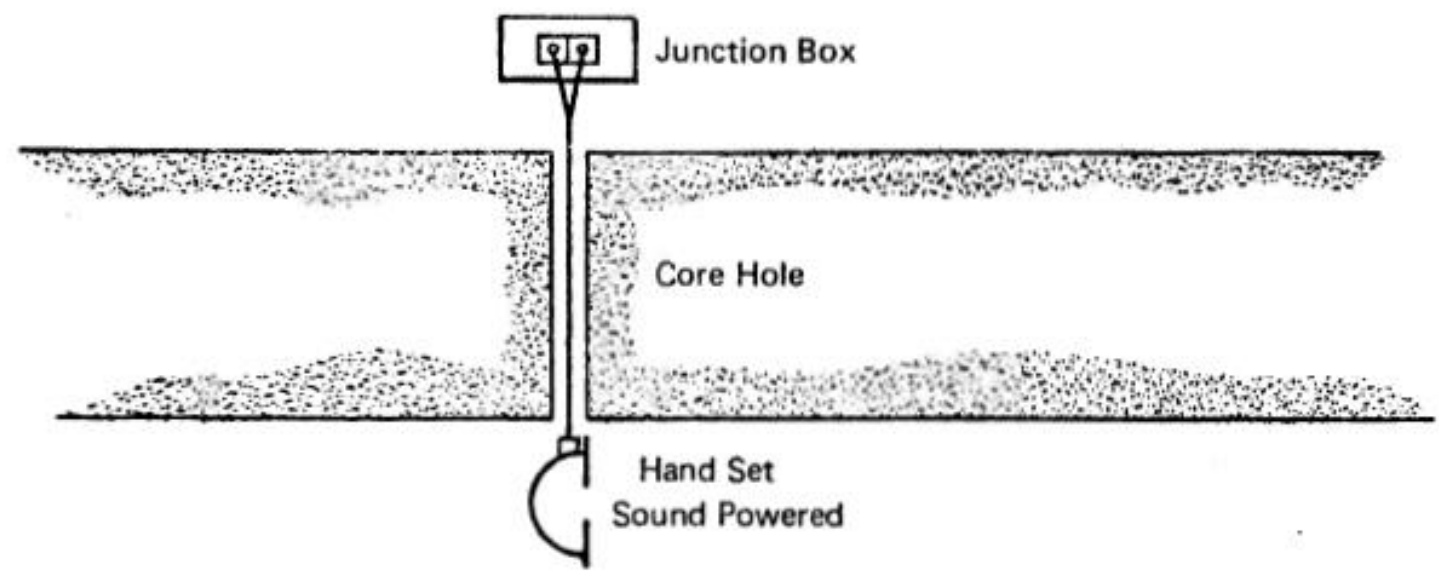

Figure 2.1: Corehole phone system (from Parkinson, 1972, p. 7).

The orientation taken by the research project herein is creation of secondary communication channels that are normally not necessarily connected to the main communication system, but can be quickly activated in the event of an emergency. This orientation draws its perspective from a white paper by Bise (2008) which says, “. . . a strategy must be developed to enable better communication between trapped miners and their rescuers if conventional communication systems are compromised because of the emergency situation. Preferably, the strategy should be established long before the mines are actually developed."

Bise recognized that the exploratory boreholes could provide a cost-effective solution to developing a network of communication links. His concept incorporated a "communication capsule" that would contain a coiled communication cable at the mine elevation of the drillhole, secured by approximately eight feet of packing material. When intersected by the continuous miner, this packing would be exposed and removed allowing access to the communication cable that was linked to the surface through the drillhole. The design developed in Sections 3-5 capitalizes on this concept with adaptations to further reduce cost, increase compatibility with existing grouting processes and provide for theoretical indifference to lightning events.

It cannot be overemphasized that, in an era when wireless technologies are receiving much attention, the problem of emergency underground-to-surface communication is still well served via physical connections due to the inherent issues with signal propagation combined with a need for clear voice communication. Note that research into through-the-earth communication and into the atomic bomb were concurrent topics of intensive effort during World War II; sixty years later, the success story has been the vast selection of nuclear weapons and not through-theearth communication. The utilization of drillholes as a conduit for the physical media seeks to utilize mature, cost-effective technologies that are well-understood to improve the safety of underground coal miners in West Virginia and the nation. The technology utilized is intentionally simple to allow cost-effective adaptation to any type of communication network that currently is, or may become, available. 


\subsection{Rationale for Simplicity}

Cost is, perhaps, the most notable feature of a simple communication link that interfaces with a larger network. The ability to be compatible with emerging technologies is likely the second. However, additional justifications can be found in other areas. These include such disparate categories as atmospheric disturbances, human behaviors, and reliability statistics, which are the described in Sections 2.2.1 through 2.2.3.

\subsubsection{Influence of Atmospheric Disturbances}

Weather conditions greatly reduced the effectiveness of global positioning system (GPS) devices during the rescue efforts at Sago as will be described in Section 2.4.2. Another weather phenomenon that has not received much attention from the mining community is the influence of solar flares, which can have a drastic effect on the reliability of GPS satellites. For most aboveground mine surveying situations, a weather delay is not a major issue (an inconvenience, perhaps) but mine emergencies do not wait to be rescheduled. While, at first glance, it may seem trivial to consider solar flares, to do so would be to discredit the influence of all weather-related events, including lightning strikes which are the subject of Chapter 6 .

The phenomenon of solar flares affecting a mine rescue attempt, while seemingly remote, is possible. A report issued by the National Academy of Sciences, and funded by the National Aeronautics and Space Administration, paints a bleak picture of the damage to modern electrical infrastructure which could result from solar distubances (Brooks, 2009). The best-known event in recorded history is the so-called "Carrington event" of 1859, the magnitude of which could have the effect of disabling some 80 earth-orbiting satellites, especially those functions related to GPS (Irion, 2011; Rodger et al., 2008). A solar proton event (SPE), one-quarter the size of the Carrington event occurred in 1972, but impacts were limited since the number of solid state devices in operation would be considered sparse by today's standards. Despite the limited attention given to solar events, their examples are plentiful:

A magnetic storm in 1921 knocked out the signaling system for New York City's rail lines. A solar storm in March 1989 crippled the power grid in Quebec, depriving millions of customers of electricity for nine hours. And in 2003, a series of storms caused blackouts in Sweden, destroyed a $\$ 640$ million Japanese science satellite and forced airlines to divert flights away from the North Pole at a cost of $\$ 10,000$ to $\$ 100,000$ each.

Our modern, globally connected electronic society is now so reliant on far-flung transformers and swarms of satellites that a major blast from the Sun could bring much of it down. According to a 2008 report from the National Research Council, a solar storm the size of the 1859 or 1921 events could zap satellites, disable communication networks and GPS systems and fry power grids at a cost of $\$ 1$ trillion or more. (Irion, 2011, p. 3).

While scientists continue to study these solar phenomena, it has been recognized that events such as these coincide with cycles of high sunspot activity, which occur roughly every 11 years. During such periods, wireless services are often disrupted, often with users of these technologies 
being unaware of the actual cause or the extent of the network disruption. For example, Gary et al. (2003) have studied the impact on cellular phone service and note that the impact on frequencies below $2.6 \mathrm{GHz}$ and above $10 \mathrm{GHz}$ are more susceptible (pp. 212-213).

In the event of weather disturbances, whether solar or otherwise, the use of communication links through boreholes that have previously been surveyed provides for documented location information that is unambiguous for such holes, and therefore their communication links, can be located by conventional surveying methods when GPS fails or is otherwise unavailable.

\subsubsection{Human Behavior and Communication Systems}

Consider this scenario. In mid-June, 2011, one version of the federally mandated wireless system was implemented at a mine in southwestern Pennsylvania, the objective of which was to be able to locate miners underground. This system was expensive and required line-of-sight communication to function and was only required to be installed in primary and alternate escapeways. A feature of this system was the addition of "text messagers"-bulky devices worn on the pit belt, resembling large-scale versions of the pagers of thirty years ago. These devices received and transmitted messages selected from a pre-programmed list, including such nebulous phrases as "there's been an earthquake" and "injured employee."

During an actual, non-serious, injury the dubious value of the "text messagers" was evident when a ten-second voice radio transaction was able to fully characterize the name of the individual, the nature of the injury, the location to which they were being transported, and the help that was required followed by a two-second return transmission that the ambulance would be there when the injured party was brought aboveground at the stated location. It was fortunate that the mine phone system was available. How long would it take to attempt to communicate the same information using the "text messagers?" None of the dozens of pre-programmed messages could relate the required information, would have required extensive interpretation, and were avoided in favor of voice communication not because the "text messagers" were new technology but because voice communication was more accurate.

The upshot of this observation is that, during an actual emergency involving miners that become trapped underground, only a system that allows two-way voice communication will guarantee that the proper information can be transmitted. Note that, during the rescue attempt at Sago, incorrect information was relayed when weak radio transmissions were not repeated for verification between sender and receiver (Gates et al., 2007, p. 54). The preference for voice communication is commensurate with early research performed by the Bureau of Mines when transitioning mine rescue teams from sash-cord-type assemblies to those with sound-powered or battery-powered telephonic two-way communication (Forbes et al., 1946).

It is worth noting an article in the January 2011 issue of Coal Age highlighting some of the newer communication technologies that resulted from the MINER Act, following the incident at Sago. One supplier, Hughes Supply, reported widespread disinterest in trolley phone, mine phone, and leaky feeder systems in 2003, prior to the MINER Act. By implementing subtle 
improvements, Hughes Supply has seen a resurgence of interest in these less complicated systems that are not only relatively easier to install and maintain, but also have a proven reliability and can be integrated with the newer, more complicated, communication systems. Mine operators are recognizing the value that only two-way voice communication can provide (Fiscor, 2011).

\subsubsection{Statistics on the Failure of System Components}

In a forthcoming section, the prospect of outfitting an exploration borehole with several communication conductors from surface to underground is considered. While some systems may seek to utilize multiple conductors (e.g. a "four-wire system") it is herein advocated that, whenever possible, a two-wire system should be employed with the remaining conductors reserved as spares. This is because ". . . replicating components leads to a higher reliability than replicating systems" (Ross, 2000, p. 510). Most stochastic processes texts that address Reliability Theory, even briefly, illustrate the theorem underlying this concept with a numerical example.

For purposes of reliability of a borehole communication link, the basics of Reliability Theory apply. The classical progression in systems reliability is to look at both series and parallel systems. In the former, every component must function for the system to function whereas, in the latter, any one of the components allows the system to function. All complex systems are combinations of series and parallel subsystems and can often be reduced to a " $k$-outof- $n$ system" where there are $\left(\begin{array}{l}n \\ k\end{array}\right)$ minimal path sets for which the overall system will function.

First, consider the simple system of two sound-powered telephones-one at the surface and one underground - connected by the borehole communication link with embedded wires, of which two are necessary and possibly one or two more are spares. Assume that the underground sound-powered phone is a single, functional component and that the surface sound-powered phone is a single, functional component. The communication link, with spare conductors, then becomes a parallel system of $\left(\begin{array}{l}n \\ 2\end{array}\right)$ minimal paths. It can be assumed that the surface phone can be easily replaced and the underground cannot. Furthermore, butt connectors (either underground or on the surface) can be ignored as failure points since the wires can be spliced directly in an emergency situation, as illustrated by the events at the Revenue-Virginius Mine in Sections 2.3.2 and 2.7.2. Thus, the overall system consists of a series of three sub-systems in series, the borehole communication link between the two sound-powered telephones being the single parallel sub-system.

Second, consider the selective looping arrangement suggested by the U. S. Bureau of Mines and others. In the simplest version, a surface mine phone is connected to a selector switch which routes to either an underground connection to the mine phone network or to an overland connection on a pole line which eventually connects into the mine phone network via a borehole, as shown in Figure 2.2. At first glance, this may seem to be the same as the aforementioned system once the selector switch is thrown for a given direction. However, the selective looping system must be viewed as a series system of many more components. A short-circuit in the 
phone system outby trapped miners may compromise the ability to establish communication via the overland line unless the remainder of the system is disconnected, and doing so under emergency conditions may not be practical. Conversely, the overland connection can also suffer from short or open circuits and troubleshooting a three-mile pole line under emergency conditions may not be practical when every minute is critical. Furthermore, all of the additional connections, such as at the selector switch or at splices in the overland or underground wires, add additional complexity to the system that lower the overall reliability. Even if the borehole used for the selective looping arrangement has redundant paths, neither the overland nor the underground segments of the loop do and, during an incident, much time could be wasted on troubleshooting efforts. Replacing any segment of the loop with a wireless radio signal introduces two more series components at the interfaces between wired and wireless systems.

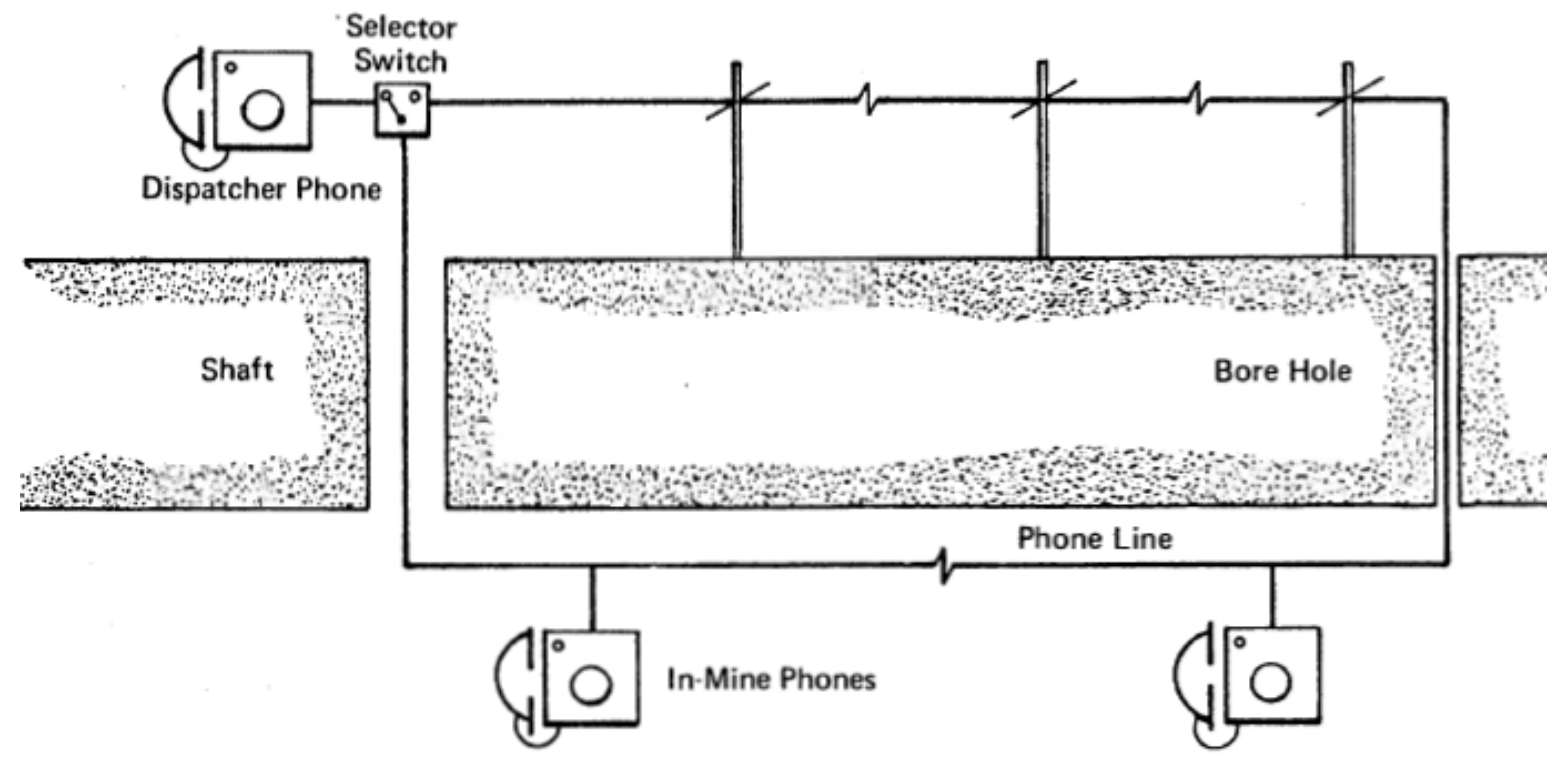

Figure 2.2: Looped Phone System (from Parkinson, 1972, p. 4)

Although advocated for general mine communication, the introduction of every additional component or connection decreases the reliability of the overall system. Thus, when the safety of miners is paramount, simplicity is advocated.

\subsection{Wired Communication Technologies}

While emphasis is often placed on the ability to be compatible with forthcoming communications technologies, it is important to also consider the existing technologies that are currently available. Since the early days of the telegraph, a two-wire system has been adaptable to almost every type of system that followed thereafter. While, in Section 2.2.3, parsimony was advocated it is likewise important to consider that: (1) some mine operators may want to interface with existing systems; or (2) technological developments may produce simple, reliable 
components with which one may want to integrate the borehole communication network. A couple common types of existing technologies, compatible with the establishment of communication networks via exploration boreholes outfitted with communication links, are reviewed in the Sections 2.3.1 and 2.3.2.

\subsubsection{Traditional Mine Telephones}

There is an advantage in using simple, traditional mine telephone systems. The technologies associated with them have been proven in hundreds of mines around the United States and the world. To quote Murphy and Parkinson (1978), "Telephones are the simplest and most reliable form of communication underground and from subsurface to surface" (p. 29). MSHA permissible phones are commercially available at reasonable cost and are often shelf items at distributors near mines or in the maintenance departments of the mines themselves. They are very robust and often survive catastrophic events even if knocked loose from their mounting locations. While there are several manufacturers of intrinsically safe mine phones, this section will concentrate on a couple of models that are frequently encountered in contemporary underground coal mines.

One model of mine phone that is suited for use with a communication network comprised of underground to surface links via exploration drillholes is the GAI-Tronics Loudspeaking Telephone (LST). Perhaps the most robust of mine telephones, this model is a self-contained unit that is MSHA permissible, meaning that it could be connected to the incoming wires from the drillhole and left in place. Alternatively, it could be kept at the ready, say in a refuge chamber, to be connected to the incoming wires from the drillhole communication link in the event of an emergency. One could easily be carried to the surface location and connected to the wires at that elevation to make contact with miners underground.

Like many of the mine telephones, the LST can be connected to any twisted telephone line network. Looping is not required so that side-branching is possible. Manufacturer GAITronics says that as many phones as desired can be placed on a system at separation distances ranging from a few miles to a few feet. No. 12 to No. 19 AWG is recommended (GAI-Tronics, 2007). As will be presented in an upcoming section, the conductors embedded in the grout of the drillhole communication link have more than enough capacity to carry this signal. One advantage of a point-to-point connection from the surface to the underground coal mine is the ability of surface personnel to perform troubleshooting on the communication network. For example, if it were necessary to adjust a matching impedance on the line, this could occur outside the mine where supplies are available.

Although more complicated, the GAI-Tronics Model 491-201 Mine Dial/Page Telephone is used in many underground coal mines, is MSHA permissible, and allows connection through PBX ("Private Branch Exchange") to outside lines, with dialing capabilities (GAI-Tronics, 2006). While the simpler system is being advocated (e.g. the LST), the important concept here is that, via the two-wire connection provided by the drillhole communication link, it would be possible to connect a Model 491-201 Dial/Page phone which would allow communication through whatever network remains undamaged underground. Often this model of telephone is 
purposefully placed in refuge chambers, meaning that refuge chambers that are connected to the mine telephone network could also then be connected to the underground-to-surface link through an exploration borehole. The caveat here is that there is an increased level of complexity. Miners underground may be required to disconnect portions of the network if the wires have been compromised by an incident. For example, if a short circuit is located someplace outby, the line may need to be severed inby of the event location to clear the short. This would also disconnect the interface cabinet, meaning that the installation aboveground would no longer be limited to a single phone but would also require a Model 495-001 Interface Cabinet.

Similar scenarios can be developed for the older model Femco AM7011, AM7022 and AM7022 mine telephones, which are also MSHA permissible but generally connected to complete underground networks (see Femco, 1982 and Femco, 1983). Conversely, the two-wire system could be made compatible with newer technologies. The Bruceton Experimental Mine has experimented with connecting a traditional mine pager phone system via fiber optics (Miller et al.,1980) and making interconnections with radio systems using primarily the UHF band (Dobroski and Durkin, 1980).

\subsubsection{Sound-powered Phones}

The sound-powered telephone, associated with mine rescue operations since its development, represents the simplest and most robust communication device to use in conjunction with a link through an exploration borehole. For example, a battery-boosted soundpowered telephone was in use at the Revenue-Virginius Mine when an avalanche blocked the portal in 1983. The crew took the sound-powered phone from the hoist room and, at the blockade, stripped the wires and established communication to the outside (Hurley, 2006, p. 25).

A 2009 article in the Bulletin of the Joseph A. Holmes Safety Association reviewed various communication systems used by mine rescue teams. For the sound-powered telephone systems, the shortcomings listed were "poor sound quality in existing systems, cumbersome and uncomfortable headsets, the need for hands-free communication, the need for wireless communication to allow members to separate yet still be in touch, [and] the benefit of more than one team member hearing the $\mathrm{FAB}^{1}$ transmissions or being able to speak to the FAB personnel" (p. 15). Only the first of these would be applicable to a sound-powered telephone used through an exploration borehole to establish communication with trapped miners in an emergency. Hence, the sound-powered telephone is, by nature, highly compatible with the objectives of immediately establishing communications via a link through an exploration borehole.

In the wake of the push for more complicated systems, the merits of the sound-powered telephone have received much less attention than they did when they were declassified after the Second World War and began to appear in civilian applications. A 1955 article, "Improved Safety and Operating Efficiency with Sound-Powered Phones" highlighted the simplicity and reliability of what was then a newer technology. Of course, the adoption of wireless radio communication has rendered the cabled system less practical for many applications. However,

\footnotetext{
${ }^{1}$ Fresh Air Base, the outby location from which rescue operations are conducted.
} 
in the scenario where miners are trapped underground inby some obstruction that has blocked communication, sound-powered phones connected through a borehole are very practical.

Since the 1940s, typical lengths of cable on reeled sound-powered telephone systems have not exceeded 1200 feet. However, some variants have been tested up to three miles with favorable results (Brown, 1957, p. 10). These sound-powered phones do not require a separate power sources, are portable, can be used in methane-air mixtures and were approved by the Bureau of Mines (Dynalec, 1986).

In addition to the electrical considerations, the sound-powered telephone has the capability of being used by trapped miners who are wearing self-contained self-rescuers via the use of vibration-powered transmitters which are placed against the larynx of the wearer (Brown, 1957, p. 3; Dynalec, 1986).

\subsection{Mine Incidents}

Despite the fact that mine-related fatalities have been on the decrease for decades, there have still been incidents involving mine fires, explosions, roof falls, and inundations. This section will review a few of these incidents with emphasis on the communication networks associated with each situation and other information pertinent to the design and implementation of a communication link via an exploration borehole. How communications may have been improved by the availability of such an alternate underground-to-surface link using a communication borehole will also be suggested.

\subsubsection{Quecreek Mine}

The Quecreek No. 1 Mine, Black Wolf Coal Company, is located in Somerset County, Pennsylvania, adjacent to the abandoned Harrison No. 2 Mine. On the evening of July 24, 2002, the 1-Left section crew was operating a continuous miner in No. 6 entry. Inaccurate mine maps had indicated that the abandoned Harrison No. 2 Mine was at least 200 feet beyond the working face. As shown on the right side of Figure 2.3, the continuous miner cut through No. 6 entry (of the 7-entry system), to the abandoned mine. This released a stream of water, reported to have had 52 feet of head pressure, that quickly began to flood the mine. Quick notification using the mine phone system allowed seven miners from the 2-Left section and two outby miners to evacuate via the portal. The miners in 1-Left, however, had their escape blocked by the rapid inrush of water.

The Upper Kittanning seam being mined is approximately four feet thick with a 3-4 percent dip to the northwest. Recognizing this dip, the miners retreated to No. 1 entry, which was at the highest elevation in the section, and began to build barricades. This area is shown in the upper right of Figure 2.3.

Figure 2.4 shows a plan view of this part of the section and depicts the rise of water which trapped the miners in No. 1 entry. On the surface, it was recognized that, had the miners 
survived the inundation, this was the only location where they could be found. Communication channels had not survived the inundation and this logic was the only guide as to the location of the miners. By the following morning, a 6.5-inch hole was drilled from the surface into 1-Left section and communication with the miners was re-established via dropping a microphone down the drillhole at 10:53 p.m. on July 27, 2002. This was three days after the initial inundation had entrapped them.

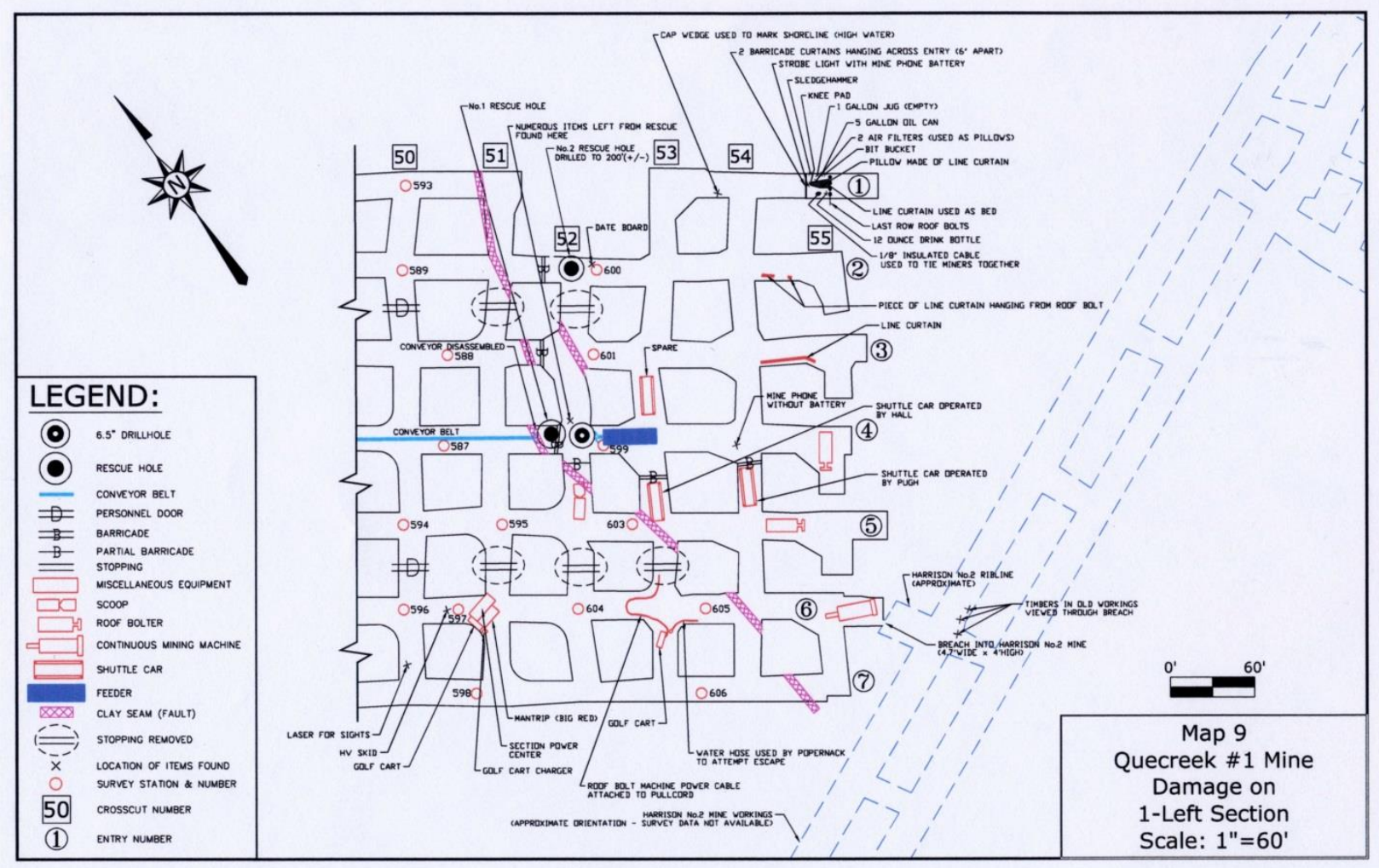

Figure 2.3: Plan view of Quecreek Mine (Brady et al., 2003).

Meanwhile, a 30-inch rescue hole had been started into 1-Left on the evening of July $25^{\text {th }}$. Despite problems with the cutting bit that caused an 18-hour delay in drilling, MSHA's rescue capsule was eventually lowered into 1-Left and the miners were individually brought to the surface, the last one at 2:45 a.m. on Sunday, July 28, 2002 (Block, 2002; Brady et al., 2003).

A significant observation from this incident is that the trapped miners, despite the inundation, had some, if limited, mobility and supplies in the section where they sought refuge. When compressed air was forced into the mine to provide oxygen in an atmosphere that would otherwise have become fatally deficient:

They noticed that the sides of the capped plastic water containers, which they brought with them for drinking water, were compressed, indicating their atmosphere was under pressure. They also heard hissing of air going through the open roof test holes. The miners conserved their cap lights by using them one at a time and only as necessary. Anticipating the need for additional lighting, they also took the nine-volt battery and 
paging light from the mine telephone. They kept track of time by referring to their watches and relating times to the different shifts (Brady et al., 2003, p. 19).

This paragraph indicates that a mine phone was accessible at some time during the inundation. If a link through an exploratory drillhole in 1-Left Section had been available, it is possible that communication to the surface could have been established much earlier in the rescue effort by grabbing the extra phone instead of just its battery.

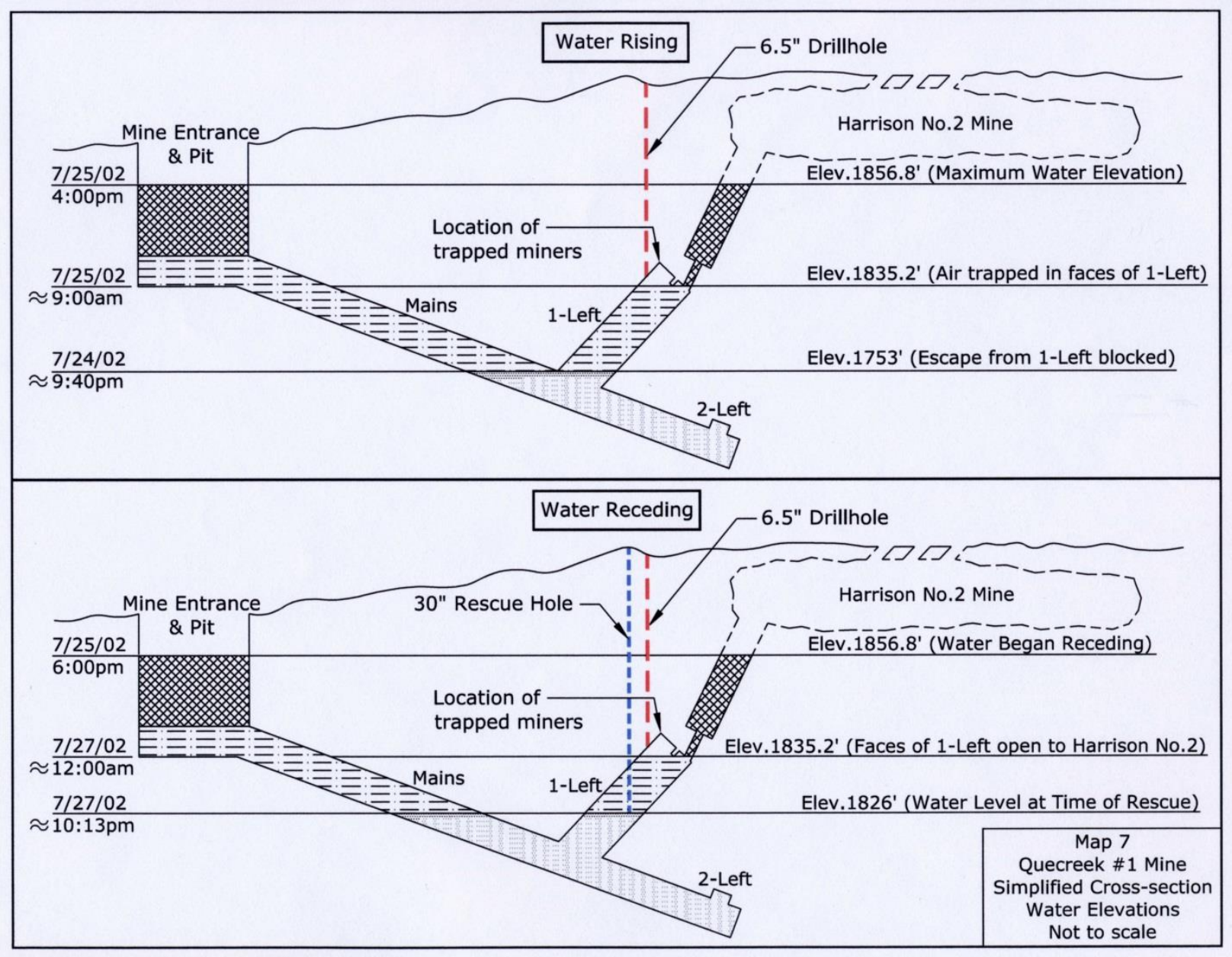

Figure 2.4: Elevation view Quecreek Mine (Brady et al., 2003).

\subsubsection{Sago Mine}

The Sago Mine incident exhibits three elements applicable to this research into exploiting exploration boreholes as communication links. First is the obvious objective of the relative ability to contact miners trapped underground. Second is the suggested effect of lightning strikes to underground workings. Third is the overreliance on complex technology, exemplified by a dependence on GPS satellites to survey a location to drill a test borehole. 
Around 6:30 on the morning of January 2, 2006, an explosion and fire occurred at the Sago Mine in Upshur County, West Virginia, initiating in a recently sealed area inby of the 2Left section due to the ignition of a methane-air mixture. It is believed that this ignition originated from indirect coupling of lightning energy to an abandoned pump cable behind the seals. Arcing from the open end of the cable to ground could have produced sufficient energy to cause the ignition (Higgins and Morris, 2006).

Twenty-nine miners were underground at the time of the incident, with thirteen located near the area of the explosion itself. Of the 29, the 1-Left crew was able to evacuate the mine, as were several others located outby of the event. Of the remaining 13, one was fatally injured by the force of the explosion. Evidence suggests that the remaining twelve who were working 2Left donned self-contained self rescuers (SCSRs) and attempted to evacuate but turned back and barricaded themselves at No. 3 entry near the working face (Gates, 2007; McAteer, 2007). Eleven would succumb to the carbon monoxide and a single survivor would be removed in serious condition.

Initial attempts to both determine the extent of the damage and rescue the trapped miners were carried out via the normal mine entries with egress being from the left (drift openings) in Figure 2.5 and the miners miles inby to the right (2 Left Parallel Section). Ultimately, rescue of the sole survivor and recovery of bodies would also occur from the entries. However, at 1:00 p.m. on the day of the incident, an attempt at boring through 258 feet of overburden above the Two Left Section, shown in Figure 2.6, commenced:

At about this time, the command center adopts a plan to drill a borehole from the surface into the Two Left section, based on the assumption that the Two Left crew, if alive, are most likely inby the mouth of that section. The borehole will help determine conditions on the section and presumably can be used to communicate with the miners if they are found alive. Surveying crews equipped with GPS instruments are sent out to determine a suitable location, but are hampered by unfavorable weather conditions, which cause difficulty and delays in getting accurate readings from GPS geosynchronous satellites orbiting the earth (McAteer, 2007, p. 28).

It took nearly 13 hours to complete the surveying, road building, and set-up of the drilling rig. The GPS signal was unreliable for ten of the 13 hours so conventional survey methods were used so that surveying was completed in time for the rig to be placed. The GPS coordinates were then found to be incorrect by 30 feet (Gates et al., 2007, pp. 56-58). It then took 23 hours to drill into 2-Left approximately 300 feet from the face. Carbon monoxide readings exceeded $1300 \mathrm{ppm}$ and physically tapping on the drill pipe did not elicit any responses from the trapped coal miners underground.

From the standpoint of including communication devices in exploratory drillholes during pre-mine planning, consider that a link for communication could be located near enough to working sections to be used by a sound-powered telephone or connection to the mine pager phone system. While the grouted borehole would not be suitable for taking gas sample readings, it would be possible to attempt communication with miners trapped underground. Furthermore, 
while excavators and drill rigs were being mobilized, a person with a shovel could walk to the aboveground location of a communication link and make connections without assistance.

Surveyors would not have to rely on GPS technology to locate a previously mapped borehole for communication (although GPS or conventional surveying would be required to locate an air hole or a rescue hole).

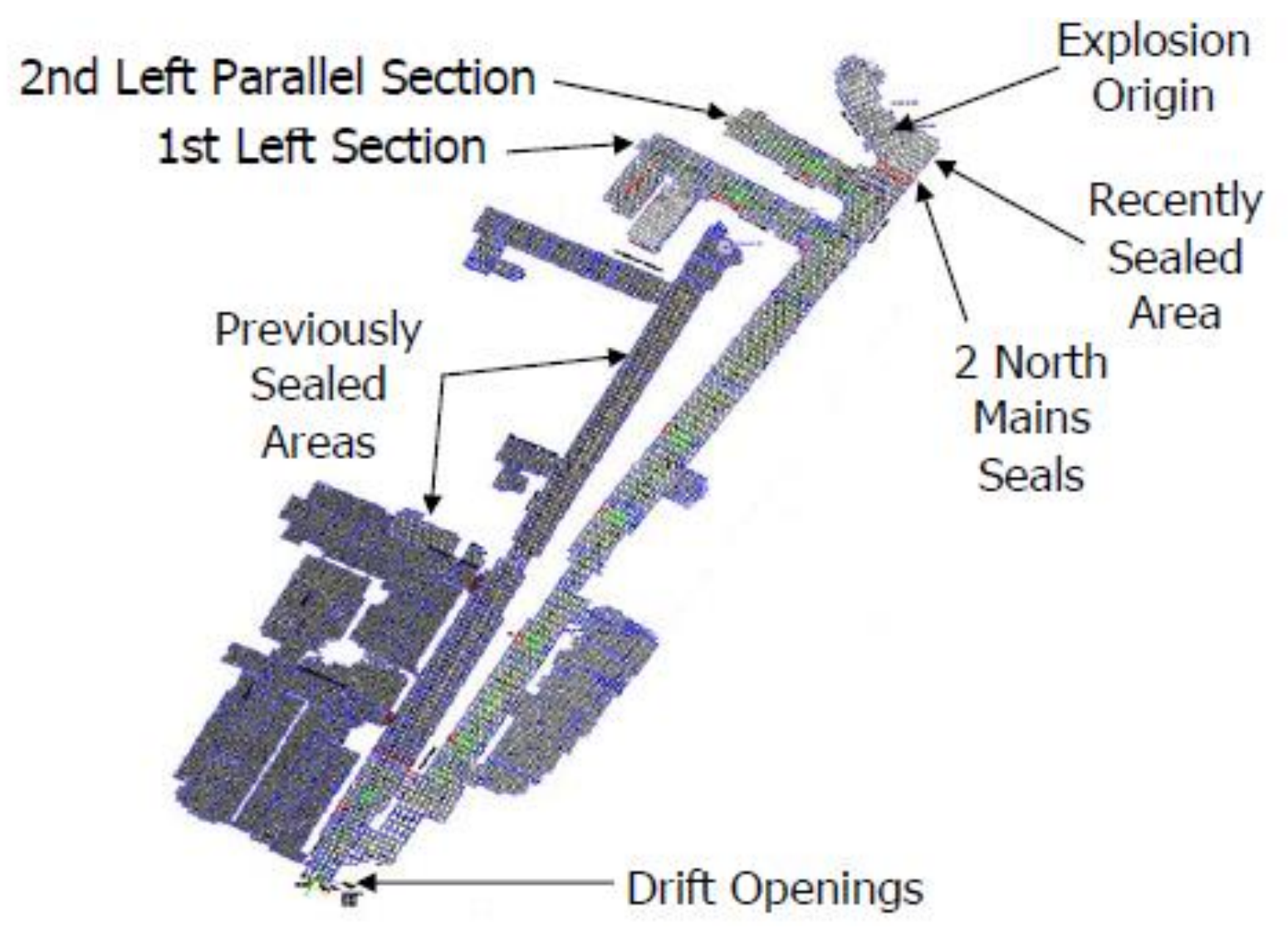

Figure 2.5: Overall mine map of Sago Mine (Gates et al., 2007). 


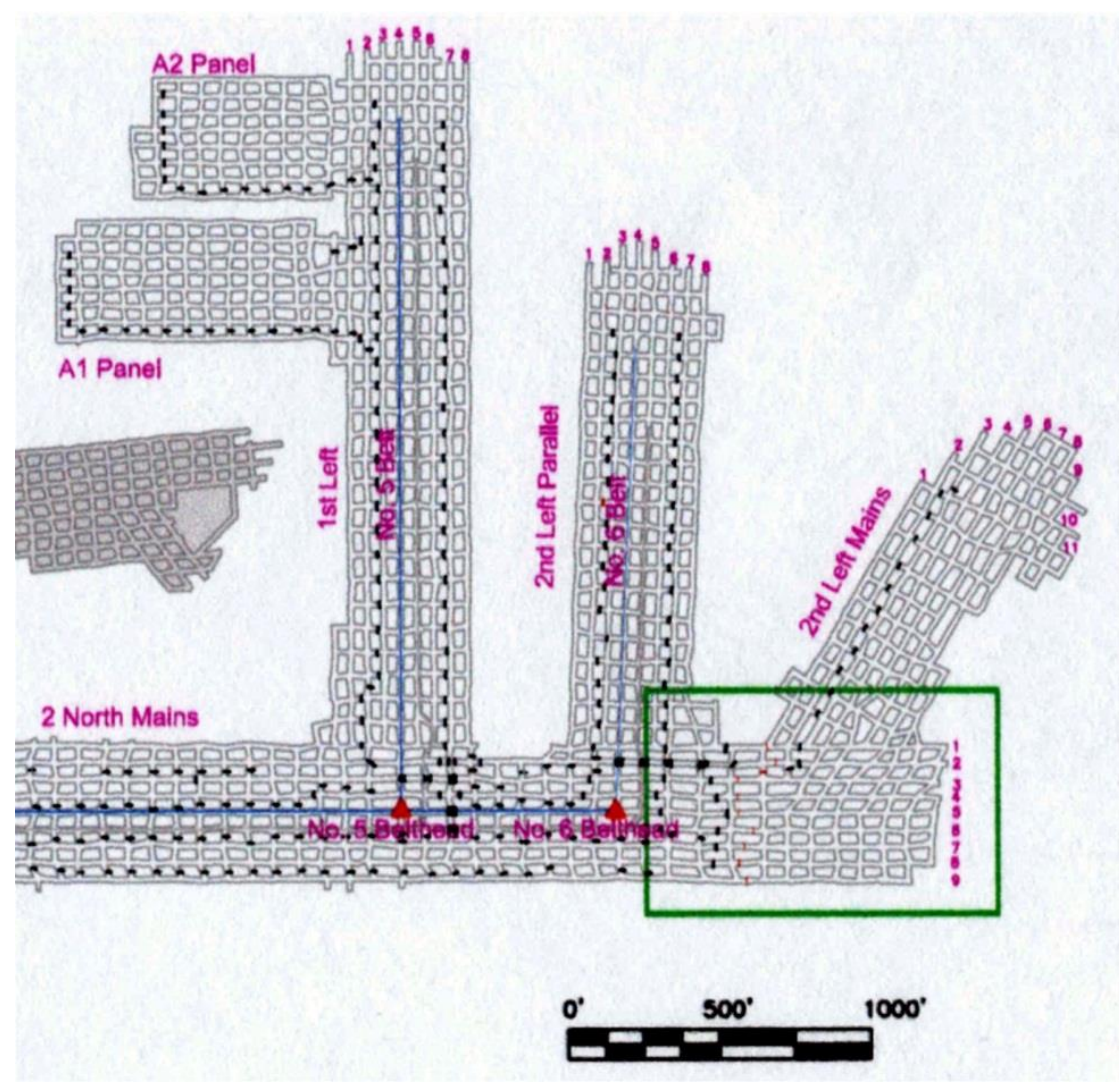

Figure 2.6: Areas of Sago Mine where miners barricaded (Gates et al., 2007).

A total station method or, less attractively, a measuring wheel from a monument could be used to find the pre-existing drillhole that had been outfitted for communication. In other words, even if redundant paths within the mine were damaged, solid contact could be re-established to inby areas within an hour.

Consider now the feasibility of using a simple mine phone system for communication. Both the independent McAteer report and the MSHA investigation into the events at Sago are populated with examples of how mine personnel were able to communicate with one another outby the explosion area via the mine phone system. Half an hour after the explosion, mine personnel, “. . . then explore inby, walking to 42 block, observing damage to ventilation stoppings, and using the phone at 41 block to call out ..." and nearly two hours later, "At 49 block, ... moves a phone and emergency first-aid supplies from the track entry to the intake entry" (McAteer, 2009, pp. 25-26).

The robustness of the mine phones currently in use could be exploited as part of a communication network utilizing exploratory drillholes. Nothing has changed since 1978 when Murphy and Parkinson described pager phones, saying, "They are simple to install, reliable in operation, and easy to maintain" (p. 30). Sound-powered telephones, intrinsically safe, Bureau of Mines approved and time-tested, are another alternative although they would not be connected to a network 


\subsubsection{Wilberg Mine}

The Wilberg Mine incident of 1984 contains a number of issues worthy of discussion. For purposes of this research, however, the focus will be on the post-fire scattering of personnel and their inability to communicate their locations. As there was only one survivor from this incident, the location of victims, as discovered by the mine rescue teams, provides only limited information as to their thought processes when attempting to evacuate the mine. Figure 2.7 shows the locations where these victims were found.

On the evening of December 19, 1984, smoke was discovered in the area of the belt drive for the $5^{\text {th }}$ Right Section and a fire was discovered thereafter. Inby at the longwall, the number of personnel was greater than normal since, pre-emergency, the mine was on-target for a production record. While they were informed of the fire immediately after its discovery, the communication system inby was disabled by the fire and contact was lost. The movements of each group of victims is not known. It is possible that some had changed course during their attempts to escape; it is also possible they did not and were time-limited by their self-rescuers. However, since many of the victims were found in groups, often wearing self-rescuers, it can be inferred that different groups attempted to leave the mine via different paths, with personnel on the outside unaware of the routes they were taking.

While, by definition, the uncertain is unknown, the availability of underground-to-surface communication links, in locations such as those depicted in Figure 2.8, and rescue chambers with extended air supply in the same vicinity, possibly could have limited the number of fatalities. 


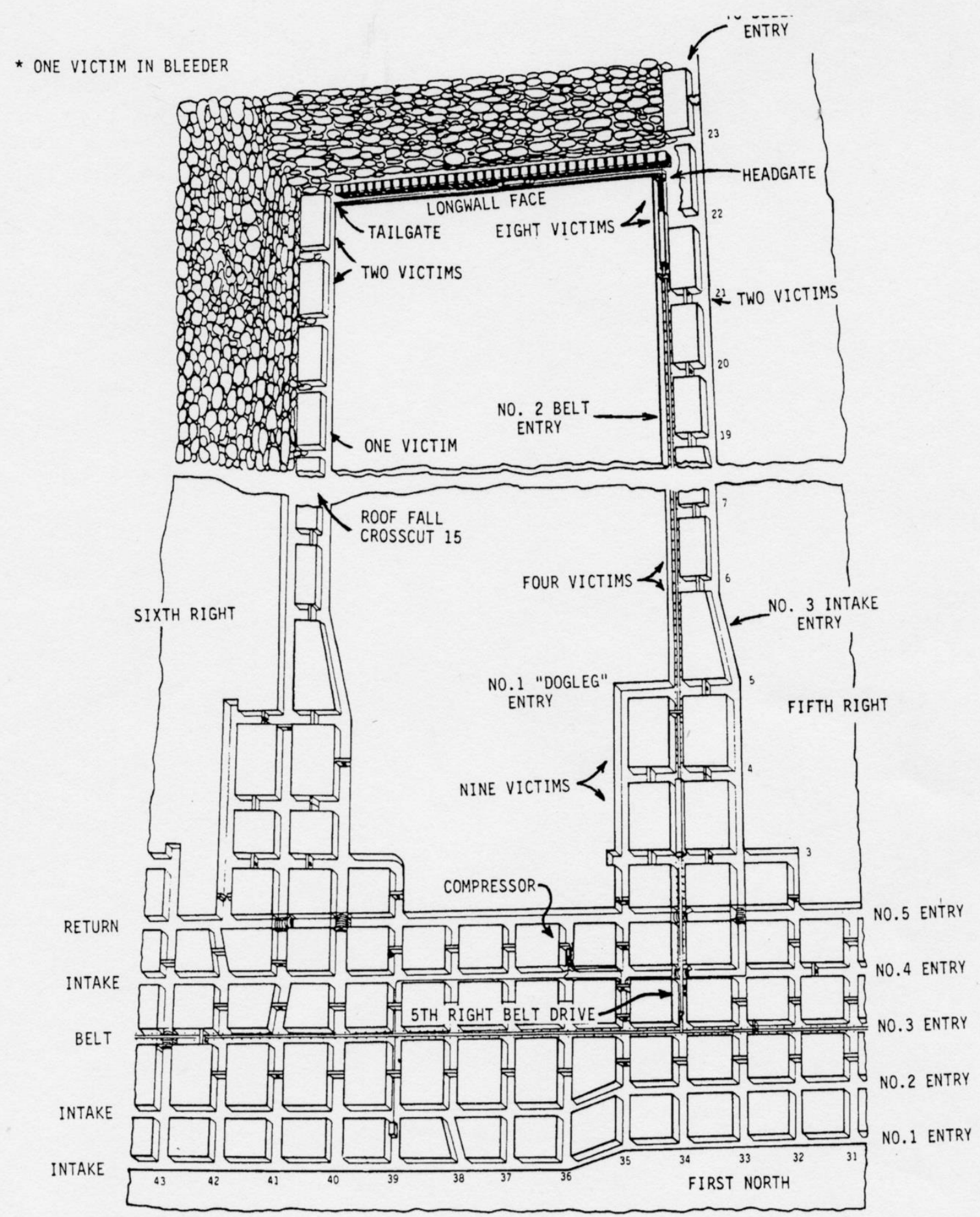

Figure 2.7: Wilberg Mine, Location of Victims (Huntley et al., 1985). 


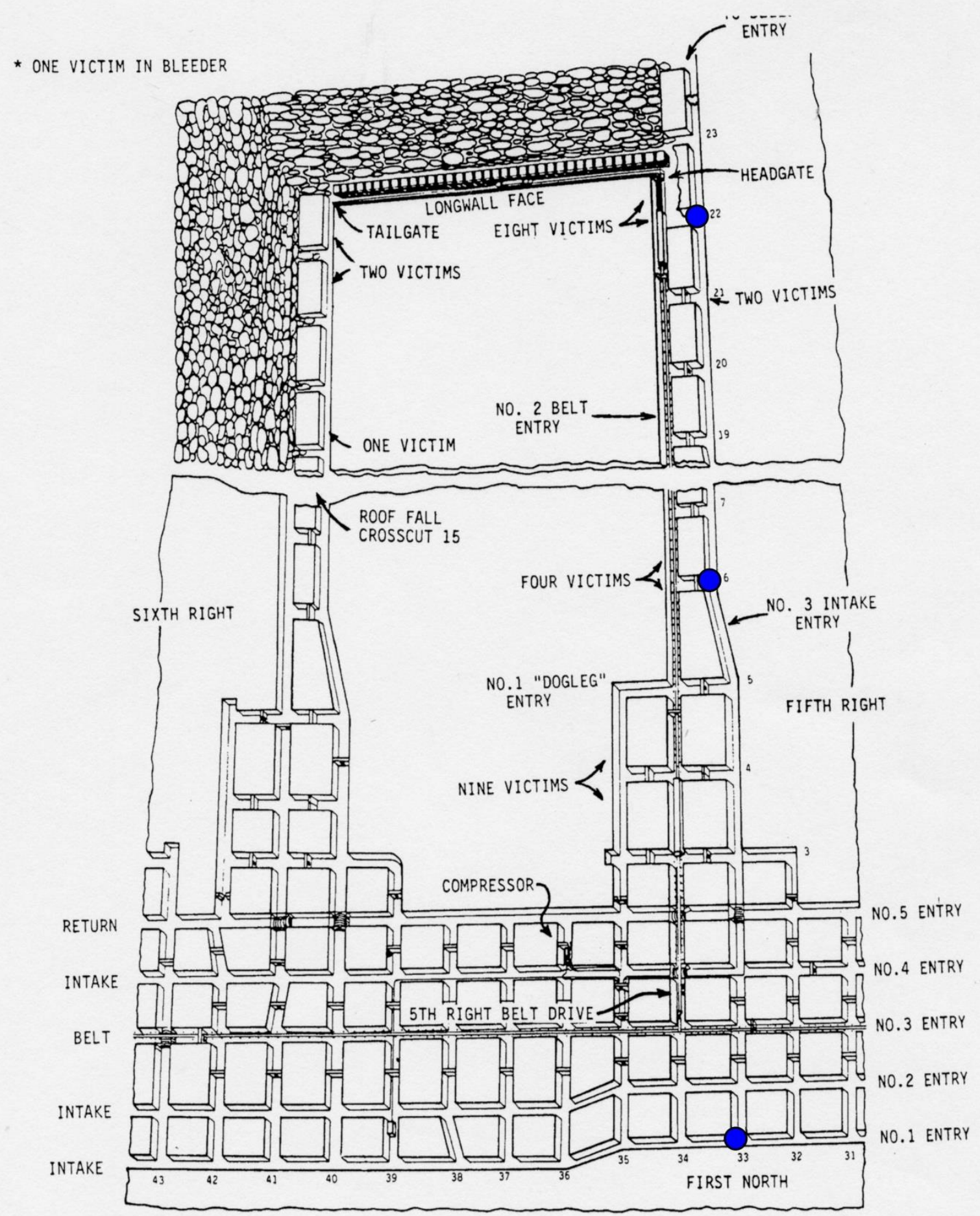

Figure 2.8: Wilberg Mine map with three possible locations of exploration boreholes along the intake (illustration modified, from Huntley et al., 1985). 


\subsubsection{Mountaineer Alma A Mine}

Massive rainfalls combined with an inability to sufficiently divert surface water resulted in the entrapment of seven miners for 24 hours in May of 2009. Severe storms passed through the area of the Mountaineer Alma A Mine around 5:00 a.m. on May 9, 2009. Informed of this by the Dispatcher, the Section Foreman decided to check a pump at Crosscut 6, to which power had been restored some two hours previously after being lost during the storm. On checking the pump, the Section Foreman recognized that the mine was becoming inundated by storm water which was pouring in through the main entries of the mine and gathered his crew and retreated inby. As Figure 2.9 shows, this water ultimately roofed the entries and entrapped the miners inby.

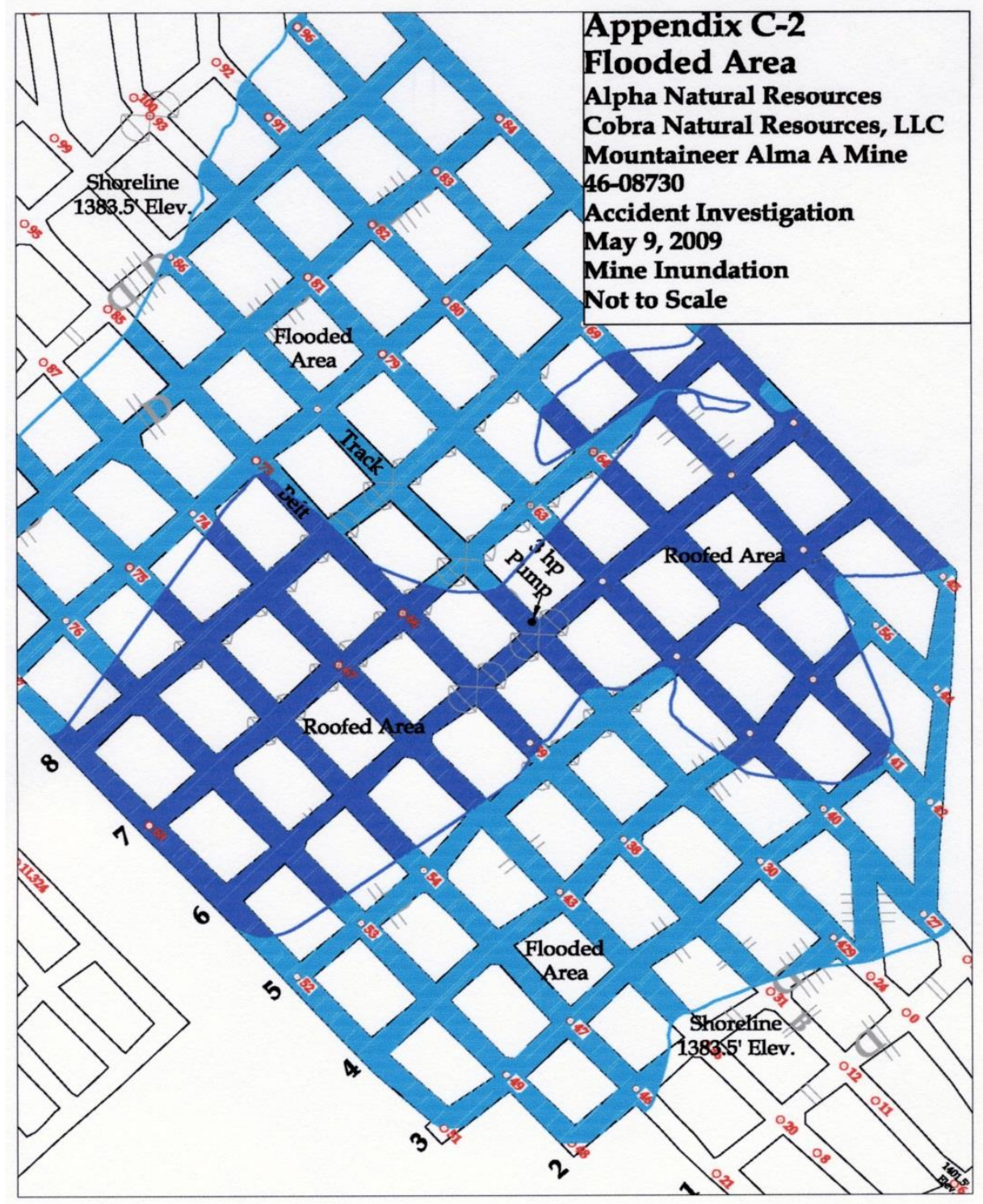

Figure 2.9: Flooded area of Mountaineer Alma A Mine (Bentley et al., 2009). 
Unlike the Quecreek inundation, the miners at Mountaineer Alma A remained dry and in communication via the mine phone system, which was not damaged. There was constant communication with the surface and the miners were able to make calls to their families (Bentley et al., 2009, p. 4). Assisted by this communication, the miners decided to remain where they were until the water was pumped down, rather than go farther inby to access an airshaft where a rescue capsule was available. After 24 hours, the miners walked out of the mine.

This incident illustrates the importance of voice communication in a mine emergency. Could the miners have retreated inby and left the mine via an existing rescue capsule? Sure. However, doing so could have subjected them to other unknown risks, including the simple possibility of a twisted ankle while walking. In having constant communication with the surface, they were aware that staying where they were, together, would lead to exiting the mine as soon as the water was pumped out.

\subsection{MINER Act and S-MINER Act}

In the wake of the events at Sago, the Second Session of the $109^{\text {th }}$ Congress, on June 15, 2006, passed the Mine Improvement and New Emergency Response Act of 2006, commonly referenced at the MINER Act, as an amendment to the Federal Mine Safety and Health Act of 1977. Included in this law were new requirements for emergency response and preparedness, some of which address communications.

Section 316(b)(2)(E)(i) requires mine operators to provide post-accident communications in their Emergency Response Plan. It states that, "The plan shall provide for a redundant means of communication with the surface for persons underground, such as secondary telephone or two-way communication." Taken as worded, the implementation of a communication network using a link through exploratory drillholes would seem to meet the requirement. However, this is a general requirement. The specific requirement of the MINER Act (2006) says:

Not later than 3 years after the date of enactment of the Mine Improvement and New Emergency Response Act of 2006, a plan shall, to be approved, provide for post accident communication between underground and surface personnel via a wireless two-way medium, and proved for an electronic tracking system permitting surface personnel to determine the location of any persons trapped underground or set forth within the plan the reasons such provisions can not be adopted. Where such plan sets forth the reasons such provisions can not be adopted, the plan shall also set forth the operator's alternative means of compliance. Such alternative shall approximate, as closely as possible, the degree of functional utility and safety protection provided by the wireless two-way medium and tracking system referred to in this subpart.

The fully functional two-way wireless communication required by law did not reliably exist three years after the passage of the act (Ward, 2010b). Research into underground wireless communication dates back at least forty years (see Murphy and Parkinson, 1978). Nonetheless, the focus continues to be oriented towards the development of expensive and complex systems 
that will comply with the regulations without a discussion of simple, cost-effective systems that can be relied upon in the event of an emergency.

On January 16, 2009, MSHA issued Program Policy Letter No. P09-V-01 with the subject line "Guidance for Compliance with Post-Accident Two-Way Communications and Electronic Tracking Requirements of the Mine Improvement and New Emergency Response Act (MINER Act)." This program policy letter (PPL), acknowledging the nascent status of the underground wireless communication industry, intended to provide guidance to miner operators seeking acceptable alternatives that would be compliant with the MINER Act. The stance is decidedly against wired communications. The alternative must " . . be capable of best approximating a fully wireless communication system ..." one-hundred percent of the underground workings at all times, to each individual miner (p. 3). It is inferred that this could be tied into a wired system that then exits the coal mine.

This PPL gave rise to more questions than answers, and an April 29, 2009 list of "Questions and Answers" issued by MSHA attempted to lend some clarity to these. Question 16 defines redundancy:

Redundancy means that the system can maintain communications with the surface when a single pathway is disrupted. Redundancy can be achieved by two or more systems installed in two or more entries, or one system with two or more pathways to the surface; provided that a failure in one system or pathway does not affect the other system or pathway.

Questions 17 and 18, respectively, suggest that the path should take two or more entries unless there is another path to the surface and that overland paths - wired or wireless - can achieve this goal. While it would be possible to connect the mine phone system through a drillhole communication link to reach the surface, doing so would have to be addressed on a case-by-case basis considering surface features, the implications of setting a pole line, and the increased complexity to an overall network (the latter was addressed in Section 2.2.3). The benefit lies in keeping this type of link unconnected unless it is needed since, in the event of an emergency, the location and extent of the damage to the existing in-mine communication network(s) is not $a$ priori knowledge but the surface-to-underground link is protected by the overburden.

There is at least some acknowledgement that a wired device may be prudent as Question 13 of the same April 29, 2009 memorandum specifically states that connections to refuge chambers do not need to be wireless. The independent investigation into Sago provided to the Governor of West Virginia recommends a hard-wired underground to surface communication link from a refuge (or refuge alternative) via a borehole (McAteer et al., 2006, p. 14). This same recommendation had previously been made in a 1983 study by Foster-Miller, Inc., where the incorporation of both the mine pager phone system and a sound-powered telephone were advocated (p. 73).

On January 16, 2008, the Supplemental Mine Improvement and New Emergency Response Act of 2007 (S-MINER Act) was passed by the U. S. House of Representatives. Subsequently, it was read twice before the Senate and then referred to the Committee on Health, 
Education, Labor, and Pensions but was never signed into law. However, given the regulatory environment that developed as a result of the events at Sago, giving rise to the MINER Act of 2006, the content of S-MINER needs to be considered as it relates to any type of communication device that is intended for the benefit of underground miners. Germane to this topic are the words:

Not later than 120 days after enactment of the S-MINER Act, a plan shall, to be in approved status, provide for a post accident communication system between underground and surface personnel, and for an electronic tracking system permitting surface personnel to determine the location of any persons trapped underground, that utilizes a system at least as effective as a 'leaky feeder' or wireless mesh type communication and tracking system currently in use in the industry. These systems shall be enhanced physically, electronically, or redundantly, to improve their survivability in the event of a mine disaster.

The important insight from this passage is that there is more emphasis placed on having a reliable system for the safety of miners than there is on using only wireless technology, as was the perspective with the language of the MINER Act. The S-MINER Act does stipulate, however, that the National Institute for Occupational Safety and Health will make the determination what technologies are considered to be suitable for communicating with trapped miners. 


\section{Chapter 3 Design for Mine Pre-Planning and Development}

The objectives of this project are addressed in sections as described with the design of the drillhole communication link, central to the establishment of a cost-effective network of surface-to-underground communication links, analyzed in some detail. The concept of simplifying the communication from surface to subsurface through a simple link assembly is presented in Section 3.1. Section 3.2 then reviews considerations of interest pertaining to locating exploration drillholes during mine pre-planning to facilitate their use as communication links. Issues with drillholes intersecting underground workings are presented in Section 3.3. Section 3.4 explains the current method of post-drilling grouting operations and how the assembly is created during the grouting process is described in Section 3.5.

\subsection{Concept of Establishing a Surface to Underground Link}

The driving force behind using exploration drillholes for a communication link between the surface and underground is to provide a cost-effective means of quickly establishing communication with coal miners who become trapped inby some event that simultaneously disrupts the primary communication system(s). Simplicity and reliability are the objectives. Figure 3.1 depicts the scenario in which an event, such as a roof fall outby the working area, not only blocks the entry but severs the communication cable. A pager phone is connected to phone wires that are connected to a drillhole communication link to the surface where another pager phone is connected and communication can be established. A sound-powered telephone would also be suitable and would not be capable of easy connection to the larger mine-wide network which may become compromised in a catastrophic event.

The non-commercially available component required for the establishment of this type of communication network using exploration drillholes concerns the design and method of placing a communication link, or conductor, into the drillhole itself without compromising established practices. Later sections address the design process, starting with an explanation of contemporary drilling and, specifically, grouting practices used on exploration drillholes. For now, consider the concept of embedding wires in the grout that is used to backfill the drillhole. Both the underground and surface elevations are the tie-in points to phones or other communication systems.

During mine planning, the exploration drillholes are located so as to coincide with an intersection underground along the mains or submains. Then, during development of the mine, the continuous miner cuts the entries and intersects the grouted, wire-embedded, drillhole at a specified crosscut. As the continuous miner advances, it cuts the grout and wires, breaking the latter in shear at the elevation of the roof as shown in Figure 3.2.

The exposed wires may then be connected to a junction box for use with a soundpowered phone, connected into the mine telephone network, or other communication system in the event of an emergency. This connection would be made once the exposed drillhole communication link along the mains or submains became located outby the first open crosscut (i.e. in the second open crosscut). A chipping hammer may be required to dig out some of the 
grout in order to make a good connection (using butt connectors), and the connection would have to be insulated per the regulatory requirements given in Section 6.3. Locating the device along planned mains or submains would place it in intake air and in an area readily accessible to underground mine personnel.

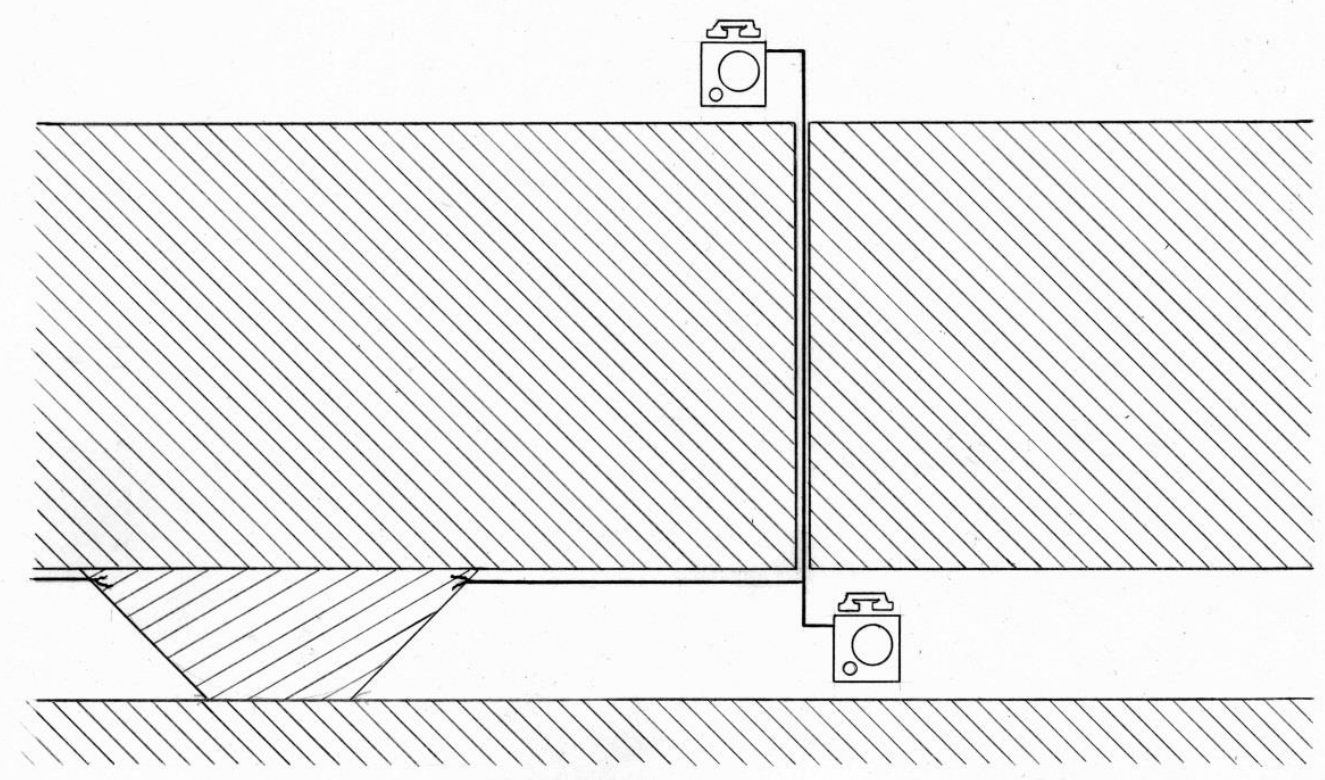

Figure 3.1: Basic concept of underground to surface communication using a drillhole, with primary communication system damaged by roof fall or similar event.

While the drillhole communication link is protected underground by the overburden until development reaches it, on the surface additional measures must be taken. Figure 3.3 shows a suggested method of protecting the communication link during the dormancy period between exploratory drilling (including placement of the embedded conductors) and underground mine development. As the conductors emerge from the grout, they are coiled around a wooden dowel approximately six inches below grade. The ends of the coiled wires are attached to a wooden cap using screws. Before the wooden cap is placed over the dowel rod around which the slack wire is coiled, the drillhole void is filled with latex rubber to provide a moisture barrier for corrosion protection. Earth is placed on top of the wooden cap, which can be marked to indicate that a communication wire is attached beneath it. When it is desired to activate the link, the cap is exposed and pulled upward, extracting the wires from the latex and rendering them available for connection to a sound-powered telephone, mine pager phone or other suitable communication device. 


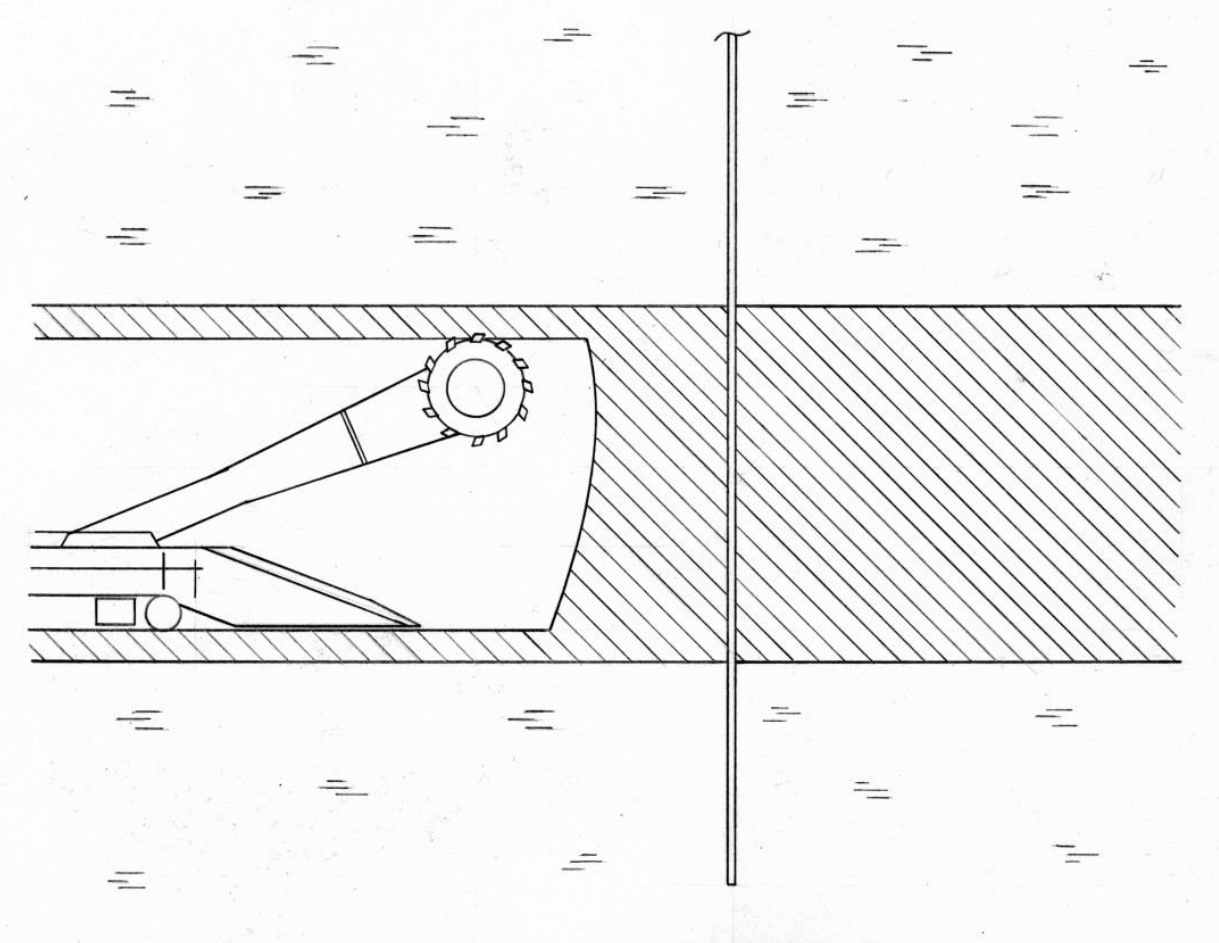

Figure 3.2: Depiction of continuous miner in coal seam prior to intersecting drillhole communication link. Drawing is to scale and represents an 8-foot coal seam with a 3-inch diameter drillhole extending approximately 7 feet below the bottom of the coal seam.

Although it would be less desirable, and obviously more difficult to install, an alternate suggestion is shown in Figure 3.4 for the requirement that the top elevation of the drillhole communication link must be buried several feet below grade. The main difference between Figure 3.4 and Figure 3.3 is the addition of a nylon rope between the top cap and the coiled wires. Note that, in this scenario, a significantly larger quantity of wire would need to be cached in the drillhole above the grout. 


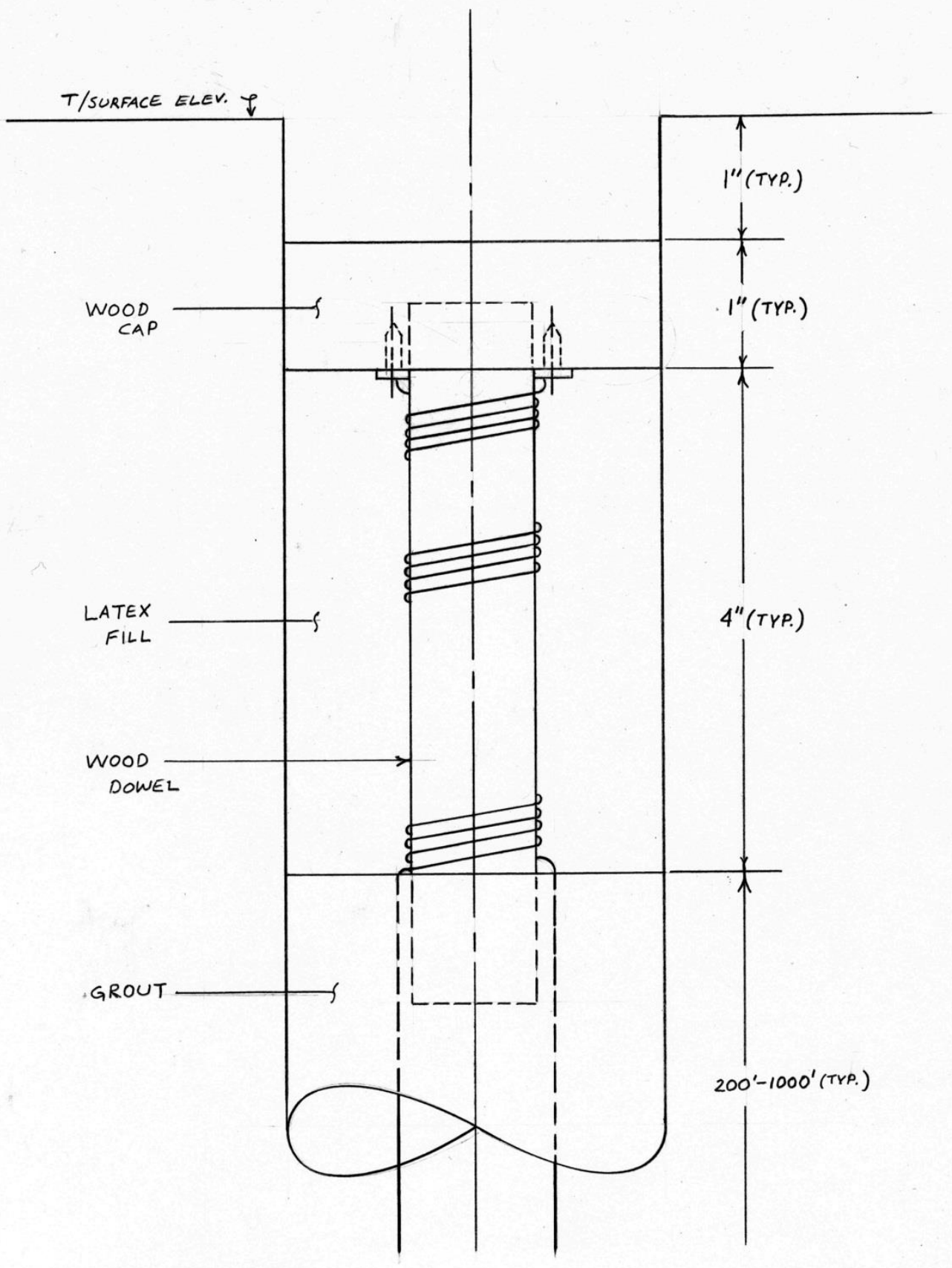

Figure 3.3: Suggested method of protection for surface elevation wires of communication link using exploration drillholes. 


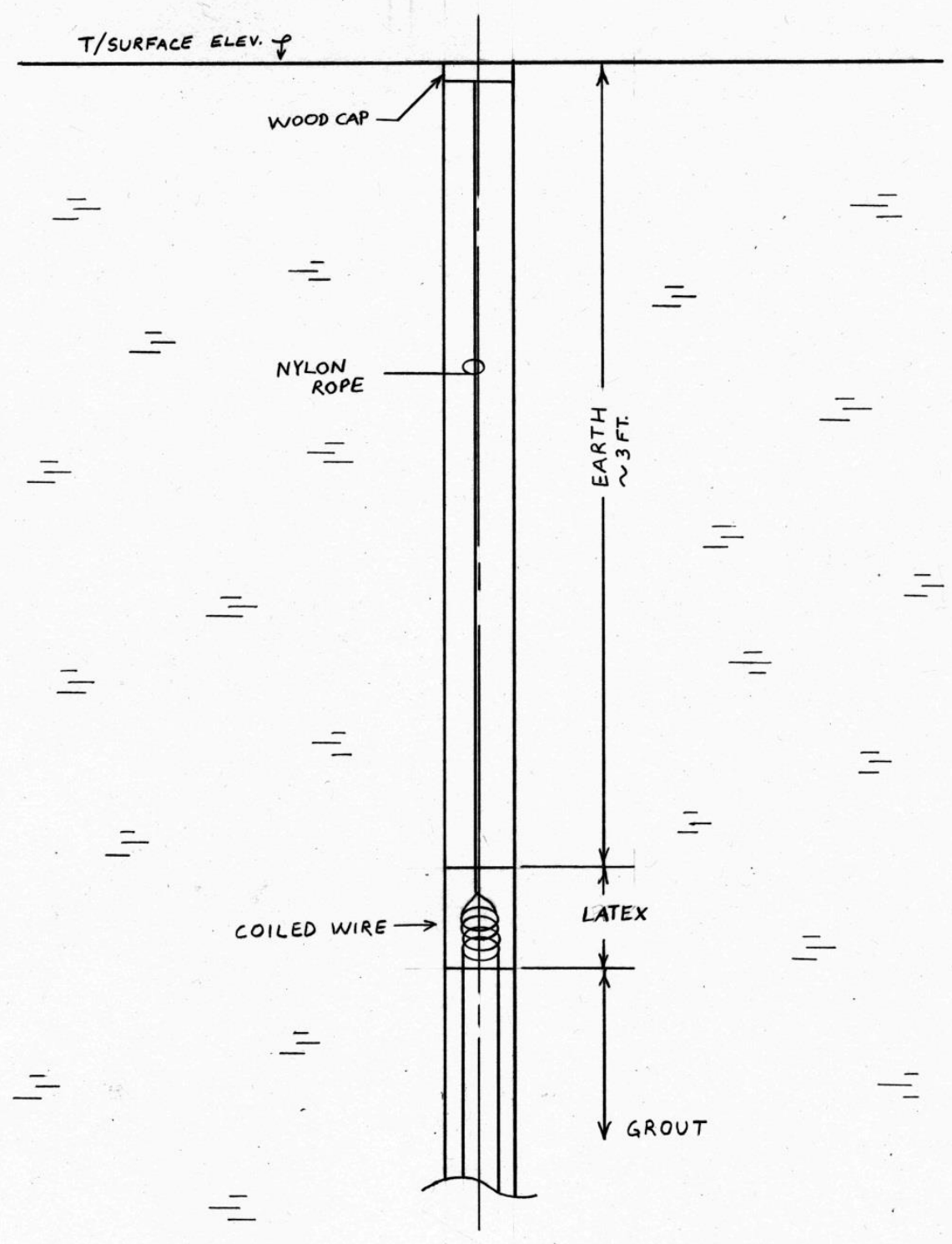

Figure 3.4: Alternate suggestion for top termination of drillhole communication link when top elevation of device must be placed significantly below grade.

The next section reviews considerations for location of the exploration drillholes to make them suitable for use as communication links during mine development. 


\subsection{Location of Drillholes During Mine Pre-Planning}

In the events at Quecreek and Sago, as well as countless others, the miners were trapped at an inby location. It is also, perhaps, intuitive that, as the working face advances, and with the exception of utilities and shops, the inby areas are the locations where one would expect to find the largest concentration of personnel. These inby locations are also generally the most distant from the traditional communication devices.

During mine pre-planning, the goal is to locate certain exploratory drillholes so that, when the mine is developed, these drillholes coincide with the mains and/or submains underground. Then, as the continuous miner cuts the mains, the drillhole is intersected as shown previously in Figure 3.2. This drillhole has previously been grouted and equipped with a communication wire as described in this chapter, perhaps several years prior to the development of the underground mine. As mentioned in Section 3.1, the conductors would be cut in shear, along with the grout, when the continuous miner passes thereby making the link available for connection underground.

Figure 3.5 represents a plan view of a coal reserve, with the layout of exploration boreholes, with the grid representing approximate half-mile spacing.

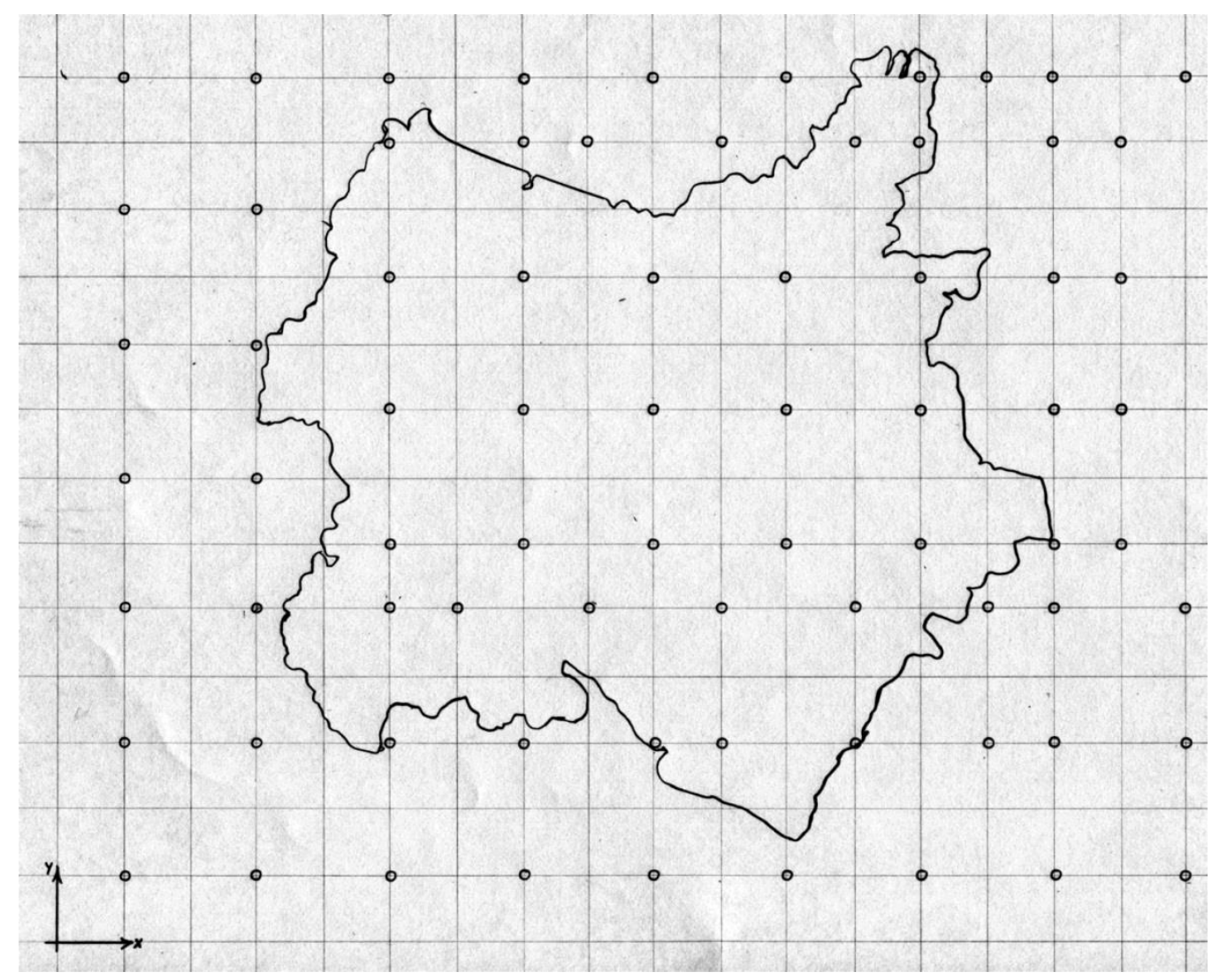

Figure 3.5: Exploration boreholes over a coal reserve. 
The principal directive is, during mine design, to layout the exploratory drillholes, which are generally located on half-mile centers, so that they also coincide with the planned underground mains, preferably at crosscuts forming intersections. This is recommended so that the holes are located in intake air instead of return or belt entries and it is desired to make any communication system as visible as possible. Additionally, locating the devices in mains provides a larger volume of intake air which may assist with the dilution of any methane which may be present. Main entries are usually part of the primary escapeway. With half-mile spacing connecting a single pager phone directly at the drillhole communication links would provide an emergency communication path, at best, every half mile along the entries as shown in Figure 3.6.

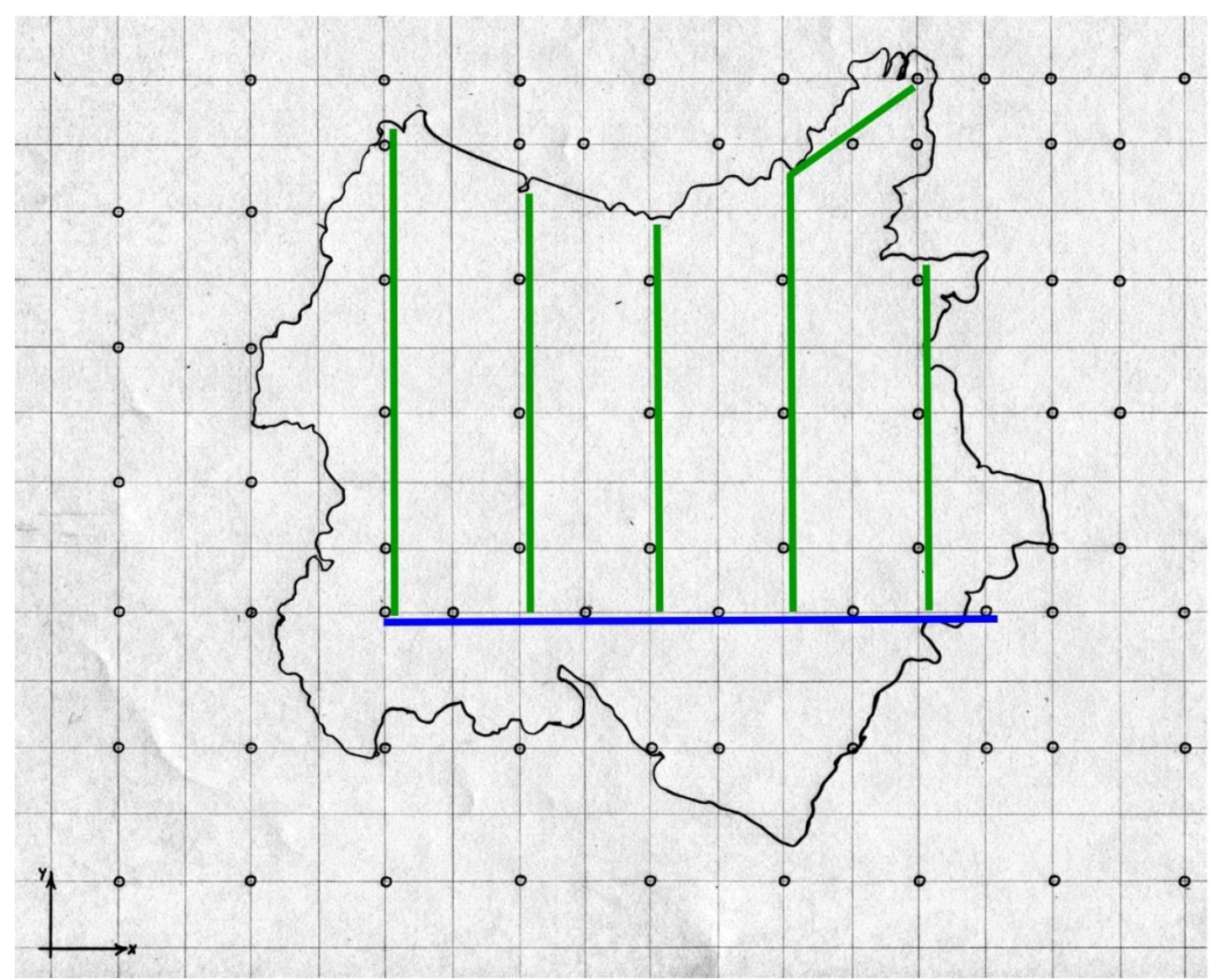

Figure 3.6: Proposed entries along paths that intersect exploration boreholes.

One enhancement would be to set refuge chambers at crosscuts near the drillholes that were outfitted with communication wires, as shown in Figure 3.7, and commensurate with the FosterWilson report of 1983 and Bureau of Mines Information Circular 8955 (1984, pp. 72-73) . Connections would also be made with the mine telephone system and could be disconnected outby in the event of a service interruption.

While this may suffice for refuge chambers that are left in place along mains designated as escapeways, it would not be sufficient in the section where the working face is continually advancing, with the refuge chamber advancing behind it. In this case, a connection to the mine telephone system would provide the link between the chambers and the drillhole communication links to the surface. The surface connections would not be made unless an emergency required 
this, and outby connections in the mine could be severed if an event rendered the primary communication paths inoperable. The advantage of making connections at or near refuge chambers is that they are clearly marked underground and their locations are updated on mine maps that are kept aboveground after every move. It should be noted that, if the communication link wires are shorted together at the surface during the dormancy period (an option discussed later) connection to an active underground network is not possible.

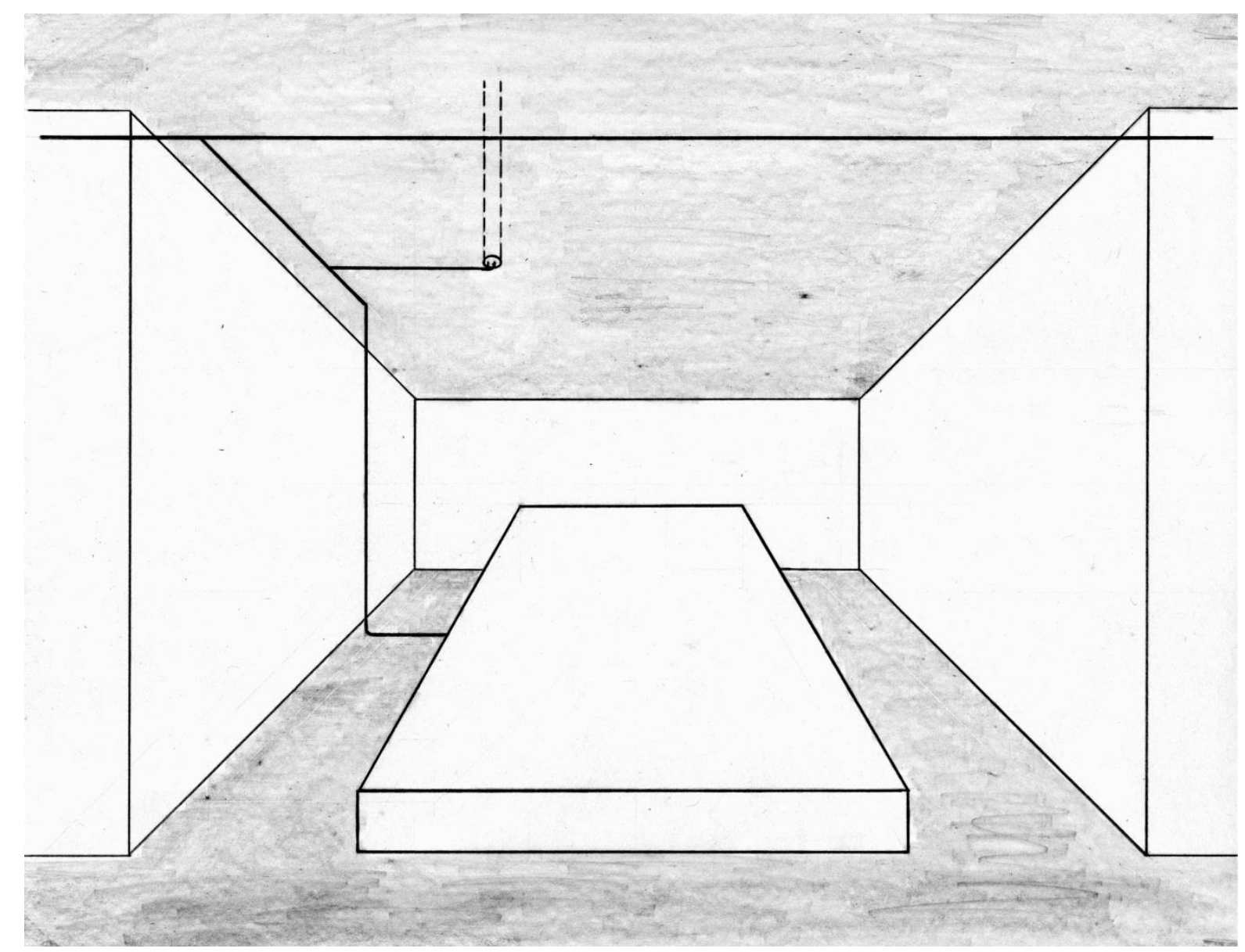

Figure 3.7: Drillhole communication link wires connected to mine telephone system and refuge chamber in crosscut.

Regarding topography, it is assumed that, if one can get a drill rig to the site to make the exploration drillhole, then one can also access the communication link embedded in that same drillhole at a future date. While this is intuitive, the larger consideration is being able to precisely locate the drillhole communication link so that connections can be made quickly, and contact established with miners trapped underground. The issues with GPS at Sago Mine were described in Section 2.4.2. It is thus highly recommended that the location of drillholes be marked not only with respect to GPS surveying coordinates, but also using a scheme whereby they can easily be located using total station methods or a measuring wheel from established monuments. Using simple location techniques, one person with a measuring wheel, a map, a shovel, and a sound-powered telephone could make contact with trapped miners in less than an hour in any type of weather conditions. Note that, since the boreholes would be filled with grout, 
an electromagnetic technique that was developed for locating open boreholes would not apply (Sacks, 1978).

Later, in Section 6.1.2, the phenomenon of side flashing by lightning is described where it is suggested that underground utility lines, such as gas and water lines, can provide a good earth ground. As the current wavefront of a lightning strike travels the metallic path its force is attenuated. Thus, one may assume that locating an exploration drillhole near such utility lines would serve as insurance against lightning. However, since side flashes have been known to travel several hundred feet, it is actually more desirable to plan to locate drillholes more distant from not only underground fixtures but also tall aboveground structures such as high voltage transmission towers that exceed the "ordinary height" as will be described in Chapter 6. Higgins and Morris (2006) hypothesize that ground currents at Sago could have, but likely did not, originate from high voltage transmission towers in the vicinity (pp. 59-61). Furthermore, as Section 6.2.1 will discuss, the likelihood of a direct strike to any given location is less than once every 10,000 years and the installation of such a device does not "attract" lightning.

\subsection{Considerations Related to Drilling}

When a continuous miner cuts through a grouted exploration borehole, the borehole itself is evident due to the cylinder of grout which often separates from the coal at the cutter head. However, locating these grouted boreholes after development of the mains has been completed becomes problematic. A field study was undertaken in an underground coal mine in southwestern Pennsylvania with the express goal of locating exploration borehole penetrations in the roof.

Numerous attempts were made to locate, underground, grouted exploratory boreholes as marked on the mine map at a longwall operation where most exploratory boreholes were located above the longwall panels, not the development entries. Since exploration was undertaken without consideration to purposefully align the hole pattern with the mains, only eight drillholes were depicted along entries on the mine map. Five of these became located in bleeders or in areas that were, for various other reasons, no longer pre-shifted by the fire boss and, therefore, could not be readily accessed. Three holes that were depicted on the mine map could not be definitively identified from underground. Two individuals were present for each attempt, and each attempt employed a different individual along with the primary searcher. Attempts to locate two of the three boreholes were undertaken twice, by different teams. Ability to differentiate grouted boreholes from the surroundings was identified as an issue, as was the possibility that drilling deviation may have driven the exploration holes into the ribs instead of the entries as depicted on the mine map. The former issue will be addressed in Section 3.4, and the latter in the next section.

\subsubsection{Accuracy of the Drilling, from Aboveground}

For nominal three-inch core holes, as would be used for the drillhole communication link, a diamond bit is generally used (Landua, 1977, p. 386). Typical core sizes recovered 
include the NX at 1-15/16" O.D. and the NC at 2.34" O.D. If only the mineralized zone requires a core, it is possible that a rotary drill may be used first, followed by a diamond drill to take the core sample (ASTM, 1992; Acker, 1974). This procedure would be more costly inasmuch as it requires additional mobilization and demobilization costs, although it would be suitable for creating a hole in which to embed a communication link.

A minimum hole depth for the often desired electronic data logging of the strata is generally accepted as seven (7) feet below the point at which readings are required. In practice, the hole is often drilled 30-35 feet deeper than necessary to hedge against caving of the side walls or other unforeseen circumstances. Depths below the seam, unlike the overburden thickness, do not contribute to the forthcoming analysis of drilling accuracy since the roof of the mine is usually established near the elevation where the coal seam is intercepted by the drill bit.

Deviation of the drill bit is not a concern when solely taking core samples. As W. L. Acker has stated, "In core drilling it is not how big the hole or how deep the hole but rather the contents of the hole that matters" $(1974$, p. 141). However, if the borehole is to be outfitted with a communication device, then the hole must intersect planned open workings, and deviation is a significant concern. Getting an open, plumb drillhole suitable for a borehole communication device is not a trivial endeavor. Of the challenges that may be encountered by the driller, Acker includes:

... blind holes where water is lost; caving holes where the hole will not stay open; squeezing holes where the material actually squeezes in when the bit has passed; and then consider that the rock can be hard, soft, extremely abrasive, fractured, or cleved in vertical seams (the worst kind); or perhaps full of voids and boulders, laden with clay seams that lead to no end of trouble (p. 144).

Multiple authors have cautioned that a skilled operator for the drill rig is a necessity, since many of the other factors cannot be controlled.

An assumption will be made herein that the results of these undesirable conditions can be encapsulated, at least partially, in the analysis of possible deviation of the drill bit during drilling operations, where such deviation is limited to angularity measured from a true vertical axis.

Referring to Figure 3.9, the maximum amount of angular deflection from vertical allowable for the drill rig, to still encounter the targeted entry, is given by

$$
\alpha=\arctan \left(\frac{w}{h}\right)
$$

where $\alpha$ represents the maximum angular deflection, $w$ is the entry width, and $h$ is the overburden height. The largest "target area" would be formed by an intersection of a crosscut with the mains, where the radius $r$ is dependent on the mined entry width, $w$, in the form

$$
r=\sqrt{2} * w
$$


which increases the maximum allowable angular deflection to

$$
\alpha=\arctan \left(\frac{\sqrt{2} * w}{h}\right) .
$$

As an example, assume an entry width for the mains is a nominal twenty (20) feet, then the maximum allowable angular deflection can be tabulated as a function of overburden height, $h$, as shown in Table 3.1 .

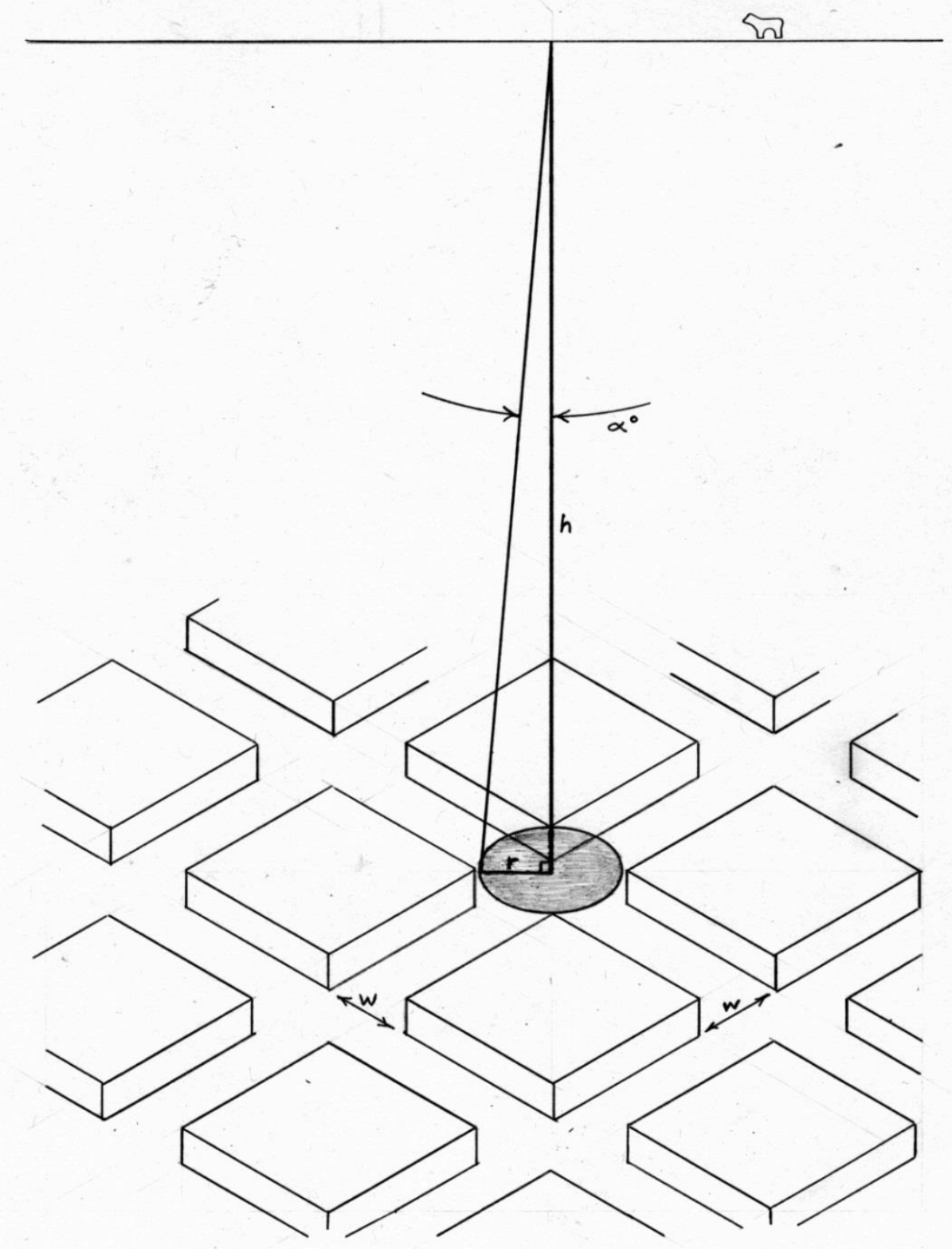

Figure 3.8: For calculation of maximum allowable angular deflection from vertical. 
Table 3.1: Maximum angular deflection as a function of overburden depth, 400-1300 feet, based on the intersections formed by entries of nominal 20 -foot width.

\begin{tabular}{cc}
$\begin{array}{c}\text { Overburden Depth } \\
\text { (feet) }\end{array}$ & $\begin{array}{c}\text { Maximum Angular } \\
\text { Deflection from } \\
\text { Vertical (degrees) }\end{array}$ \\
\cline { 2 - 2 } 400 & 4.045 \\
425 & 3.807 \\
450 & 3.597 \\
475 & 3.408 \\
500 & 3.238 \\
525 & 3.084 \\
550 & 2.944 \\
575 & 2.816 \\
600 & 2.699 \\
625 & 2.591 \\
650 & 2.492 \\
675 & 2.399 \\
700 & 2.314 \\
725 & 2.234 \\
750 & 2.160 \\
775 & 2.090 \\
800 & 2.025 \\
825 & 1.964 \\
850 & 1.906 \\
875 & 1.851 \\
900 & 1.800 \\
925 & 1.751 \\
950 & 1.705 \\
975 & 1.662 \\
1000 & 1.620 \\
1025 & 1.581 \\
1050 & 1.543 \\
1075 & 1.507 \\
1100 & 1.473 \\
1125 & 1.440 \\
1150 & 1.409 \\
1175 & 1.379 \\
1200 & 1.350 \\
1225 & 1.323 \\
1250 & 1.296 \\
1275 & 1.271 \\
1300 & 1.246 \\
&
\end{tabular}

The data of Table 3.1 is charted in Figure 3.7 and shows, as would be expected, that the greater the amount of overburden, the more accurate would have to be the plumbness of the exploration borehole drill rig. This accuracy asymptotically approaches a value approximately $1.2 \%$ 
allowable deviation from vertical assuming the diamond drilling bit remains aligned with the intended path.

Accuracy Required to Intersect 20-ft. Main at Crosscut as a Function of Borehole Drilling Depth

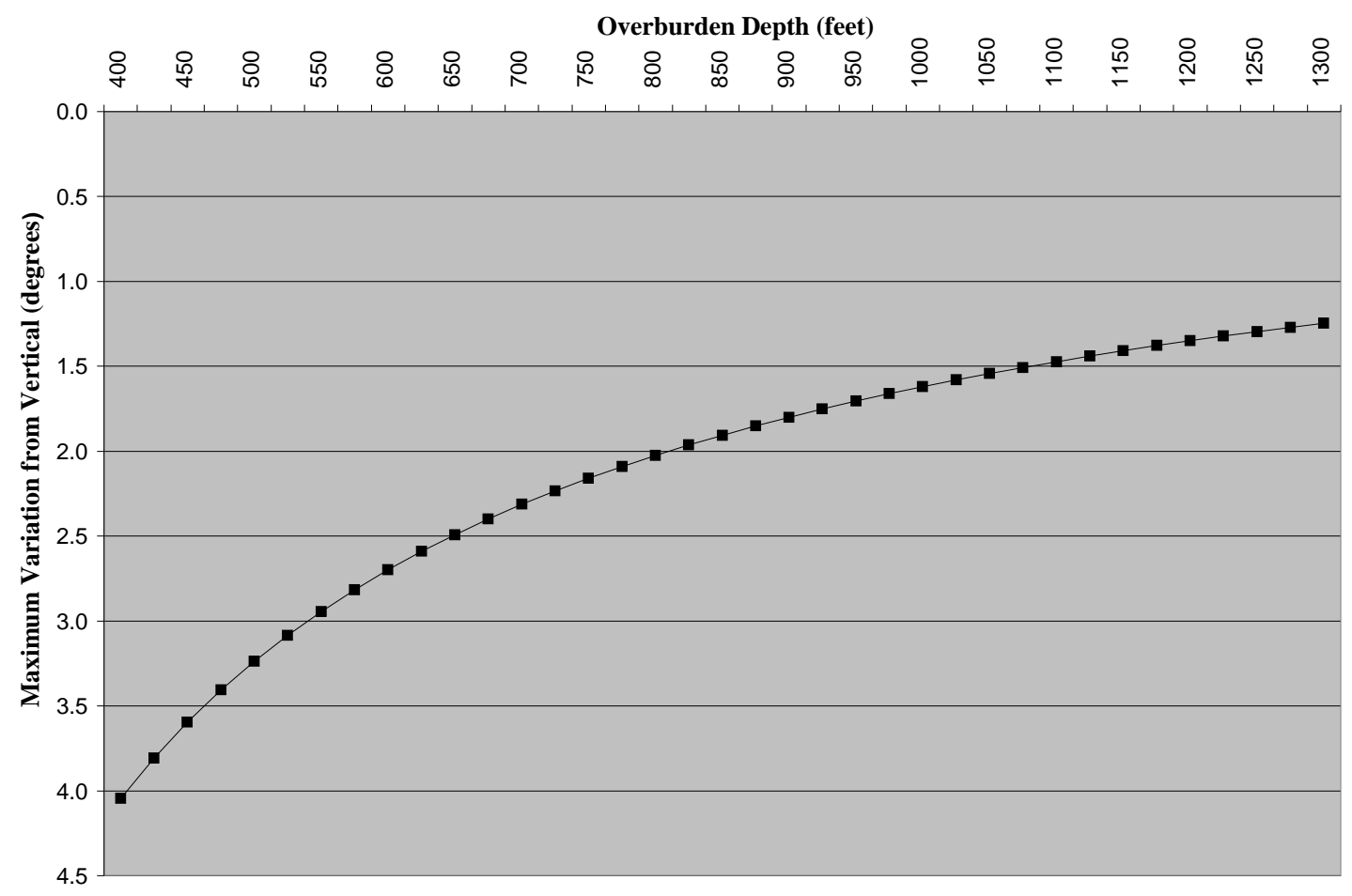

Figure 3.9: Maximum deviation from vertical for an exploration drillhole rig to be able to intersect a 20-ft. $x$ 20 -ft. intersection, as a function of overburden depth.

Warner (2004) says that driller technique is of less importance to plumbness than the effects of the initial drill rig positioning and the geology penetrated. According to Warner, "In relatively homogeneous formations and with reasonable care in setup and drilling, the holes should remain within a tolerance of approximately 3 degrees to a depth of $100 \mathrm{ft}(30 \mathrm{~m})$ and 5 degrees to $250 \mathrm{ft}(75 \mathrm{~m}) \ldots$... (p. 203). At $250 \mathrm{ft}$. overburden, this corresponds to a possible deviation from vertical of $21.87 \mathrm{ft}$. at the target area. If it is assumed that the drill rig is properly centered at the surface, as in Figure 3.8, this deviation corresponds to a great deal of uncertainty as to the eventual location of the drillhole underground with respect to the intended location.

Expanding on the concept shown in Figure 3.8, and assuming that the target entry such as a main or submain is in intake air, then the acceptable target radius can be expanded down the entry and crosscut with the exception of those locations where the rib projects into the radius. 
This area is shown in Figure 3.10. The expected value (probability) of the drill hole intersecting a usable area, therefore, is the ratio of the usable area to the total area of the deviation radius

$$
\text { Ratio }=\frac{A_{\text {avail }}}{A_{\text {deviation }}}
$$

where the total area of the deviation radius is

$$
A_{\text {deviation }}=\pi R^{2}
$$

and the deviation radius, $R$, is a function of the deviation angle, $\alpha$, previously shown in Figure 3.8 and the overburden height, $h$,

$$
R=h \tan (\alpha)
$$

The available area, $A_{\text {avail }}$, is a function of the deviation radius and, therefore, the deviation angle and overburden height. Referring to Figure 3.10, the available area, shown in the first quadrant, is the area created by the deviation radius less the area occupied by coal

$$
A_{\text {avail }}=A_{\text {deviation }}-A_{\text {coal }}
$$

where the area occupied by coal can be represented by the sum of the triangles $S-L-S$ plus the circular segment at $L$ in Figure 3.10, with the area of the circular segment calculated by subtracting the area of triangle $R-L-R$ from the sector created by the angle $\varphi$. 


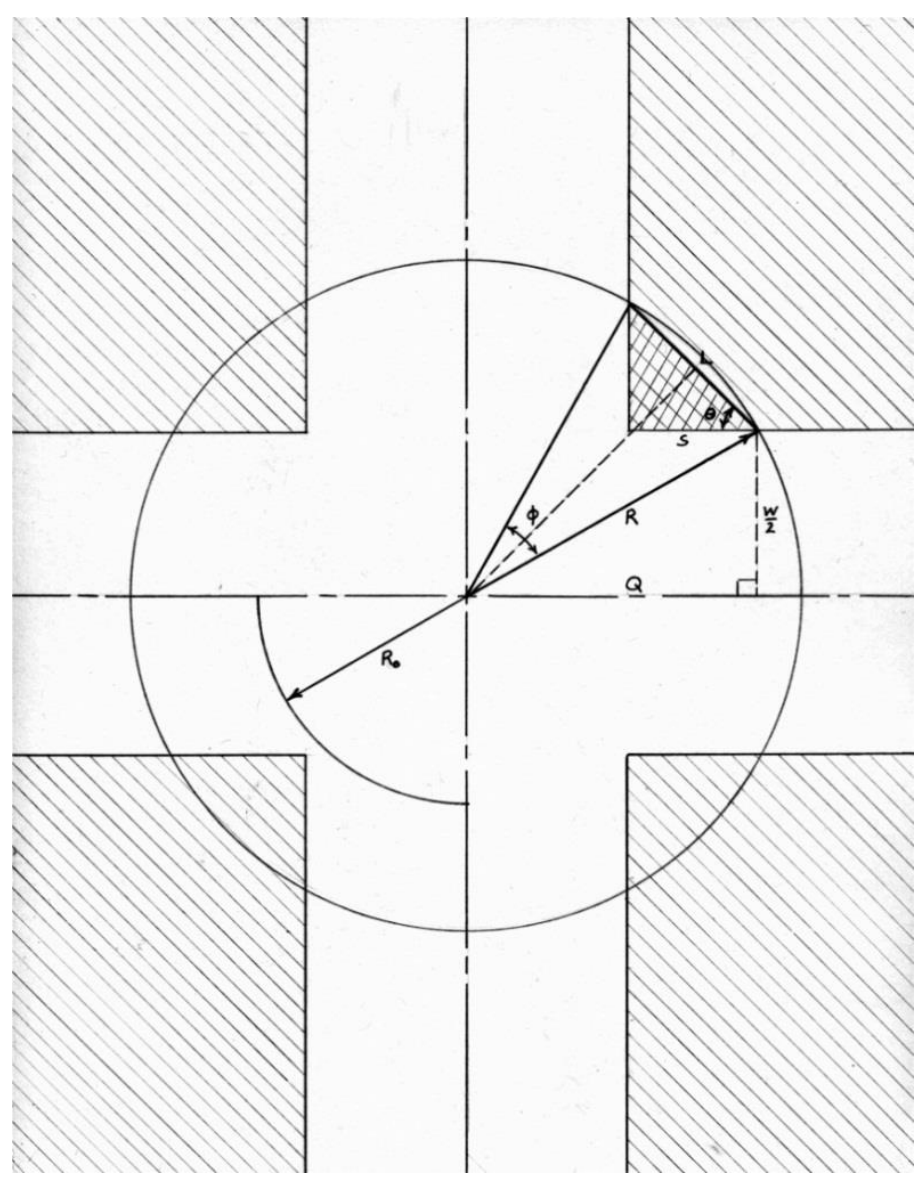

Figure 3.10: Drilling deviation radius with relation to underground intersection.

\subsubsection{Derivation of Drilling Equation}

Before deriving an equation to determine the probability of intersecting a feasible planned intersection with the mains, a couple assumptions are made. First, that the deviation of the drill rig is uniform in all directions. In practice, differing geologic conditions could have adverse effects on the deviation angle. However, these conditions are not known at the time of drilling, so uniformity is assumed so that the deviation is likely to occur in any direction from the vertical axis of the drill rig. Second, the workings are assumed to be square. Again, it is possible that a turnout is in a given intersection, and it is also likely that the ribs are not perfectly square and true. However, an ideal intersection as shown in the figures of this section suffices as a start point.

It has already been noted that the probability of intersecting an area intended as open workings can be expressed as a ratio of the area of open workings contained within the drilling deviation radius divided by the drilling deviation radius itself. This ratio is a function of the overburden height, $h$, the deviation angle, $\alpha$, and the entry width, $w$. The deviation radius, $R$, is a function of overburden height, $h$, and deviation angle, $\alpha$.

$$
R=h \tan (\alpha)
$$


This will be substituted back into the derivation later. For now, consider Figure 3.11. Instead of dividing the circle into the four standard quadrants, as in Figure 3.10, consider four quadrants separated by axes defined on $(\pi / 4)$ and $(-\pi / 4)$. Now, the open workings for any such quadrant are comprised of the area of the triangle, $A$, the rectangle, $B$, and the circular segment, $C$.

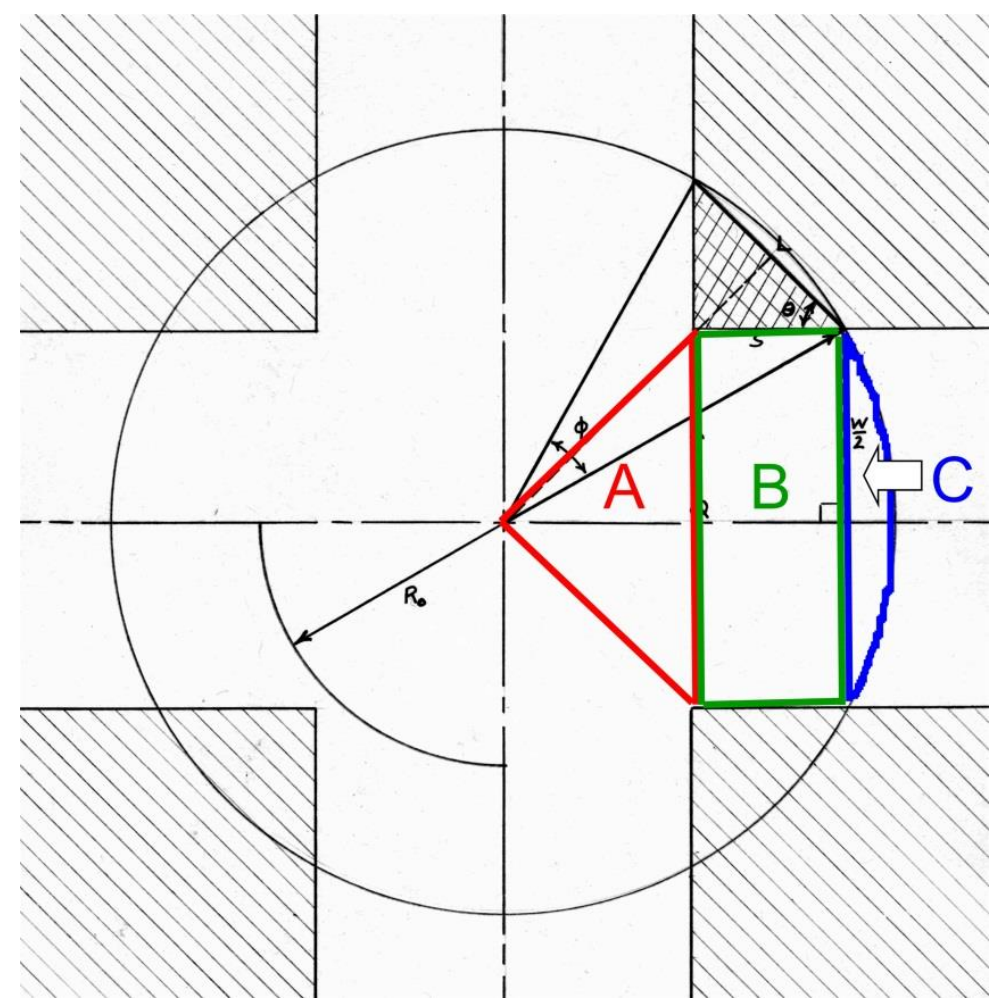

Figure 3.11: Three areas used for calculation of open workings.

In the reduced case, where the drilling deviation radius forms a circle inscribed in the intersection, the rectangular area, $B$, reduces to zero. The area of open workings, then is

$$
A_{\text {open }}=A_{A}+A_{B}+A_{C}
$$

The area, $A$, is a scalene triangle with a base the length of the entry width and a height of half the entry width. The area of this triangle is

$$
A_{A}=\frac{1}{2}(\text { base })(\text { height })=\frac{1}{2}\left(\frac{w}{2}+\frac{w}{2}\right) \frac{w}{2}=\frac{1}{4} w^{2}
$$

where $w$ is the entry width. 
The area, $B$, is formed by a rectangle with one side equal to the length of the entry width, $w$, and the orthogonal side labeled as $s$, to give an area

$$
A_{B}=s w
$$

As Figure 3.12 shows, for a deflection angle $\Delta$, a triangle can be formed with a hypotenuse equal to the deviation radius, $R$, and a short side with a length of half an entry width.

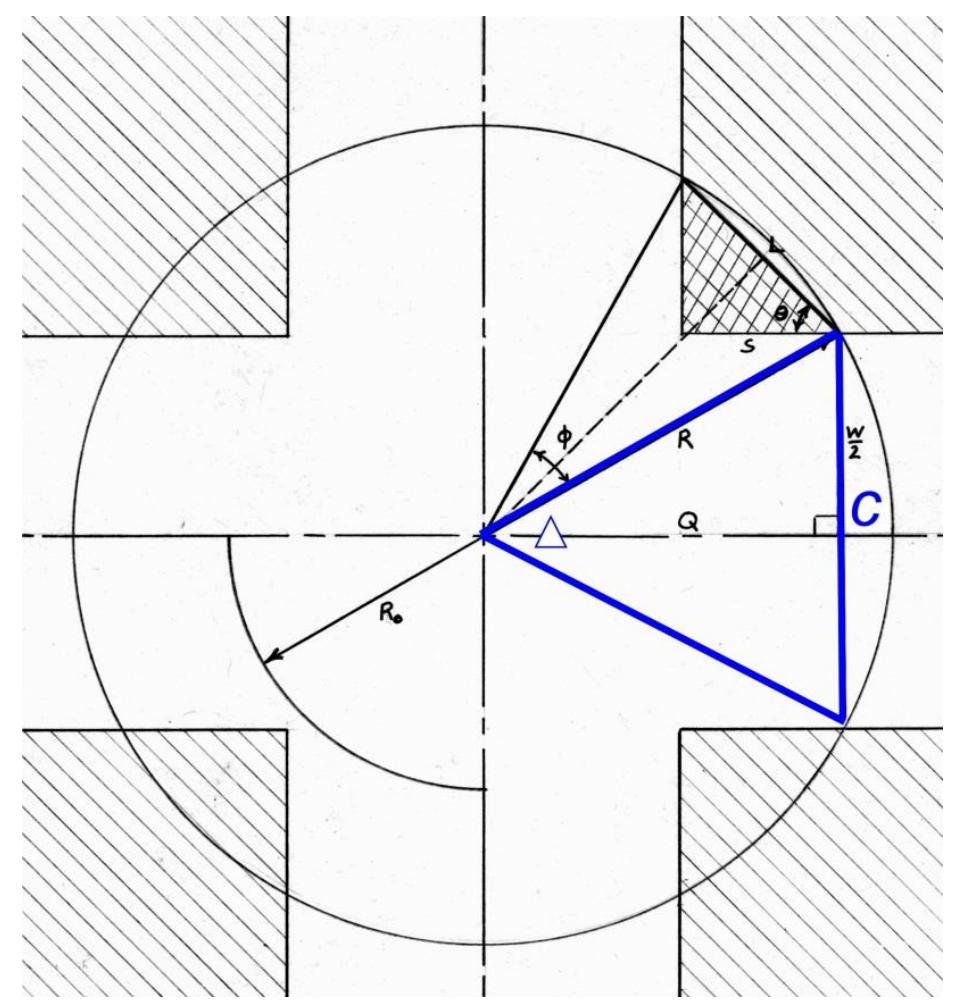

Figure 3.12: Deflection angle and long chord.

The long side is the projection of the deviation radius and is equivalent to the sum of half an entry width with the length $s$. The included angle between the projection and the deviation radius is, then, half of the deflection angle. Thus,

$$
\tan \left(\frac{\Delta}{2}\right)=\frac{\frac{w}{2}}{\left(\frac{w}{2}+s\right)}
$$

so that

$$
\cos \left(\frac{\Delta}{2}\right)=\frac{\left(\frac{w}{2}+s\right)}{R}
$$


or

$$
R * \cos \left(\frac{\Delta}{2}\right)=\left(\frac{w}{2}\right)+s
$$

and

$$
s=R * \cos \left(\frac{\Delta}{2}\right)-\frac{w}{2}
$$

Then, the area of rectangle $B$ is

$$
A_{B}=\left(R * \cos \left(\frac{w}{2}\right)-\frac{w}{2}\right)(w)=w R * \cos \left(\frac{\Delta}{2}\right)-\frac{w^{2}}{2}
$$

The area of the circular segment, $C$, is found from the formula

$$
A_{C}=\frac{1}{2} R^{2}(\Delta-\sin (\Delta))
$$

To get the deflection angle, $\Delta$, it is recognized that the length of the long chord, $c$, is equivalent to the entry width, $w$ and the long chord is given by the equation

$$
c=2 R * \sin \left(\frac{\Delta}{2}\right)
$$

If $c=w$, then

$$
w=2 R * \sin \left(\frac{\Delta}{2}\right)
$$

Solving for the deflection angle gives

$$
\Delta=2 * \arcsin \left(\frac{w}{2 R}\right)
$$

which can be substituted into the total area equation.

Substituting Equations 3.10, 3.16, and 3.17 into the total area equation, Equation 3.9, gives

$$
A_{\text {open }}=\frac{1}{4} w^{2}+w R * \cos \left(\frac{\Delta}{2}\right)-\frac{w^{2}}{2}+\frac{1}{2} R^{2}(\Delta-\sin (\Delta))
$$

Substituting the value of the deflection angle, from Equation 3.20 into Equation 3.21 gives

$$
\begin{aligned}
& \quad A_{\text {open }}=\frac{1}{4} w^{2}+w R * \cos \left(\frac{1}{2}\left(2 * \arcsin \left(\frac{w}{2 R}\right)\right)-\frac{w^{2}}{2}+\frac{1}{2} R^{2}\left(\left(2 * \arcsin \left(\frac{w}{2 R}\right)-\sin ((2 *\right.\right.\right. \\
& \left.\left.\arcsin \left(\frac{w}{2 R}\right)\right)\right)
\end{aligned}
$$


which simplifies to

$$
A_{\text {open }}=-\frac{1}{4} w^{2}+w R * \cos \left(\arcsin \left(\frac{w}{2 R}\right)\right)+R^{2} \arcsin \left(\frac{w}{2 R}\right)-\frac{1}{2} R^{2} \sin \left(2 \arcsin \left(\frac{w}{2 R}\right)\right)
$$

Considering the term second term in Equation 3.23, $\arcsin (w / 2 R)$ can be represented as angle $\theta$ in a right triangle with hypotenuse $2 R$ and short side $w$. The cosine of this angle is

$$
\cos (\theta)=\frac{\sqrt{(2 R)^{2}-w^{2}}}{2 R}
$$

which can be substituted into Equation 3.23 to give

$$
A_{\text {open }}=-\frac{1}{4} w^{2}+w R * \frac{\sqrt{(2 R)^{2}-w^{2}}}{2 R}+R^{2} \arcsin \left(\frac{w}{2 R}\right)-\frac{1}{2} R^{2} \sin \left(2 \arcsin \left(\frac{w}{2 R}\right)\right)
$$

Now, let $\theta$ represent the angle related to the last term so that

$$
\theta=\arcsin \left(\frac{w}{2 R}\right)
$$

and Equation 3.25 becomes

$$
A_{\text {open }}=-\frac{1}{4} w^{2}+w R * \frac{\sqrt{(2 R)^{2}-w^{2}}}{2 R}+R^{2} \arcsin \left(\frac{w}{2 R}\right)-\frac{1}{2} R^{2} \sin (2 \theta)
$$

Further, trigonometry shows that

$$
\sin (2 \theta)=2 \sin (\theta) \cos (\theta)
$$

so

$$
A_{\text {open }}=-\frac{1}{4} w^{2}+w R * \frac{\sqrt{(2 R)^{2}-w^{2}}}{2 R}+R^{2} \arcsin \left(\frac{w}{2 R}\right)-\frac{1}{2} R^{2}(2 \sin (\theta) \cos (\theta))
$$

and, substituting Equation 3.26 back into Equation 3.29 gives 


$$
\begin{gathered}
A_{\text {open }}= \\
-\frac{1}{4} w^{2}+w R * \frac{\sqrt{(2 R)^{2}-w^{2}}}{2 R}+R^{2} \arcsin \left(\frac{w}{2 R}\right)-\frac{1}{2} R^{2}\left(2 \sin \left(\arcsin \left(\frac{w}{2 R}\right)\right) \cos \left(\arcsin \left(\frac{w}{2 R}\right)\right)\right)
\end{gathered}
$$

and, using the properties of triangles, the last term simplifies, yielding

$$
A_{\text {open }}=-\frac{1}{4} w^{2}+w R * \frac{\sqrt{(2 R)^{2}-w^{2}}}{2 R}+R^{2} \arcsin \left(\frac{w}{2 R}\right)-R^{2}\left(\frac{w}{2 R}\right)\left(\frac{\sqrt{(2 R)^{2}-w^{2}}}{2 R}\right)
$$

Then, rearranging and simplifying gives

$$
A_{\text {open }}=-\frac{1}{4} w^{2}+\frac{1}{4} w \sqrt{(2 R)^{2}-w^{2}}+R^{2} \arcsin \left(\frac{w}{2 R}\right)
$$

Equation 3.32, however, was developed for a single "quadrant" with the axes rotated to a principle angle of $\pi / 4$, so that the entire open area is four times that of Equation 3.32, or

$$
A_{\text {OT }}=A_{\text {open, total }}=4 R^{2} \arcsin \left(\frac{w}{2 R}\right)+w\left(\sqrt{(2 R)^{2}-w^{2}}-w\right)
$$

after rearranging.

Recall that $R$ is a function of the overburden, $h$, and the deviation angle, $\alpha$, as shown in Equation 3.8. Substituting Equation 3.8 into Equation 3.31,

$$
A_{O T}=4(h \tan (\alpha))^{2} \arcsin \left(\frac{w}{2 h \tan (\alpha)}\right)+w\left(\sqrt{(2 h \tan (\alpha))^{2}-w^{2}}-w\right)
$$

The total area of the deviation radius is

$$
A_{R}=\pi R^{2}
$$

or, after substituting Equation 3.8,

$$
A_{R}=\pi(h \tan (\alpha))^{2}
$$

Now, the ratio giving the likelihood of intersecting planned open workings is

$$
\text { Ratio }=\frac{A_{O T}}{A_{R}}
$$


which is Equation 3.34 divided by Equation 3.35

$$
\text { Ratio }=\frac{A_{O T}}{A_{R}}=\frac{4(h \tan (\alpha))^{2} \arcsin \left(\frac{w}{2 h \tan (\alpha)}\right)+w\left(\sqrt{(2 h \tan (\alpha))^{2}-w^{2}}-w\right)}{\pi(h \tan (\alpha))^{2}}
$$

which simplifies to

$$
\text { Ratio }=\frac{4}{\pi} \arcsin \left(\frac{w}{2 h \tan (\alpha)}\right)+\frac{w\left(\sqrt{(2 h \tan (\alpha))^{2}-w^{2}}-w^{2}\right)}{\pi(h \tan (\alpha))^{2}}
$$

This equation, Equation 3.39, applies when the deviation radius extends beyond the corner of the rib, as shown in Figures 3.8-3.10. If the deviation radius is completely inscribed in the intersection, the ratio for the probability of intersecting open workings is unity. Thus, the full equation becomes

$$
\begin{aligned}
& \text { Ratio }=\left\{1 \quad \text { if } h \tan (\alpha) \leq \frac{\sqrt{2}}{2} w\right. \\
& \left\{\frac{4}{\pi} \arcsin \left(\frac{w}{2 h \tan (\alpha)}\right)+\frac{w\left(\sqrt{(2 h \tan (\alpha))^{2}-w^{2}}-w^{2}\right)}{\pi(h \tan (\alpha))^{2}} \quad \text { if } h \tan (\alpha)>\frac{\sqrt{2}}{2} w\right.
\end{aligned}
$$

This can be checked by examining the border conditions created by the situation where

$$
R=h \tan (\alpha)=\frac{\sqrt{2}}{2} w
$$

Substituting this into Equation 3.39,

$$
\text { Ratio }_{\text {check }}=\frac{4}{\pi} \arcsin \left(\frac{w}{2\left(\frac{\sqrt{2}}{2} w\right)}\right)+\frac{w\left(\sqrt{\left(2\left(\frac{\sqrt{2}}{2} w\right)\right)^{2}-w^{2}}-w^{2}\right)}{\pi\left(\frac{\sqrt{2}}{2} w\right)^{2}}
$$

and the right-hand term cancels out with the left-hand term becoming

$$
\text { Ratio }_{\text {check }}=\frac{\pi}{4} \arcsin \left(\frac{1}{\sqrt{2}}\right)=1.00
$$

An algorithm was programmed to generate the Ratio of equation 3.40, for the parameters of Table 3.2. Note that these values were not chosen from any particular field case but, rather, were chosen to characterize the behavior of the expected value over a range of values approximately centered on values that would be considered common. 
Table 3.2: Input values for calculation of Ratio indicating expected value of drillhole intersecting an open area of an entry, depending on deviation of drill rig, overburden, and entry width.

\begin{tabular}{|c|c|c|c|}
\hline$\underline{\text { Variable }}$ & Minimum Value & Maximum Value & $\underline{\text { Step Increment }}$ \\
\hline Overburden $(h)$ & $200 \mathrm{ft}$. & $2200 \mathrm{ft}$. & $50 \mathrm{ft}$ \\
\hline Entry Width $(w)$ & $16 \mathrm{ft}$. & $22 \mathrm{ft}$. & $2 \mathrm{ft}$ \\
\hline Deviation Angle $(\alpha)$ & 0 degrees & 8.5 degrees & 0.5 degrees \\
\hline
\end{tabular}

Also note that the " 0 degrees" of minimum deviation in Table 3.2 was actually represented as 0.01 degrees for a starting value to avoid division by zero in the sequential calculations. The algorithm was also designed to return an expected value of unity for the condition when the deviation radius would fall within the intersection as depicted in Figure 3.10, shown in the third quadrant as $R_{0}$.

This condition occurs when

$$
R \leq \frac{W}{2} \sqrt{2}
$$

The data generated was plotted in Figures 3.13-3.16 for ascending values of the entry width. The $x$-axis shows, moving from left to right, an increase in overburden depth. The $y$-axis gives the ratio, or likelihood of intersecting a planned, open, and usable area underground given the specified parameters with the deviation from center, 0.5 to 8.5 degrees, depicted by the series of curves.

These calculations and curves should be viewed as generating a conservative estimate since empirical studies have indicated that ". . . the sum of the diagonals was 3-4 ft. wider than in the shallow mines with the same entry width, probably because of greater rib sloughage" (Molinda et al., 2000, p. 69). 


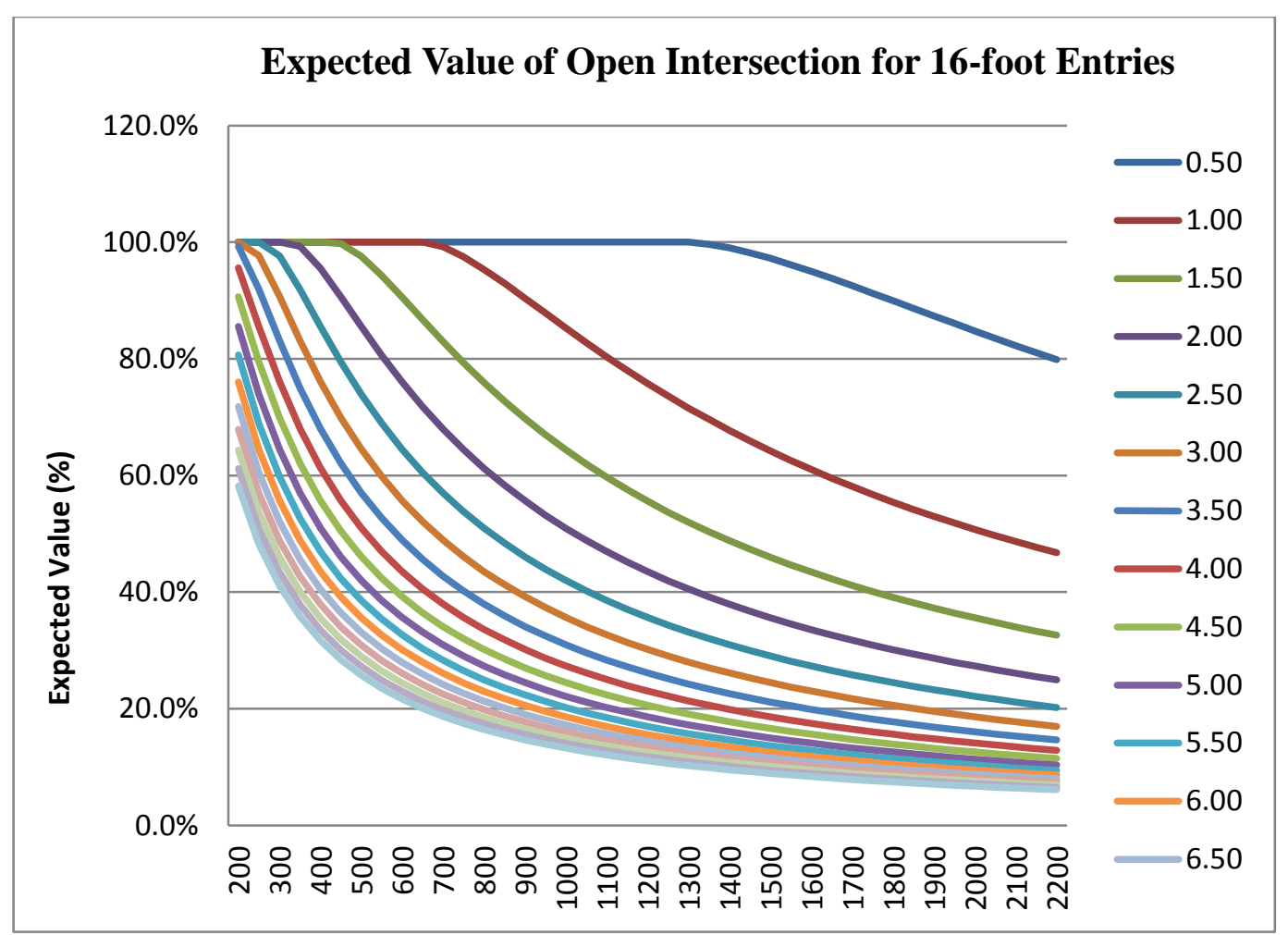

Figure 3.13: Likelihood of intersecting open area vs. overburden, 0.5-8.5 degrees deviation, 16 ft. entry.

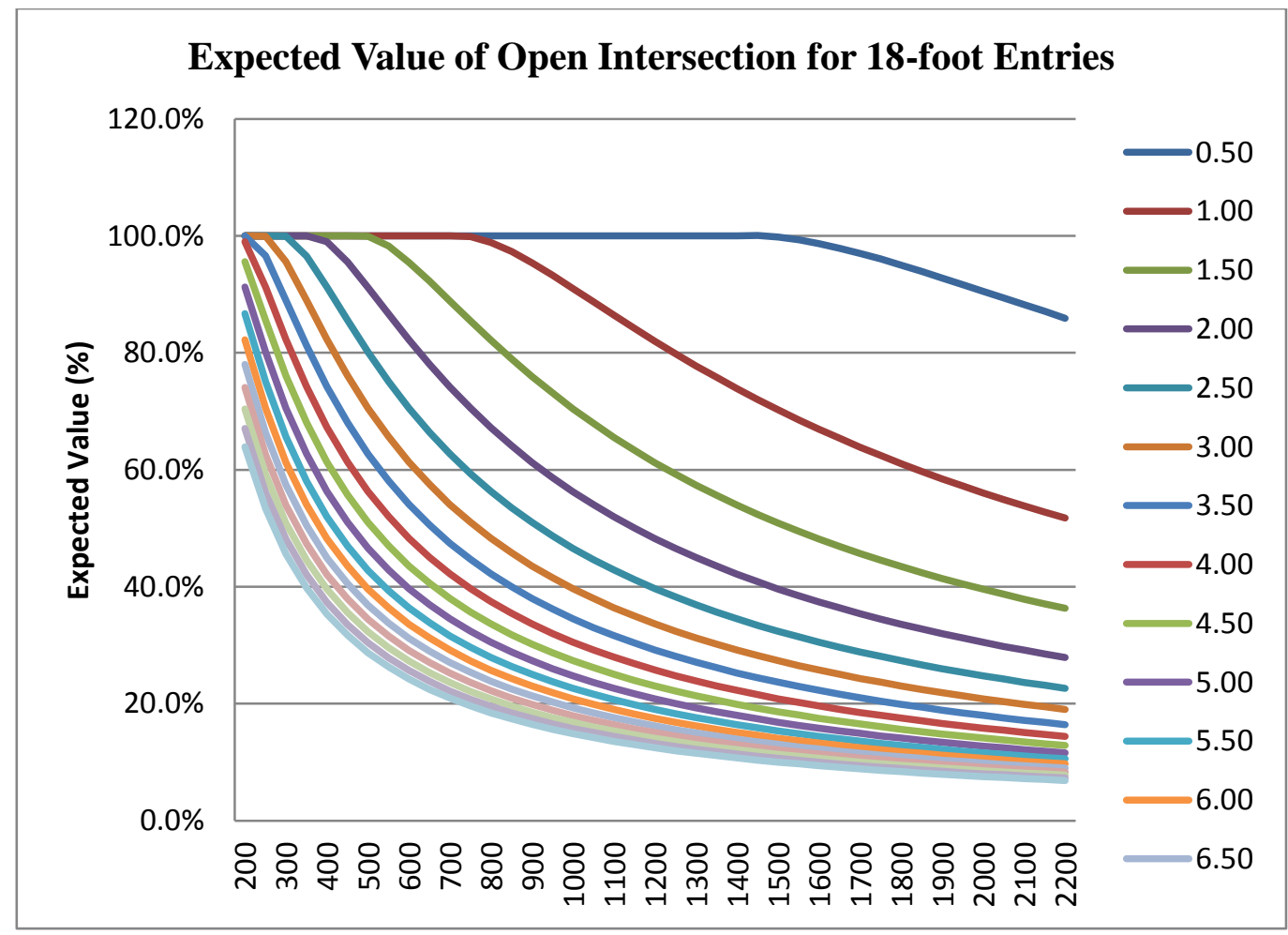

Figure 3.14: Likelihood of intersecting open area vs. overburden, 0.5-8.5 degrees deviation, 18 ft. entry. 


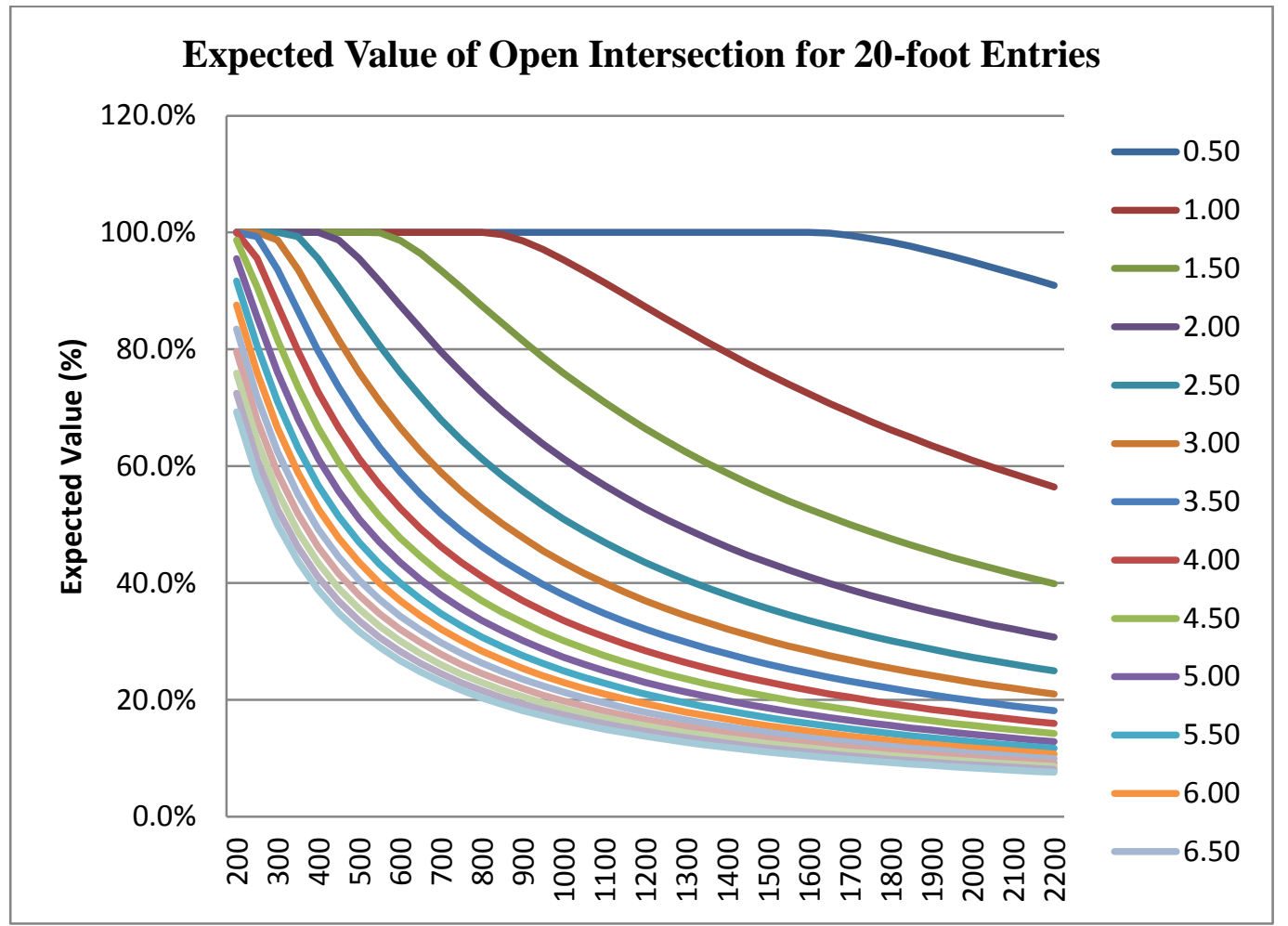

Figure 3.15: Likelihood of intersecting open area vs. overburden, 0.5-8.5 degrees deviation, 20 ft. entry.

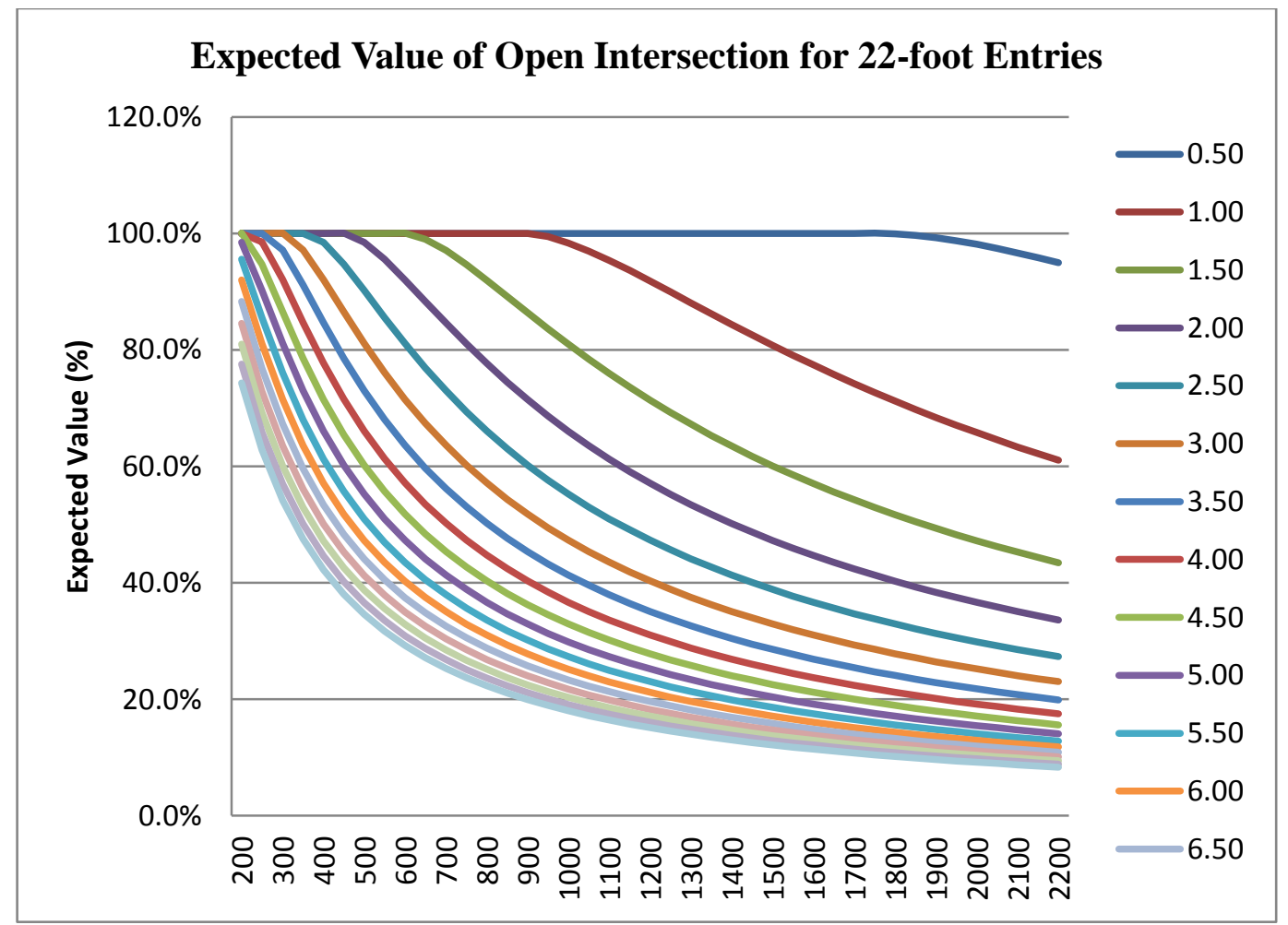

Figure 3.16: Likelihood of intersecting open area vs. overburden, 0.5-8.5 degrees deviation, 22 ft. entry. 
The upshot of the data portrayed in the curves of Figures 3.13-3.16 is that the deeper the overburden and the narrower the entry width, the less robust the intended target is to deviation of the drill rig. For a twenty foot main entry, with nearly 1000 feet of overburden, there is a eighty percent chance of intersecting the main at a crosscut even if the deviation is 1.5 degrees. However, the curves show that, as the deviation increases, the likelihood of intersecting a planned open area drops quickly. In all scenarios developed, the worst case asymptotically approaches a value around $10 \%$.

Given that the probability of missing a feasible target area underground can hover around $60 \%$ for deeper overburden, there are a couple suggestions to mitigate this inconvenience. Unfortunately, some of these would add additional costs to the installation of a communication link device in an exploration borehole.

First, it may be possible to angle the drill rig at a purposeful deflection angle along the centerline axis of the proposed mains. Should an obstruction be struck during the drilling process, the deviation would, hopefully, be directed towards the deflection angle and remain closer to the centerline of the entry, emerging farther inby (or outby) along that centerline. This, of course, is dependent on unknown geological conditions at the precise location of drilling.

Second, it is possible to put a down-the-hole device into the borehole to more precisely determine its location at the elevation of the coal seam. If the location of the borehole does not intersect the planned main entry in a usable manner, a decision has to be made if this distance is significant. Large deviations may "require" the undesirable action of changing the mine plan to ensure that an entry or crosscut intersects the borehole. Small deviations, however, may be mitigated by expanding the entry width slightly where the borehole is located and placing additional cribs for roof support, similar to the methods often used when making turnouts off a main entry.

These scenarios must be considered in conjunction with a recognition that there may be limitations on feasible aboveground locations for the drilling rig which must be able to accurately locate above a projected development entry while adapting to the topography (e.g trees, property lines, utilities) which place additional constraints on site access. Thus, installation of the device to intersect planned mains or submains is preferred.

\subsubsection{Location of the Device, Underground}

Consideration must be given to the long-term placement of any drillhole communication device with respect to the type of entry in which it is to be located. Occasionally, air changes may convert an intake entry into a return entry, or vice versa. Powered devices, with the exception of certain intrinsically safe monitoring systems, are generally not permitted to be located in return air. Thus, although it could theoretically be located in a return and activated during an emergency situation, the drillhole communication device should not be connected to the mine communication network and located in a return entry. 


\subsection{Considerations Related to Grouting}

The design of the drillhole communication link has to be compatible with standard drilling and grouting procedures. This particularly applies to grouting as the drilling is somewhat independent of any devices placed into the hole once it physically exists. In order to refine a conceptual design of the drillhole communication link, a site visit was made to investigate current grouting, and associated drilling, practice. The installation of any communication assembly within the drillhole must be viewed as a simple modification to those performing the drilling and grouting operation. This approach reduces the possibility of making installation errors as well as avoids adding any additional cost to the drilling and grouting operation.

In addition to the physical grouting operation, another consideration relates to the color of the grout itself. In the environment of a coal mine, a grouted borehole, at the point of penetration through the roof, quickly blends into its surroundings. Field observations revealed concerns related to the ability to identify the grouted boreholes. Thereafter, the concepts of color recognition and color diagnosticity were applied to improve this condition.

\subsubsection{Field Observations of Contemporary Grouting Procedure}

On September 14, 2010, a site visit was undertaken at the Sutton Farm near Cassville, West Virginia where Three-D Drilling ${ }^{2}$ was on-site performing grouting operations. The drillholes at this site were exploratory drillholes for a future surface mining operation and were, therefore, shallow in comparison to those that would be expected for an underground mine. Additionally, with the exception of a pilot hole for each three-group cluster, the holes were drilled to a diameter of 5-1/2" instead of three-inch (nominal) holes as would be employed for underground mining coreholes and the proposed borehole communication link.

Grout consisted of Saylor Portland Cement Type I/II mixed at a ratio of one 94-lb. bag to five (5) gallons of water. One 94-lb. bag, so mixed, is sufficient to file a 5-1/2" diameter hole approximately five (5) feet. Obviously, the smaller diameter of an NX or NC three-inch drillhole would require less grout per five feet of vertical fill. This mixture meets ASTM specifications and is considered for the lab experiments of Chapter 5.

The grouting operation was performed by mixing the grout and water in a portable mixer to form a liquid slurry. This mixture was then pumped through a one-inch diameter rubber hose a minimal distance (less than twelve feet) to the drillhole where it was delivered to the bottom via consecutively linked twenty-foot sections of Schedule 80 PVC pipe (PVC 1120 PS21-70 ASTM D-1785) supported from a clevice-type fastener mounted to the boom on the drill rig. The pipe was retracted as the hole was filled, maintaining the delivery near the top level elevation of the grout. The pipe sections were sequentially detached after retraction, rinsed with water and thus salvaged for reuse. Not only is it preferable to salvage the pipe for economic

\footnotetext{
${ }^{2}$ Morgantown, WV (304) 864-3755.
} 
considerations but if too much pipe remains down the hole during grouting the pump may not be able to overcome the head pressure developed by the grout itself.

While sectionalized pipe is more common, in some cases a semi-flexible hose has been used instead of rigid PVC pipe sections to deliver the grout to the bottom of the drillholes. In winter months, such a substitution is problematic since this flexible pipe desires to maintain its spooled configuration in cold temperatures. It is common to stretch out this style of tube in the sunlight to allow it to warm up and, therefore, become more flexible. Additionally, the drillers often attach a long wooden pole to the end of the tube in order to prevent it from curling during insertion. This tubing on the jobsite visited was supplied in 1" $\mathrm{x} 200$ ' rolls. Whether flexible or rigid pipe for grout delivery, any down-the-hole jig for placement of communication conductors must be capable of interfacing with a one-inch "pipe."

In summary, the field visit reinforced that the method of establishing the communication link between the surface and the underground workings should employ the contemporary, accepted method of using a one-inch rigid PVC supply pipe for grout delivery. Since the pipe sections are added as needed (and similarly removed on extraction), any conductors used for the communication must be independent of the pipe employed. Some consideration was given to the concept of researching pipe with conductors embedded in the side walls. While such a pipe could theoretically be left in the hole, field experience has shown that the pump can experience difficulty overcoming the static pressure of the increasing grout column around the delivery pipe. Additionally, an excessive number of electrical connections would be introduced by such an arrangement and this is undesirable per the reliability theory guidelines introduced in Section 2.2.3. In Section 3.5, installation of the embedments is integrated with the grouting procedure.

\subsubsection{Identification of the Hole, from Underground}

From underground, it is assumed that the grouted borehole should appear with a somewhat circular shape, the color of the grout, nearly flush or slightly recessed into the roof. The most beneficial time to identify that the borehole device has been exposed is immediately after the continuous miner (CM) cuts through it. Once the area is rock dusted (and regulations are requiring ever-increasing amounts of rock dust) it is difficult to distinguish variations of color and shape in the roof.

The assumption here is that the entries are being cut leaving some coal top or other darkcolored rock with which the grout of the borehole will contrast in its appearance. The reality is that the roof could contain sandstone, slate, clay, or shale at the point of cut-through. These materials have color variations that affect the ability to differentiate a grouted borehole from the incumbent roof material.

A pigment could be added to the first forty feet of grout to aid in identification, recognizing that the rock being cut will have an effect on the color selected. Light colored sandstone is similar in color to the grout. However, red tints would be hard to detect if there is a layer of pyrite. Note that the geological composition will not be known at the time of the drilling and grouting, as it is the sample core obtained thereby that is used for the analysis. Therefore, a 
bright blue or green pigment would be the only colors that would likely contrast with all types of top, meaning that pigments derived from oxides of iron should be avoided. Blue or green coloration can be achieved through the addition of cobalt oxide or chromium oxide, respectively, to the grout mixture. The amount of pigment should not exceed ten percent, by weight, of the cement (PCA, 1951). This percentage is commensurate with ASTM C979/C979M-10 for colored concrete.

There is additional justification to using a pigmented grout for the portion of the borehole that is to extend through the workings. The term "color diagnosticity" refers to the concept that certain colors are associated with certain objects. As Tanaka and Presnell (1999) explain, "Color diagnosticity refers to the degree to which a color is associated with or symptomatic of a particular object. For example, whereas the color red might be diagnostic of the object fire engine, red would not be diagnostic of the object car" (p. 1141). Much research has been performed attempting to differentiate the influence of color diagnosticity versus shape recognition, and which is more influential (Bramáo et al., 2011; Tanaka and Presnell, 1999; Nagai and Yokosawa, 2003; Wurm et al., 1993). For example, one may recognize an apple by shape or by color. In the case of the apple, most study participants (97\%) associate the color red with apples but others associate shades of yellow and green with apples (Tanaka and Presnell, 1999).

The continued research into the question of shape versus color for object recognition supports the addition of pigment to the grout in the lowest section of the borehole grout fill. Which characteristic is most likely to aid in identification is of less concern; the fact that both characteristics aid in object identification is what is important. A miner operator, aware of both the shape and color of an anticipated borehole communication link through which a cut is to be made, will be very aware when it is encountered. Furthermore, the coloration of the grout, and the distinctive circular shape of the borehole in the mine roof, suggest that identification thereof will be aided even after mining is completed and the area is roof-bolted ${ }^{3}$ and rock dusted. While it is assumed that the device would be located before rock dusting occurs, the possibility that rock dust is present cannot be ignored. Light-colored rock at the elevation of the penetration is also a possibility.

Returning to the discussion of color choice for the pigment, it was previously mentioned that pigments containing oxides of iron would result in grout in colors similar to those of the rock being mined. Thus, it was suggested that blue or green pigments would be preferable. The visibility of the projected light in underground coal mines has been investigated by NIOSH with respect to laser light and Cyalume ${ }^{\mathrm{TM}}$ light sticks, the former being used for underground surveying and the former and latter both being used in mine rescue. Green lasers $(\lambda=532 \mathrm{~nm})$ were described as appearing "brightest to the eye" and in smoke-filled scenarios, green filters applied to cap lamps reduced the glare from smoke particles. In the evaluation of the filters in smoke, green, blue, orange, and red filters were tested and "Green was the most visible color seen by 38 pct of the miners" (Conti, 2001, p. 3). While a pigmented borehole would be viewed

\footnotetext{
${ }^{3}$ There is anecdotal evidence to suggest that, in mines using roof straps, the bolter operators may slightly offset the straps so as to cover grouted boreholes in an attempt to secure them against any cylindrical cores falling out. This practice must be addressed with bolter operators in the case of boreholes outfitted with communication links to ensure that the links are not covered by roof straps.
} 
using reflected light, as opposed to projected light, the visibility of green wavelengths was considered promising in consideration of the NIOSH research. In Section 5.3, however, a study is presented which indicates that, for the borehole communication link which is viewed in reflected light, blue pigment should be used instead of green.

\subsection{Recommended Process for Installing Drillhole Communication Link}

The integral part of using an exploration drillhole for communication is design of a feasible method to embed communication wires in the drillhole before it is sealed with grout. Based on observations of the grouting procedure, an initial design concept was developed. This design was further refined and appropriate materials were simultaneously selected.

Figure 3.17 shows the original concept drawing for a sacrificial plug which could be pushed to the bottom of the drillhole by the one-inch diameter grout delivery rigid pipe (or tubing), with the conductors extending upwards toward the surface. The pilot shaft on the plug would engage the grout delivery pipe to keep the plug vertical until it reached bottom. As grout would be pumped through the delivery pipe, it would quickly surround the plug in the drillhole and the viscosity of the grout would provide enough weight and frictional fluid restriction to prevent significant movement on retraction of the grout delivery pipe, leaving the plug to hold the conductors in place in the drillhole, embedded within the grout. Should the grouting operator be concerned about flotation of the plug, a spring assembly such as that found on extensometers could also be used. 


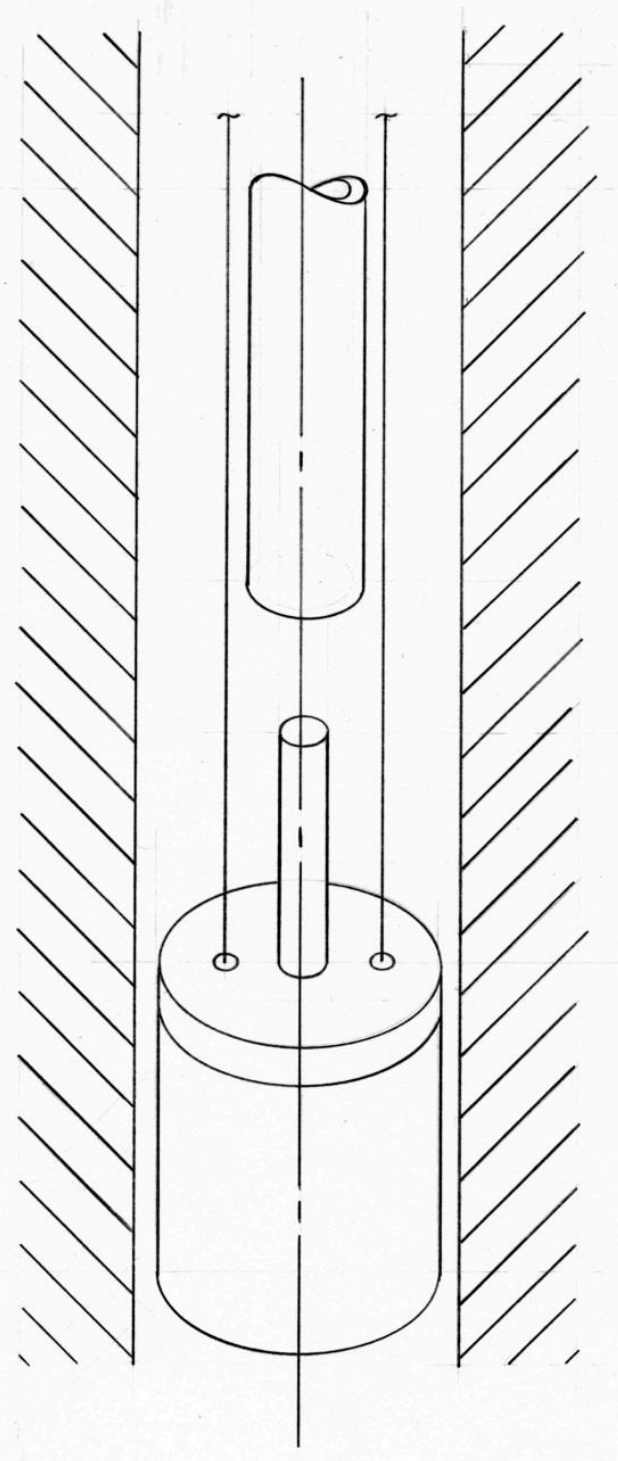

Figure 3.17: Original concept sketch depicting a "plug" delivered to the bottom of the drillhole via the grout delivery pipes.

Figure 3.18 shows the concept sketch for two spools of conductors, located approximately 180 degrees apart and generally in an area that would be clear of other equipment required for the grouting operations. This arrangement is similar to that which is used for the installation of borehole extensometers and time domain reflectometry (see Dowding et al., 1986, for example). The conductors are slowly fed from the spools as the grout delivery pipe pushes the plug to the bottom of the drillhole. Minimal resistance would need to be applied to the spools to maintain tension on the conductors during descent. 


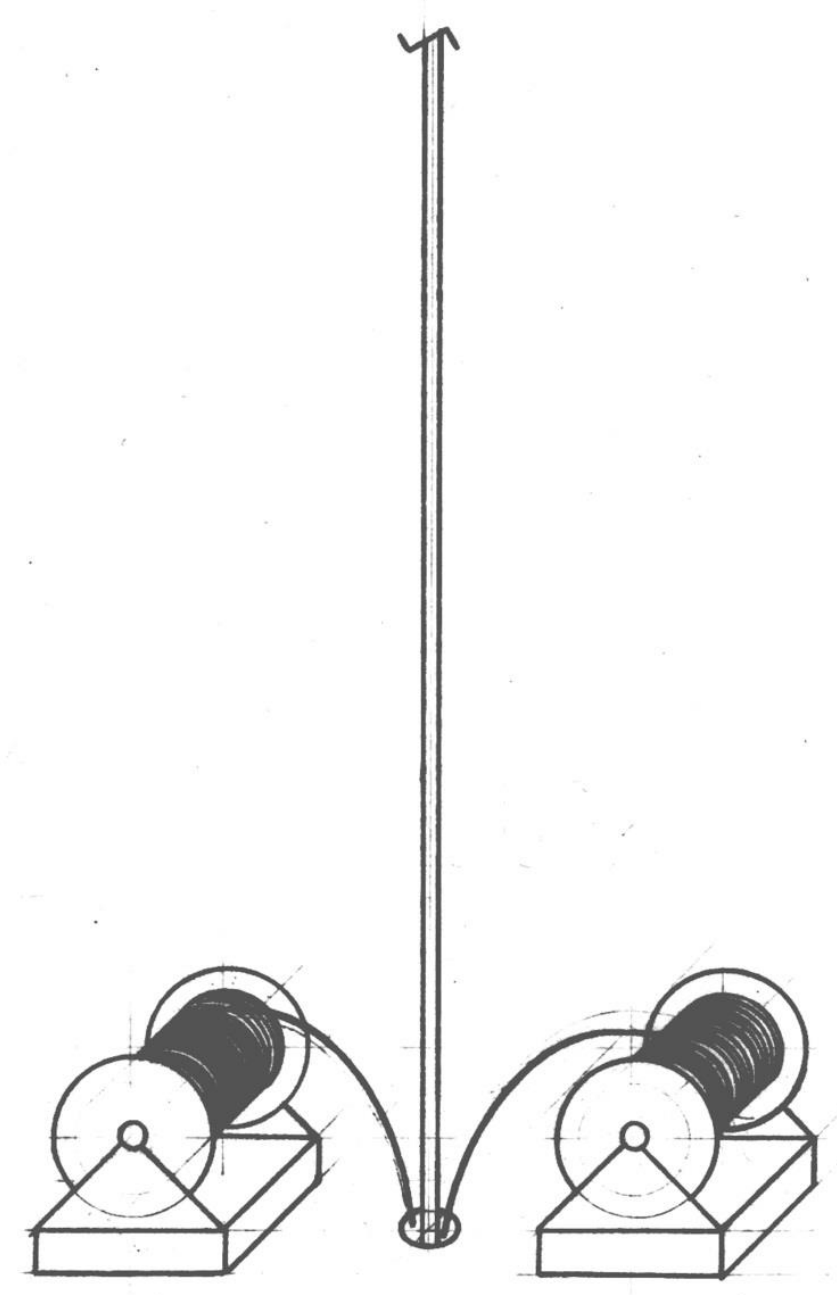

Figure 3.18: Original concept sketch for feeding of communication conductors.

Several feet of "extra" conductor remaining on the reels at the end are then coiled into the drillhole and the drillhole is topped with RTV (or latex rubber) to protect the wire from weathering effects. It would also be prudent to place the top elevation of the grout/RTV at a counterbore depth of roughly three feet to prevent damage by any passers-by. The ends of the conductors should be connected together to maintain the same potential on the wires, such as is common with detonator wires, unless it is to be connected to the underground phone network in the near future.

The final design of the wooden plug is presented in Chapter 4. 


\section{Chapter 4 Design Considerations-Materials Selection}

Materials for the drillhole communication link were selected to balance economy and functionality, while creating minimal impact on existing processes and attempting to avoid the introduction of any safety hazards. Two main aspects are considered herein. Section 4.1 considers the design of a sacrificial plug, whose purpose is to pilot the communication conductors into the borehole during the grouting operation as described in Section 3.5. Once conductors are embedded into the grout of the exploration borehole, this assembly becomes the borehole communication link. Section 4.2 considers the conductor based on various properties such as tensile strength, electrical conductivity, economy, and compatibility with grout. Materials exhibiting characteristics in a workable range included 7 x 19 wire rope and copper wire. Each of these has benefits as well as drawbacks, some of which were more evident after the laboratory tests presented in Chapter 5.

\subsection{Plug}

In Figure 3.17 the original concept sketch, it will be noticed that there is an interface between the "top deck" of the plug and the remainder of its body. Originally, it was conceived to make the primary body of the plug from a grout material, some mixture employing Portland cement, in order to provide weight. However, on later consideration, it was decided that an entirely wooden plug may be sufficient as the side walls of the drillhole combined with the pilot shaft shown in Figures 4.1 and 4.2 would provide enough stabilization to the plug on descent. Furthermore, tension from the conductor spools and would also tend to keep the plug in-plane during the descent.

Brass wood screws are recommended to affix the conductor to the plug. This is primarily since brass is less subject to corrosion. In the event that the coal seam elevation, as determined from the drillhole cores, is incorrect the wooden plug can be shredded as the continuous miner passes through. Thus, the plug must be sacrificial and should, therefore, be fabricated from material that is softer than its surroundings.

This design also incorporates a pin that fits into a slot on the inboard end of the grout delivery pipe, as shown in Figure 4.1. While the pilot shaft provides vertical alignment, the pin prevents rotation of the sacrificial plug on descent. If such a slot has not been prepared in a pipe delivered to the field site, a "V"-shaped notch can be cut in the end of any one of the grout delivery pipes to saddle the alignment pin shown in Figure 4.2. Combined with the tension on the conductors this assembly would hold the plug in place until delivery of grout cause it to remain at the bottom of the borehole. 


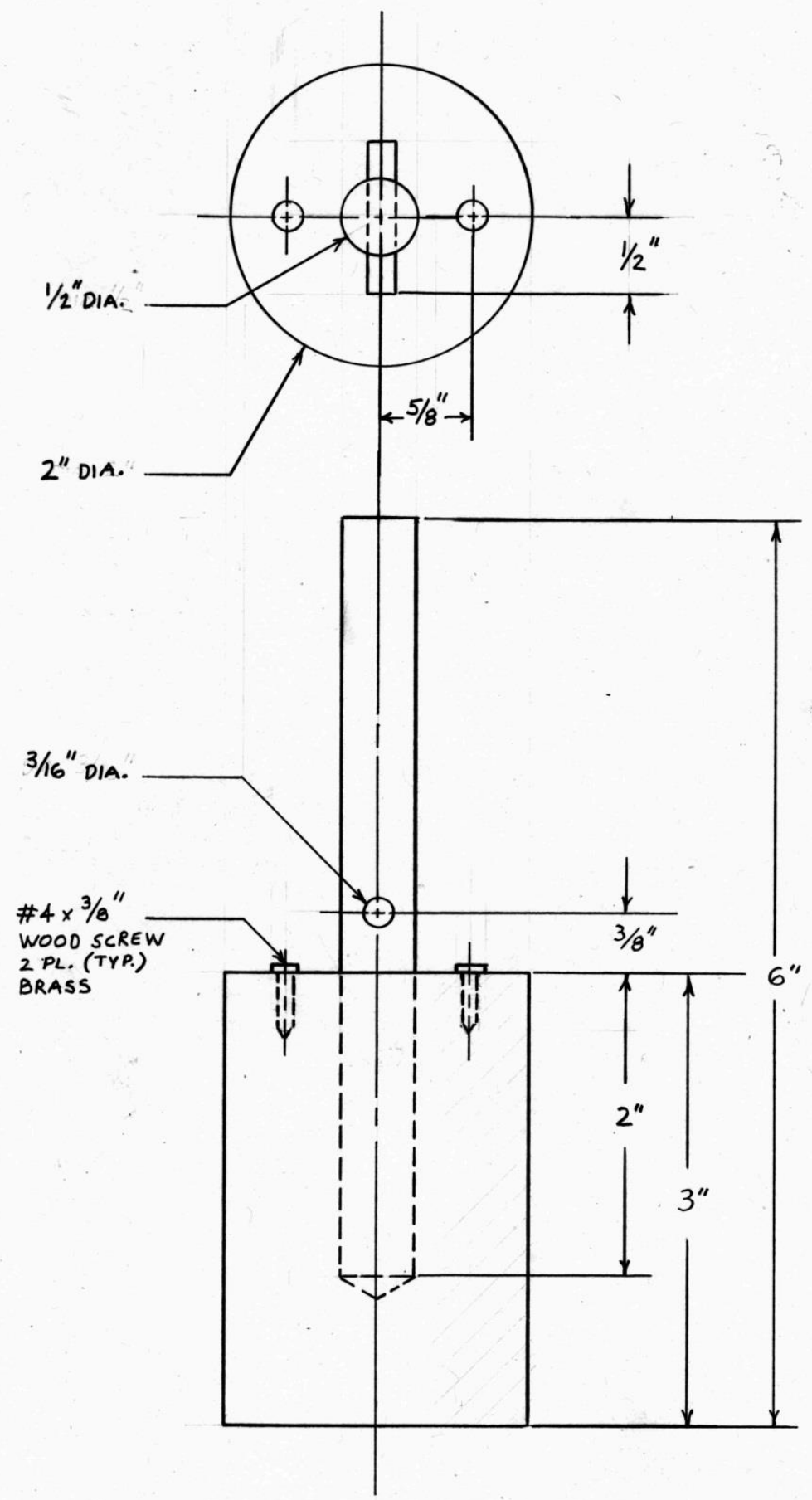

Figure 4.1: Plug design with anti-spin pin. 


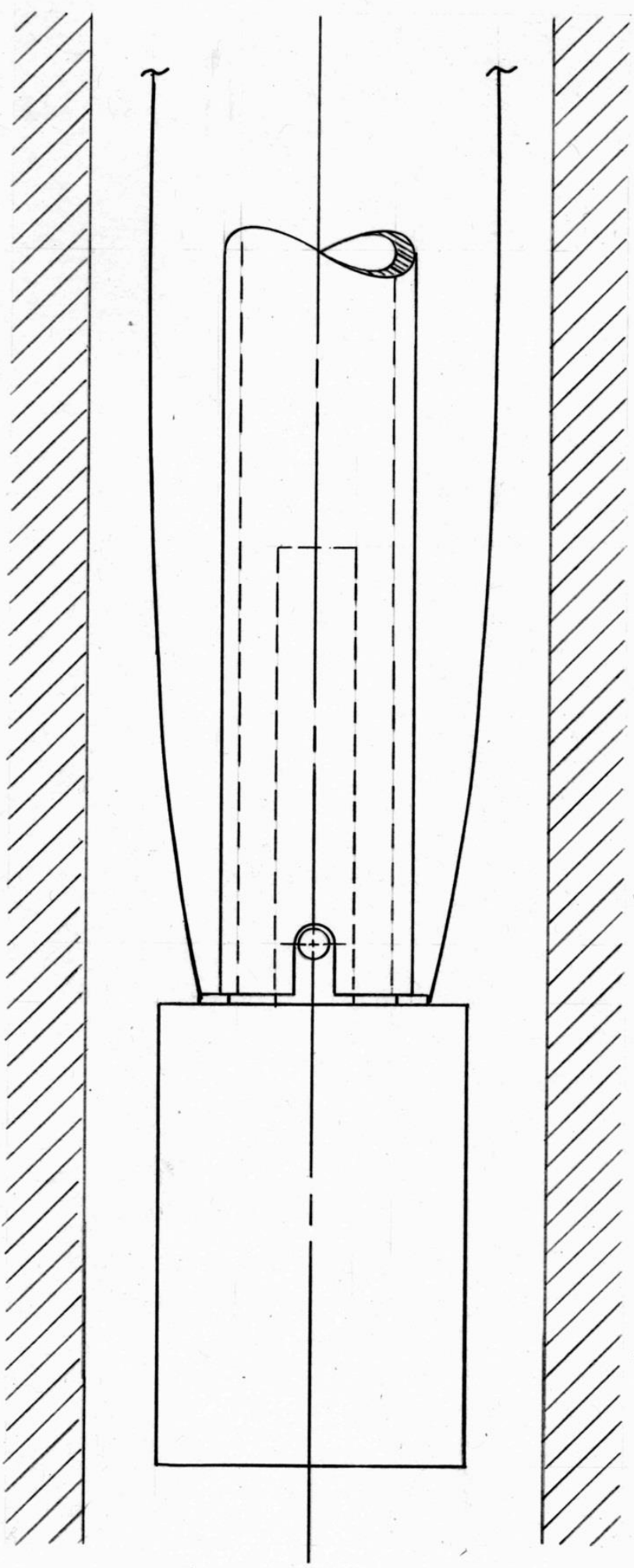

Figure 4.2: Plug with anti-spin pin on end of grout delivery pipe inside drillhole. 


\subsection{Conductor}

While copper wire is often the first consideration for electrical communication circuits, braided galvanized steel wire (3/32") was also considered for the communication link. A steel wire of diameter 3/32" falls between A.W.G. Sizes No. 11 and No. 10 as shown in Table 4.1 and is used as the basis for comparison.

Table 4.1: Comparison between steel and copper wires (data from Fink \& Beaty).

$\begin{array}{ccc}\text { Description of Wire } & \text { Diameter in Inches } & \text { Diameter in Millimeters } \\ \text { A.W. G. No. 11 Copper } & 0.0907 & 2.305 \\ \text { 3/32" Stranded Steel } & 0.09375 & 2.387 \\ \text { A. W. G. No. 10 Copper } & 0.1019 & 2.588\end{array}$

The following sections will compare the two materials in the categories of electrical conductivity, material cost, grout compatibility, and tensile strength. The laboratory tests of Section 5 reveal performance characteristics about the materials selected. While wire rope would be preferred for various reasons the laboratory test results contraindicate its use.

\subsubsection{Electrical Conductivity}

Even considering the possibility of $1000+$ feet of overburden, the higher resistance of steel compared to the lower resistance of copper for this length and diameter is negligible. Note that for decades steel has been successfully used as a conductor in short- and long-range communication circuits, such as trolley phones in mines and with overhead crane phones in steel mills. Early telegraph lines were often ferrous metal that was replaced with copper (see, for example, Santa Cruz Sentinel, 23 April 1907, p. 5). The conductivity of standard annealed copper is commonly given as $5.8 \times 10^{7}$ mhos/meter (Rao, 1994, p. 86; Sadiku, 1989, p. 749). Because of the multitude of alloys available, steel cannot be precisely characterized without performing laboratory tests. However, iron can reasonably be used as a reference. The conductivity of pure iron is typically in a range centered on $1 \times 10^{7} \mathrm{mhos} / \mathrm{meter}$ (Sadiku, 1989, p. 749; Smith, 1990, p. 191). Thus, the conductivity of steel compared to copper is within one order of magnitude. Contrast this with the conductivity of Portland cement, which is $14.4 \times 10^{-3}$ mhos/meter (McCarter et al., 2000, p. 1399). Clearly, the grout in the drillhole is believed to act as an insulator to the communication circuit, whereas the difference between using a steel conductor and a copper conductor is negligible. If insulated wire is used, this still applies in the event the insulation is compromised.

\section{$\underline{\text { 4.2.2 Economics }}$}

Steel is generally less expensive than copper. As of this writing, a 500-ft. spool of 3/32" 7 x 19 galvanized wire rope is available for less than $\$ 80$ and a 500-ft. spool of AWG No. 10 copper (THHN insulated) is selling for $\$ 95$. This represents a $15 \%$ savings. It should be noted that this cost advantage could be larger in the future based on normal metal market fluctuations. 
However, the cost savings may not be significant versus the other design considerations. Common THHN insulated copper wire is used for this comparison; stranded copper wire, without insulation, is less readily available. Based on these prices, the cost of conductors for one drillhole communication link would be less than $\$ 400$. This conservative estimate uses the scenario where the overburden depth exceeds a standard spool length of 500 feet.

\subsubsection{Compatibility with Grout}

Galvanized steel is commonly embedded in cementatious mixtures and would provide for a watertight seal at the outer diameter. Reinforcing bar and steel mesh, both galvanized and bright, used in concrete pours are common examples. One concern, specific to wire ropes, is wick bleed which occurs when capillary action pulls water towards the king wire, the central wire in an $7 \times 19$ wire rope that is surrounded by a symmetrical pattern of six other wires (Warner, 2004, p. 346). Although typically experienced with larger diameters as used for posttensioned tendons in construction, this phenomenon cannot be dismissed in the case of embedments employed for a borehole communication link, despite the plausible argument that the length of wire rope used would result in ad hoc pretensioning that would limit the likelihood of occurrence. Then, with possible movement of overburden, it is possible that the grout could crack and would thereby allow ground moisture to invade the wire rope in a similar manner to classical wick bleed. Unlike reinforced concrete construction designs, the objective with the drillhole is to not allow contact between the two wires within the hole, which may result in a short circuit of the system. While ground movement is less of a concern for short circuits, the introduction of water along the king wire, and subsequent corrosion thereof, could lead to an open circuit condition in the system.

Vinyl coated 7 x 19 wire rope is readily available and would suffer less from wick bleed by virtue of the vinyl coating which would prevent water infiltration even on movement of the overburden and subsequent fracture of the grout. One advantage to the vinyl coated steel would be the ability to coil two wire ropes around one another to form a twisted pair, a common electrical wire arrangement that would tend to reduce electromagnetic interference (EMI) on the signal. The magnitude of this advantage is difficult to quantity as there would not be much interference expected as the wire is embedded in grout from the surface to the workings. The consideration of vinyl coated wire rope relies mainly on its ability to be effectively embedded in the grout.

Insulated copper wire illustrates a different case. First, consider that No. 10 AWG copper wire, devoid of insulation, is less commonly available. While not rare, it is also not conveniently available compared with a common insulated variety such as No. 10 THHN. Second, consider that insulation does achieve the objective of keeping the two conductor wires from making contact with one another. Even without the barrier provided by the existence of the grout, the wires would not short circuit if they came in contact, as long as they were insulated and the insulation itself was not compromised. From the standpoint of corrosion resistance, copper would be superior to steel should any ground water be introduced due to grout fracture on strata movement. Exposed copper would develop an oxide coating but would not form a brittle rust compound such as steel, meaning that the potential for an open circuit condition in the system 
years after installation would be greatly reduced. The most critical issue, then, is the interaction of the grout with THHN insulation. THHN is a polyvinyl chloride (PVC) plastic that is designated THHN for Thermal High Heat Nylon, where the "nylon" refers to a thin exterior coating. This grade of wire is subjected to many tests, including immersion in water and was selected as preferable among similar insulation classes such as MTW and THWN for its resilience, cost-effectiveness, and availability. Following the same rationale as that of the vinyl coated wire rope, a twisted pair configuration could be used in the communication link, formed from the twisting together of two insulated single conductor wires.

\subsubsection{Tensile Strength}

The tensile strength of both the galvanized wire rope and the insulated copper wire is sufficient to withstand some minimal motion of the overburden strata, when embedded within the grout, without shearing. Common 3/32" galvanized, 7 x 19 braided steel wire rope has a breaking strength of half a ton compared to the minimum breaking strength for hard copper wire, AWG No. 11 at 423 lbs. (these tables apply to solid wire). Additional values, based on ASTM Specifications are shown in Table 4.2. This table shows that the values are somewhat commensurate for the two materials for the diameters under consideration.

Table 4.2: Rated breaking strengths for copper wire compared with 3/32" wire rope (Fink \& Beaty, p. 4-47).

\begin{tabular}{|c|c|c|c|c|}
\hline & \multicolumn{4}{|c|}{ Breaking Strength (lbs.) } \\
\hline Description of Wire & $\underline{\text { Hard }}$ & Medium & $\underline{\text { Soft }}$ & $\underline{\text { Rated }}$ \\
\hline $\begin{array}{l}\text { A.W. G. No. } 11 \text { Copper } \\
\text { 3/32" Stranded Steel }\end{array}$ & $423 \mathrm{~min}$. & 327 min. & $249 \max$. & 1000 \\
\hline A. W. G. No. 10 Copper & $529.3 \mathrm{~min}$. & $410.5 \mathrm{~min}$ & 314.0 max. & \\
\hline
\end{tabular}

From this it appears that there is no benefit in increasing the strength, nor the diameter, of the wire rope material beyond this point. For example, 1/4" IPS wire rope is rated at 2.94 tons, and XIPS wire rope of the same diameter is rated at 3.40 tons. The same argument can be applied to the copper wire, although strengths do not reach that of IPS or XIPS steels. The desired effect is to resist movements in the strata but not to be so strong as to prevent the continuous miner from being capable of dynamically breaking the wire in shear when it intersects the communication drillhole link as already depicted in Figure 3.2.

Now, compare these values to the force generated at the cutter head of a continuous miner. Assume a 38-inch cutter head powered by two 235-hp motors, typical values at the lower end of the continuous miner range (Joy, 2009). While the mechanism of the actual shearing of the conductors would vary with conditions, the force developed is sufficient to cut the conductors. 


\section{Chapter 5 Laboratory Evaluation of Design}

Three laboratory evaluations were performed to generate data which was analyzed to assist the design recommendations. The objective of the first evaluation was to determine the preferable material and configuration for the embedments of the communication link. Based on the results of the first evaluation, the second evaluation sought to determine the effect of adding additional embedments to the same grout pour. This was believed to be a pre-emptive measure necessary prior to any field tests, as the question of the number of embedments to place would likely arise irrespective of the reliability considerations of Section 2.2.3. The third evaluation was a designed as a qualitative assessment of pigments that can be added to the grout to increase visibility underground. Another objective of the third evaluation was to make a comparison with published studies related to color diagnosticity presented in Section 3.4.2.

\subsection{Evaluation for Selection of Material}

The objective of the first evaluation was to test the characteristics of six types of samples, from which a follow-up evaluation would be performed based on the front-running performer. All the samples were three-inch (3") diameter grout cylinders of length five inches (5"). Six types of samples were initially prepared:

1) Plain grout, nothing embedded

2) Grout with embedded $7 \times 19$ bright steel wires, in parallel

3) Grout with embedded $7 \times 19$ vinyl coated steel wires, in parallel

4) Grout with embedded $7 \times 19$ vinyl coated steel wires, twisted pair

5) Grout with embedded No. 10 AWG copper THHN wires, in parallel

6) Grout with embedded No. 10 AWG copper THHN wires, twisted pair.

All samples were prepared using Portland Type I/II cement in the same mixture as that observed in Fall 2010 at the field site and are consistent with typical grout that would be expected for similar borehole sites. The testing method employed was a hybrid based on ASTM specifications both for rock cores, commonly obtained from exploratory drilling, and for concrete cylinders, a material closer in composition to the grout mixture of interest.

\subsubsection{Sample Preparation}

The samples were prepared using forms constructed from cardboard tubes of nominal inside diameter three (3) inches. The tubes were first cut to lengths of five (5) inches length to match dimensions of the direct shear testing device. A bottom for each tube was made from a sheet of corrugated cardboard and this was taped in place, creating forms that could be filled with grout. In the typical case, the embedments were cut slightly longer than the cylinders and pushed through holes, spaced two inches apart on a centerline through the diameter, in the corrugated cardboard, and affixed with tape to prevent excessive movement (see Figure 5.14). This was deemed to be representative of the nature of the wires within the grout for an actual 
borehole during the grouting process using the delivery device ("plug") described in Sections 3.5 and 4.1. Twisted pair arrangements were also considered and similarly prepared.

Grout was then mixed using the same proportions as that observed in the field and commensurate with ASTM C150/C150M-11 for Portland cement. The grout batches were serially numbered and this was necessitated solely from the mixing vessel size/time balance necessary to prepare the samples since an industrial grade mixer was not justified by the quantity required for the experiments. Thus, this factor was not suspected to be a source of significant variance. All grout batches were mixed to the same proportions. The "tube grade" in Appendix A refers to the quality of the tube used for formation of the sample. If the tube grade is "A," this indicates that one end was a factory-cut end and if the tube grade is " $\mathrm{B}$ " then both ends of the tube were saw cut. This was correctly anticipated not to be a significant source of variation (conceptually, more saw cutting on the tubes could theoretically result in more flexing of the form). Although this would not be expected to have any effect on the outcomes of shear testing, the information was recorded for completeness and thereafter deemed insignificant.

The initial samples were poured on May 8, 2011 and were tested well after achieving the minimum thirty (30) days cure time to reach appropriate strength for shear testing. The ASTM specification for Portland Type I/II was used for guidance. For the first phase of tests, six of each sample type were prepared, along with some "blanks" to use for machine set-up, for a total of 36 samples, not including set-up blanks. For the second phase of tests, six each of No. 10 AWG arranged as two-, three-, and four-wire configurations were poured at a later date and are the subject of Sections 5.2 and 5.3. In addition, three each of green and blue pigmented lean grout were poured. The latter samples were not for shear tests but rather for determining attributes related to visibility underground.

\subsubsection{Sample Testing Method}

The hydraulic sheer testing machine required machining of two (2) platens to accommodate the three-inch sample diameter. Unlike the ASTM D5607, the samples were placed directly in the platens. The ASTM D5067 method encapsulates the samples into a grout. However, the material of interest for these tests is grout, so that encapsulating per ASTM D5607 was perceived to introduce additional variables.

Since it is less common to test grout specimens for shear strength, guidance was obtained from ASTM D5607-08, Standard Test Method for Performing Laboratory Direct Shear Strength Tests of Rock Specimens Under Constant Normal Force and ASTM C496/C496M-11, Standard Test Method for Splitting Tensile Strength of Cylindrical Concrete Specimens. The ASTM D5607 method is commonly used for the testing of rock specimens such as those extracted as core samples during the drilling of exploration boreholes and ASTM C496/C496M for construction concrete. As early as 1943, there was a general migration away from testing samples composed only of cement (Davis, 1948, p. 311). Better test results could be obtain with cement/sand mixtures and other mixtures more commonly used in actual construction. A number of factors cause variation in the test results and, although briquettes are often used instead of cylinders for these tests, the recommendation is that, for any run of tests, the highest 
tensile strength, not the average tensile strength, should be used. As long as the samples are prepared with reasonable care, ". . . the variations obtained are due to the human factor and not to the cement" (Davis, p. 311).

The test was performed by placing each three-inch diameter sample into two 2-1/2" tall circular platens stacked vertically on their centerline. With the bottom platen is held in a fixed position, the top platen was moved by a hydraulic ram attached to a dial indicator that recorded the highest strength obtained before failure of the sample. A normal load was also applied. The testing device used was the Structural Behavior Engineering Laboratories, Inc. Direct Shear Machine, Model No. RM101. ${ }^{4}$ This machine is pictured in Figure 5.1.

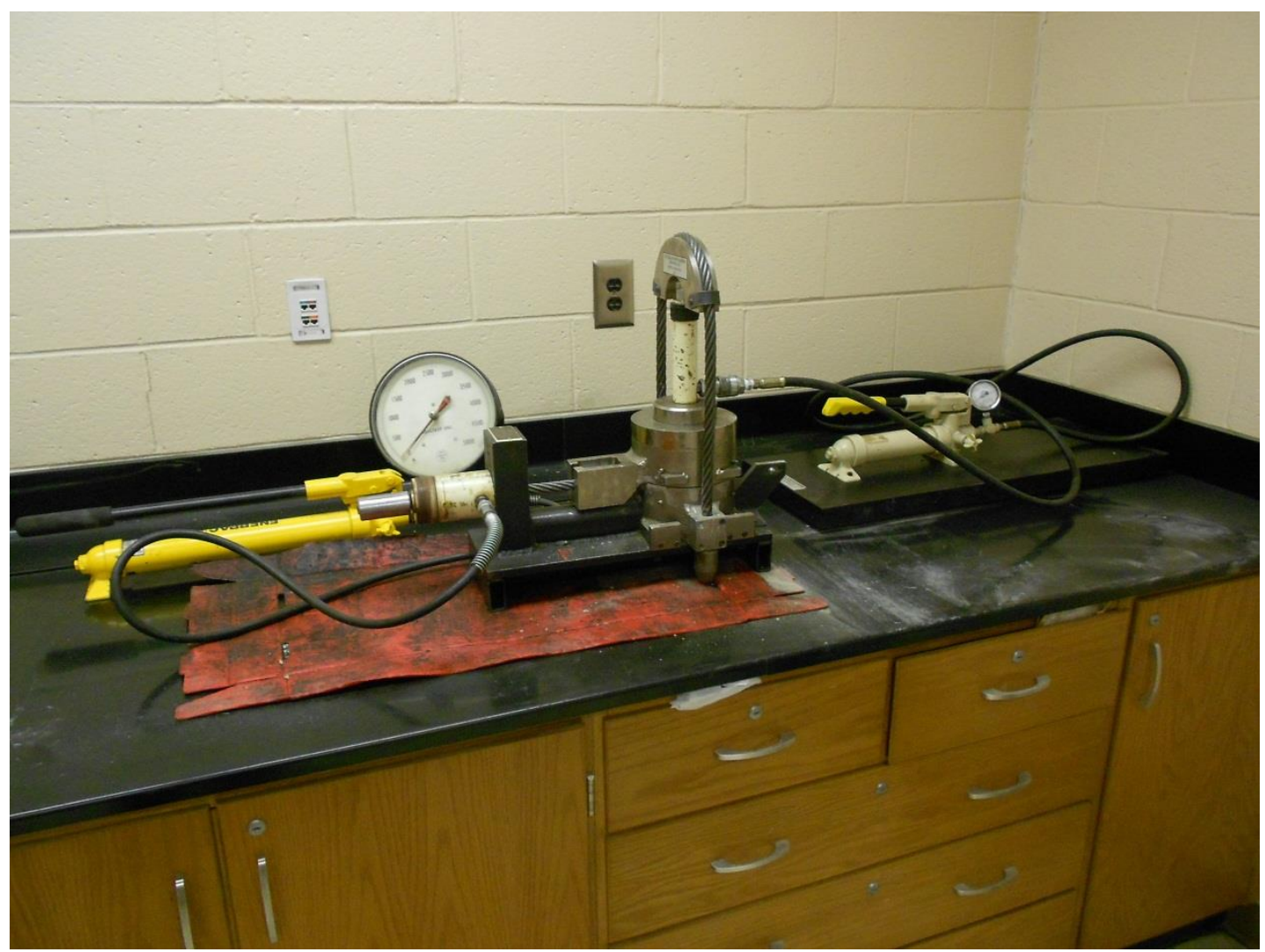

Figure 5.1: Direct shear testing device. Hydraulic press for normal load on top right (white) and for shear load on left (yellow).

In addition to the shear force required to break the samples, qualitative assessments of the behavior of the embedded conductors was made for each of the sample types. From this, a preference was determined and additional samples were prepared for testing, using different embedment configurations, as described in Section 5.2.

The sample testing method employed used a standardized form documenting these procedural steps:

\footnotetext{
${ }^{4}$ P. O. Box 23167, Phoenix, AZ 85019. Reference Drawing for machine dated April 24, 1979.
} 
1) Sample number and date of test were recorded.

2) The grout batch and tube grade were transferred to the sample test record sheet from the information sheet generated when the samples were poured.

3) Images of the sample, prior to testing, were taken.

4) A normal load of 500 psi was applied to the sample in the direct shear device.

5) A direct shear load was applied until the maximum was reached and the sample failed in shear.

6) Normal and shear loads were removed from the sample, images were obtained, and a description of the failure was recorded.

7) In some cases, the normal and shear loads were re-applied to characterize any effect on the embedded wires with horizontal displacement of the sample "halves." (This information was gathered as forward-looking for the configuration tests of Section 5.2.)

The calculation for the shear load, $\tau$, was calculated as

$$
\tau=\frac{\sigma}{A}
$$

where the values of $\sigma$ was obtained (in psi) from the instrument gage as shown on the left in Figure 5.1 and the area, $A$, was constant at 2.761 square inches, the value supplied by the equipment manufacturer. The shear load value was converted to tons for analysis. The confining load was also calculated from Equation 5.1, with the area, $A$, being 0.994 square inches. The confining load on the instrument was set, by gage, to 500 psi for all tests, resulting in 0.252 tons.

\subsubsection{Results of Material Evaluation}

From Table A-1, in Appendix A, the minimum, maximum, and mean direct shear load were determined; these are summarized in each of the following sections. All of the values were commensurate, indicating that the embedments did not have a substantial effect on the properties of the grout itself. There were also no cases in which the embedments were severed when the grout fractured. This indicates that all systems should be robust to movements of the overburden. Although these results do not confirm the ability of the continuous miner to cut the embedments in shear during operations, the impact force developed at the bits of the cutter head, as shown by the calculations of Section 4.2.4, are an order of magnitude in sufficiency. 


\subsubsection{Lean Grout, Without Embedments}

The six samples of lean grout, without embedments, represent the baseline case, or control, representative of the current practice of backfilling exploration boreholes. ${ }^{5}$ The mean, minimum, and maximum direct shear loads, in tons, were $0.25,0.43$, and 0.31 , respectively. The lean grout samples provided the highest maximum load. The failure mode for all six samples was a clean break transverse to the longitudinal axis of the sample, directly in-line with the shear load. Figure 5.2 shows a view looking downward with the bottom half of the sample in the platen on the right and the top half removed from the platen and inverted, oriented horizontally in-line with the direct shear load.

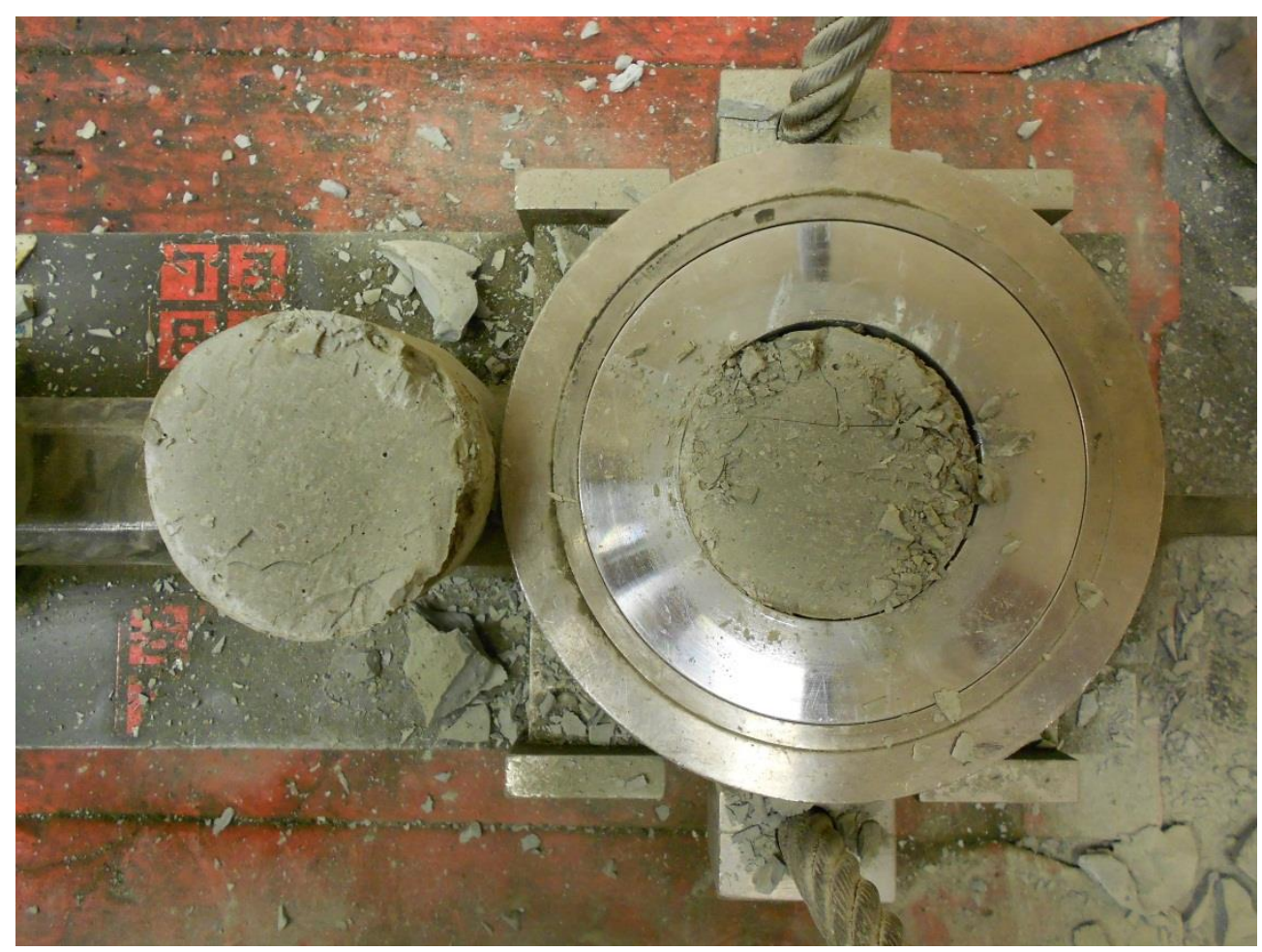

Figure 5.2: Sample A05 Post-Test. Lean grout without embedments.

\subsubsection{Wire Rope, 7 x 19 Bright, Parallel Path}

Bright steel wire rope, $7 \times 19$, oriented in parallel path configuration represented a strong candidate for the communication link, concerns about wick bleed corrosion notwithstanding. The mean, minimum, and maximum direct shear loads, in tons, were $0.29,0.19$, and 0.35 , respectively. With the exception of a single test (sample B06), all samples experienced not only a fracture at the plane of the direct shear load but also propagation of cracks along the embedded wire rope. Figures 5.3 and 5.4 depict this. In comparison with other samples containing different embedments, there was reason to suspect that the wire rope segments, removed from a spool and cut to length, contained residual stresses that were imparted during the wire rope

\footnotetext{
${ }^{5}$ In addition to the six lean grout samples, several "grout blanks" of lean grout were prepared for machine set-up but were not recorded as part of the sample testing scheme.
} 
manufacturing and spooling process. In an application with unspooling motion, these stresses would likely work themselves out but it appears that, in the case of the five-inch samples, the forces that remained were dissipated along the line of embedment during the fracture of the sample itself. In the majority of the cases, the sample became lodged in the lower platen during the test.

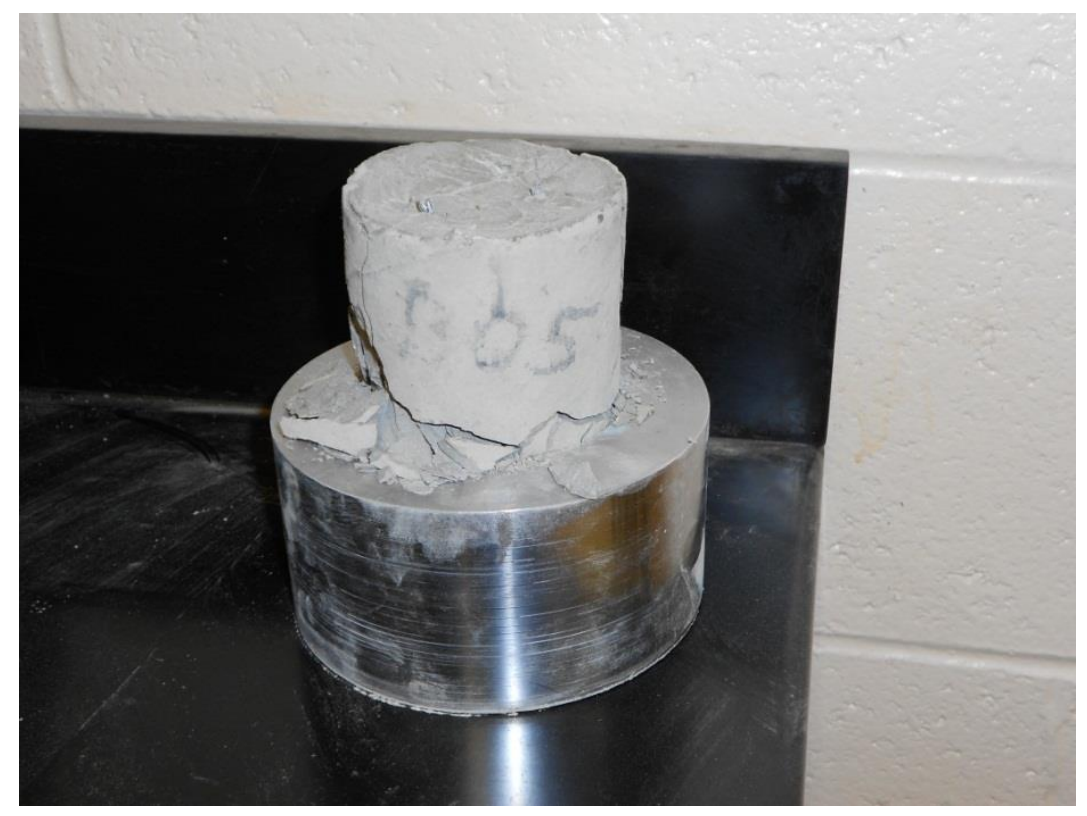

Figure 5.3: Sample B05 Post-Test. Fractures propagating along embedments.

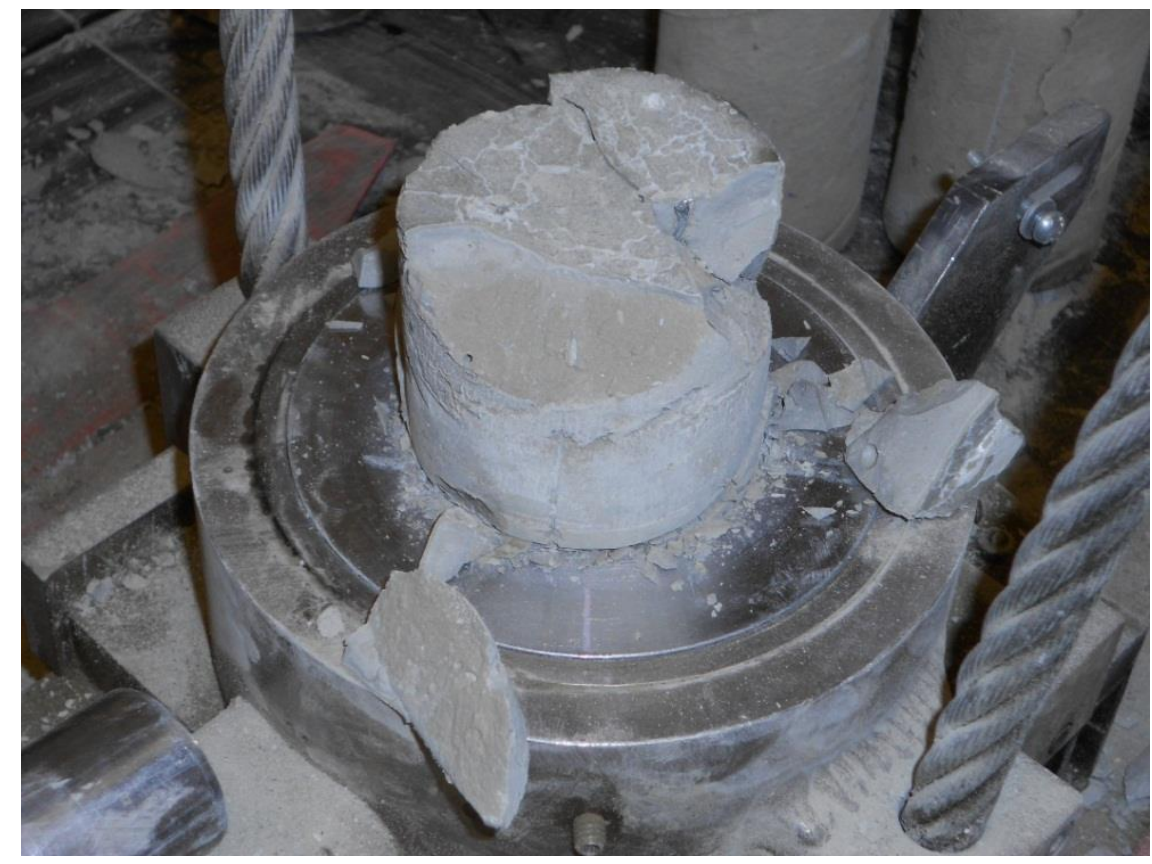

Figure 5.4: Sample B01 Post-Test. Fractures propagating along embedments. 


\subsubsection{Wire Rope, 7 x 19 Vinyl Coated, Parallel Path}

As a possible alternative to the bright wire rope, six samples of vinyl coated steel wire rope, $7 \times 19$, oriented in parallel path configuration were considered. The mean, minimum, and maximum direct shear loads, in tons, were $0.31,0.28$, and 0.33 , respectively. The failure characteristics for this group were bimodal with a nearly clean break at the plane of direct shear load and either solidly retained embedments or fracturing and spalling along the line of the embedments. Figure 5.5 shows the former case and Figure 5.6 shows the latter case.

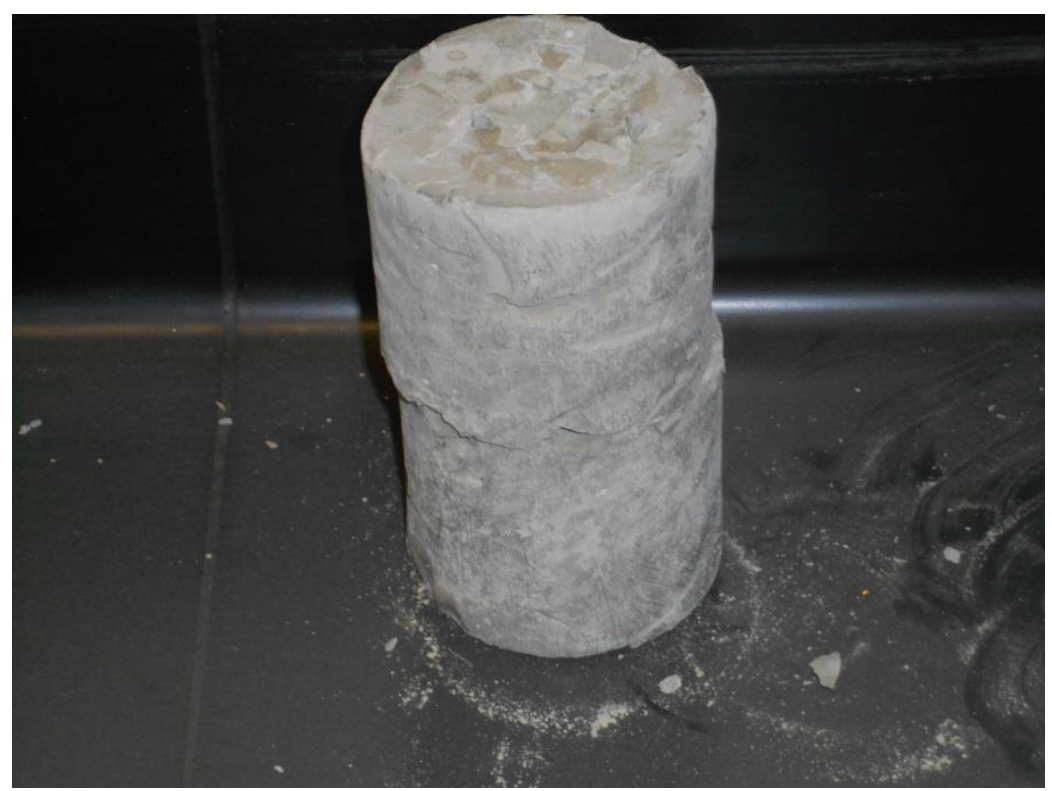

Figure 5.5: Sample C03 Post-Test. Embedments solid with fracture confined to plane of shear force.

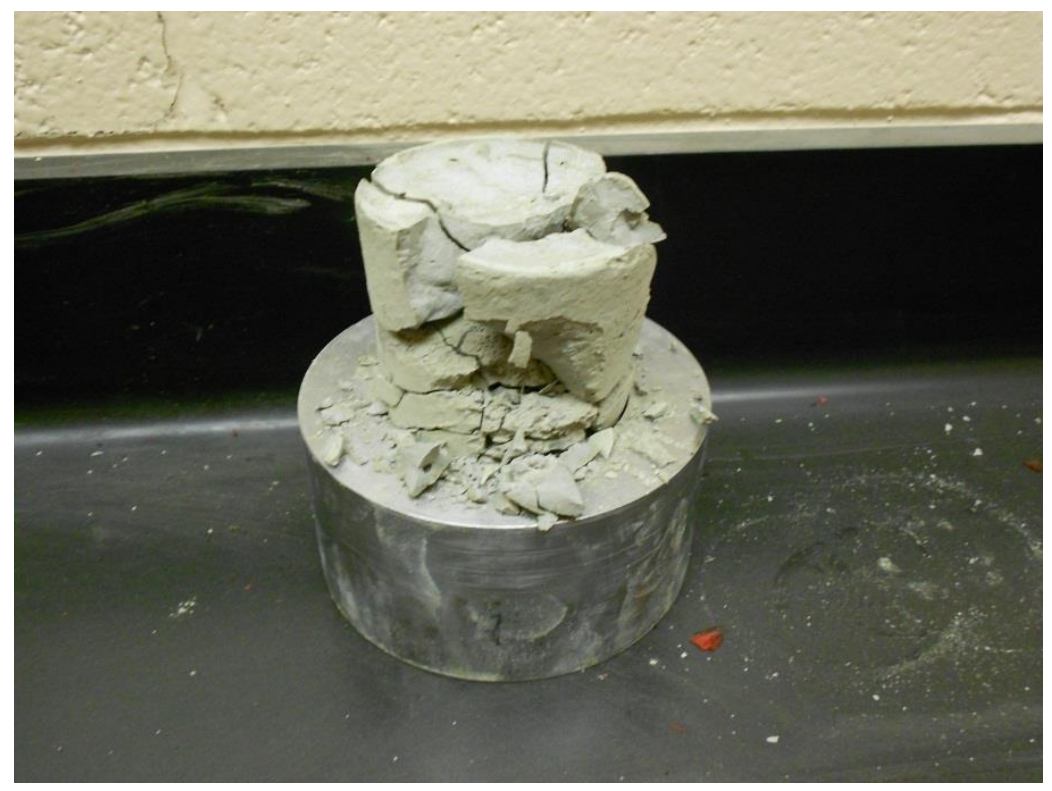

Figure 5.6: Sample C05 Post-Test. Shattering around embedments. 


\subsubsection{Wire Rope, 7 x 19 Vinyl Coated, Twisted Pair}

Six samples of vinyl coated steel wire rope, $7 \times 19$, were prepared as if the wire were common copper signal wire used in a typical twisted pair configuration. The mean, minimum, and maximum direct shear loads, in tons, were $0.24,0.17$, and 0.30 , respectively. These loads at failure are the lowest of all the sample types tested, although the ranges were not dissimilar from the others. In Section 5.1.3.1 it was suggested that the wire rope contained some stresses that were relieved on fracture of the encapsulating grout. In this case, where wire rope was intentionally twisted, albeit wire rope with a vinyl coating, it is known that a force was imparted into the embedments. Furthermore, the twisted pair configuration may have prevented grout from completely surrounding and adhering to the wire rope. However, this could not be ascertained from simply viewing the samples either pre- or post-test.

Similar to the samples described in Section 5.1.3.3., where vinyl coated wire rope in parallel path configuration was used, there appeared to be poor adherence by the grout to the vinyl coating, either due to material composition or due to imparted forces. Longitudinal cracks were usually prevalent post-test, and in half the cases the propagation was predominantly downward, the direction of the normal load. As Figure 5.7 depicts, the top half was often undamaged and the bottom half severely fractured.

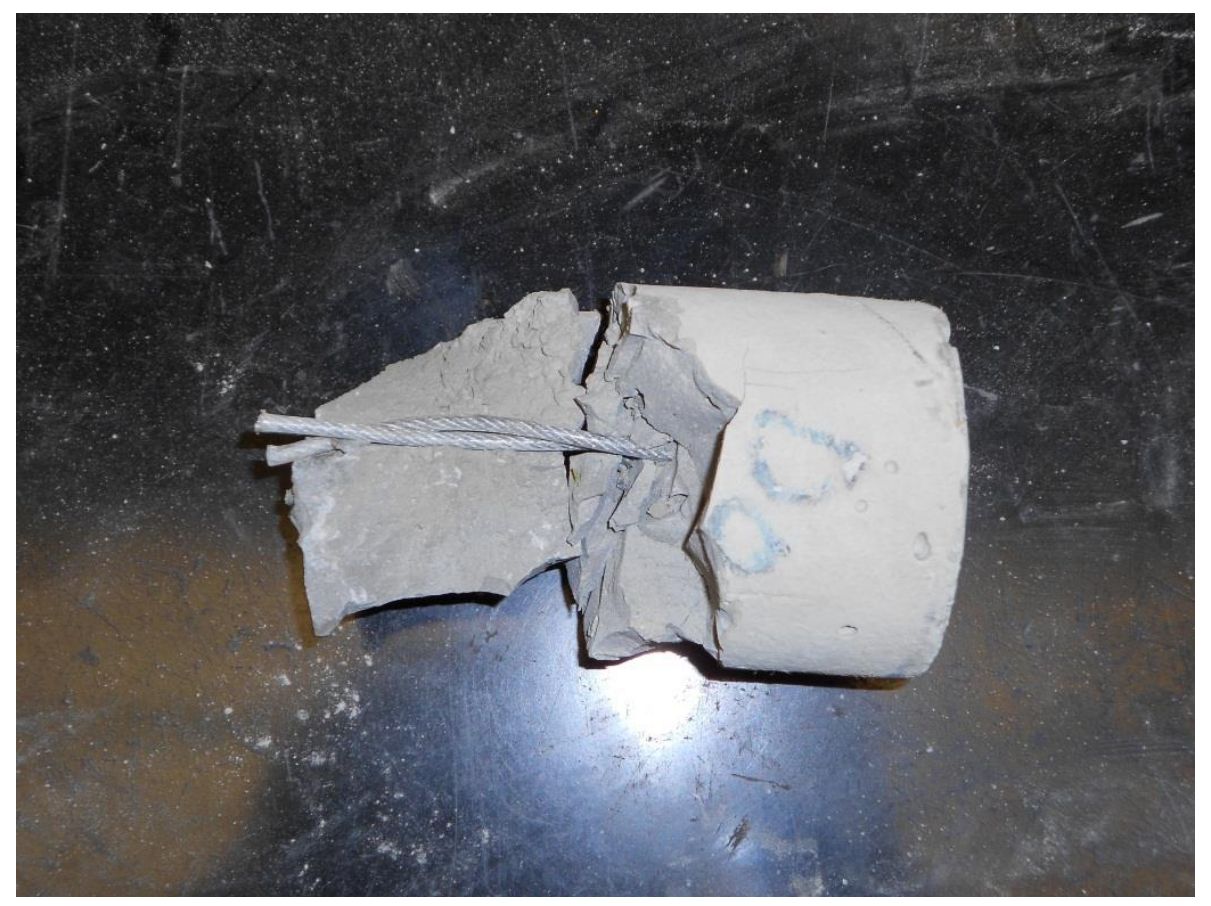

Figure 5.7: Sample D05 Post-Test. Top of sample to right. 


\subsubsection{THHN Insulated No. 10 AWG Copper, Parallel Path}

Similar to the configuration of Sections 5.1.3.2 and 5.1.3.3, parallel paths were employed for these six samples. For this group, copper wire, No. 10 AWG with THHN insulation was embedded. The mean, minimum, and maximum direct shear loads, in tons, were $0.28,0.25$, and 0.32 , respectively. Of particular significance with this group is that it behaved most similarly to the baseline case of lean grout. In all cases, the insulation was intact after a break in line with the direct shear load. In one case (Sample E01), there was a radial crack for one-third of the circumference but spalling was minimal in all cases. Figures 5.8 and 5.9 show typical fracture patterns.

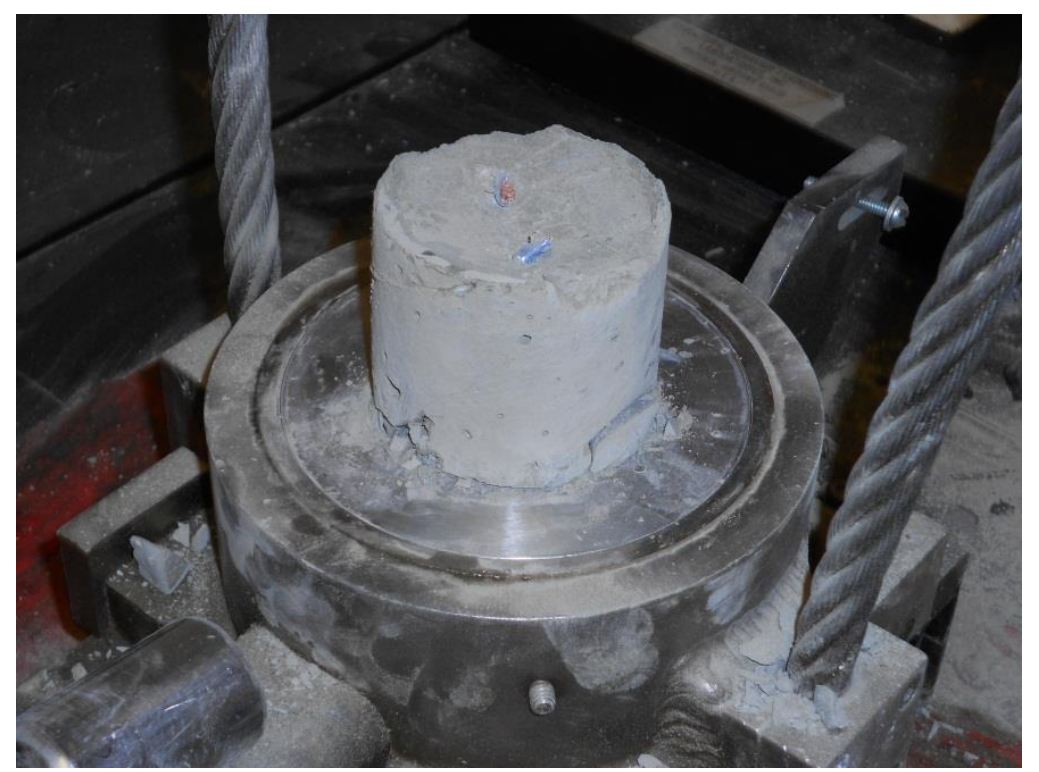

Figure 5.8: Sample E05 Post-Test. Before removal from platen. Shows structure of fracture.

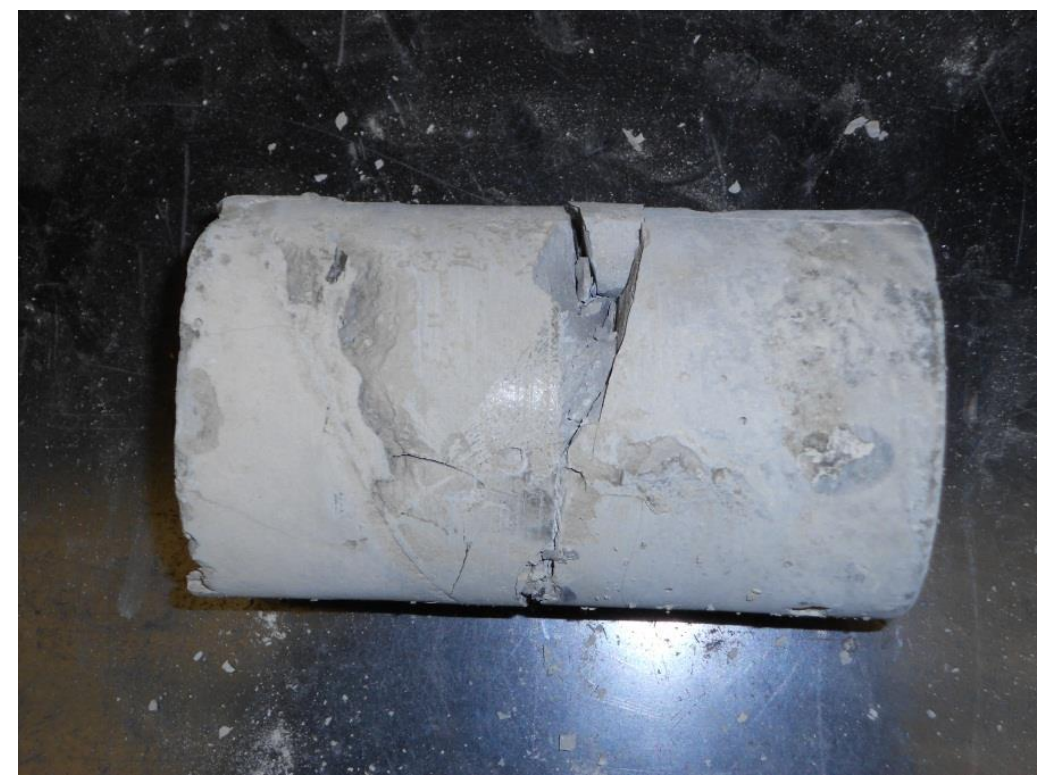

Figure 5.9: Sample E01 Post-Test. Fracture along plane of direct shear load. 
After failure, several of these samples were placed back into the direct shear device and displacement was increased to the limit of the loading capability see the effect on the embedded conductors. In a single case, eight strands were broken in one wire. In most cases, the insulation was degloved on portions of the wire but the strands remained intact and distant from each other such that contact would not be made (in operation, resulting in a short circuit condition).

Figure 5.10 shows a sample after a displacement pull following the main sample shear load test. Characteristic of this material and configuration was the tendency for the wires to remain firmly embedded in the grout and for the grout to fracture mostly in the plane aligned with the direct shear force. This is unlike the vinyl coating on the wire rope which appeared to have poor adhesion to the grout.

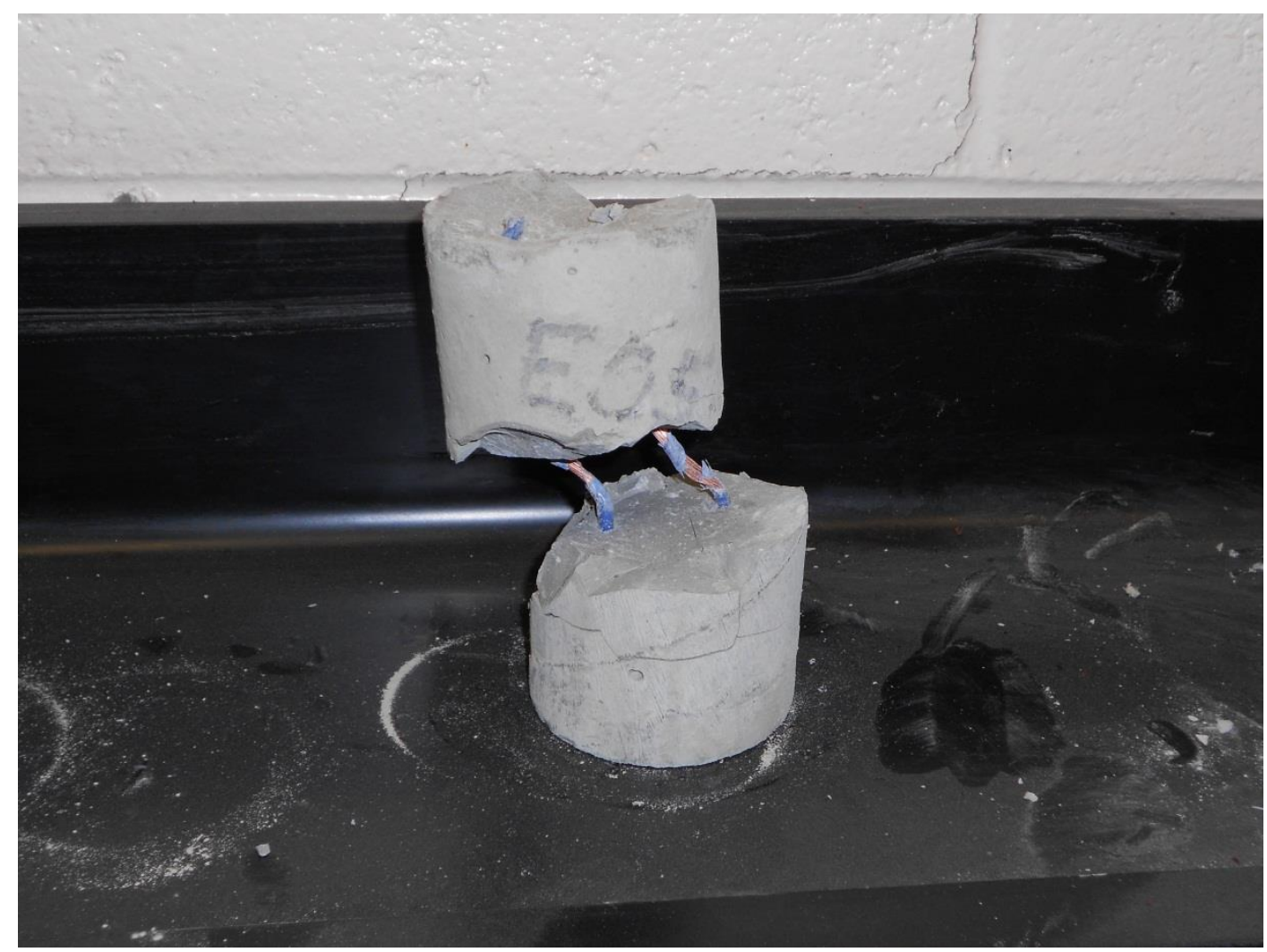

Figure 5.10: Sample E05 Post-Test, after displacement pull.

\subsubsection{THHN Insulated No. 10 AWG Copper, Twisted Pair}

To replicate a typical twisted pair configuration, copper wire, No. 10 AWG with THHN insulation was embedded in six samples. The mean, minimum, and maximum direct shear loads, in tons, were $0.27,0.18$, and 0.34 , respectively. With the exception of one maximum value, these statistics are slightly better than the wire rope twisted pair but not as good as the other configurations. While the fracture generally occurred on the plane of the direct shear force, there were also often angled cracks propagating from the point of load to the outer circumference of the sample. Figure 5.11 depicts an example. 


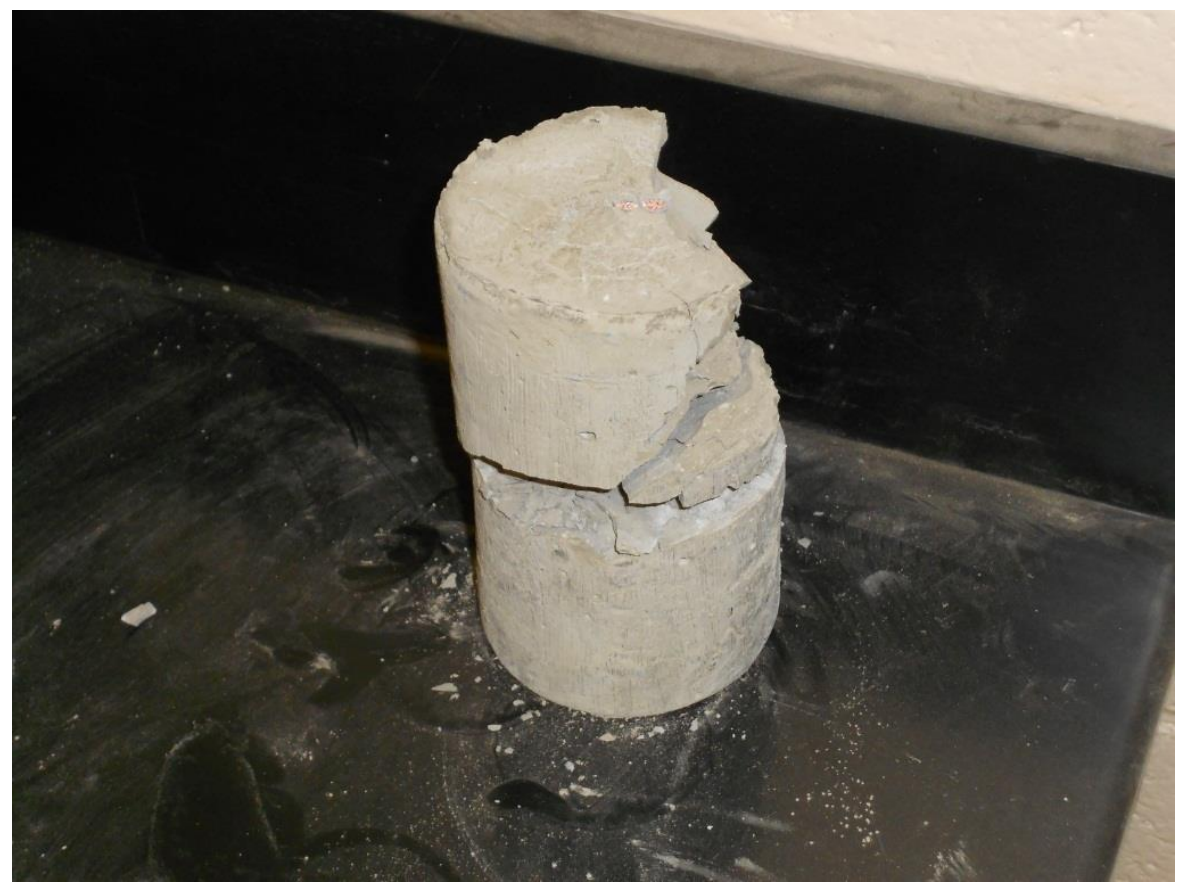

Figure 5.11: Sample F04 Post-Test. Angular cracks from plane of direct shear load.

For several samples, after the failure test, the samples were placed back in the platens and displacement of the halves increased to the load limit of the test machine. As Figure 5.12 shows, not only was the grout further compromised, but the insulation was stripped from the wires allowing them to contact which, in a field situation, could result in a short circuit.

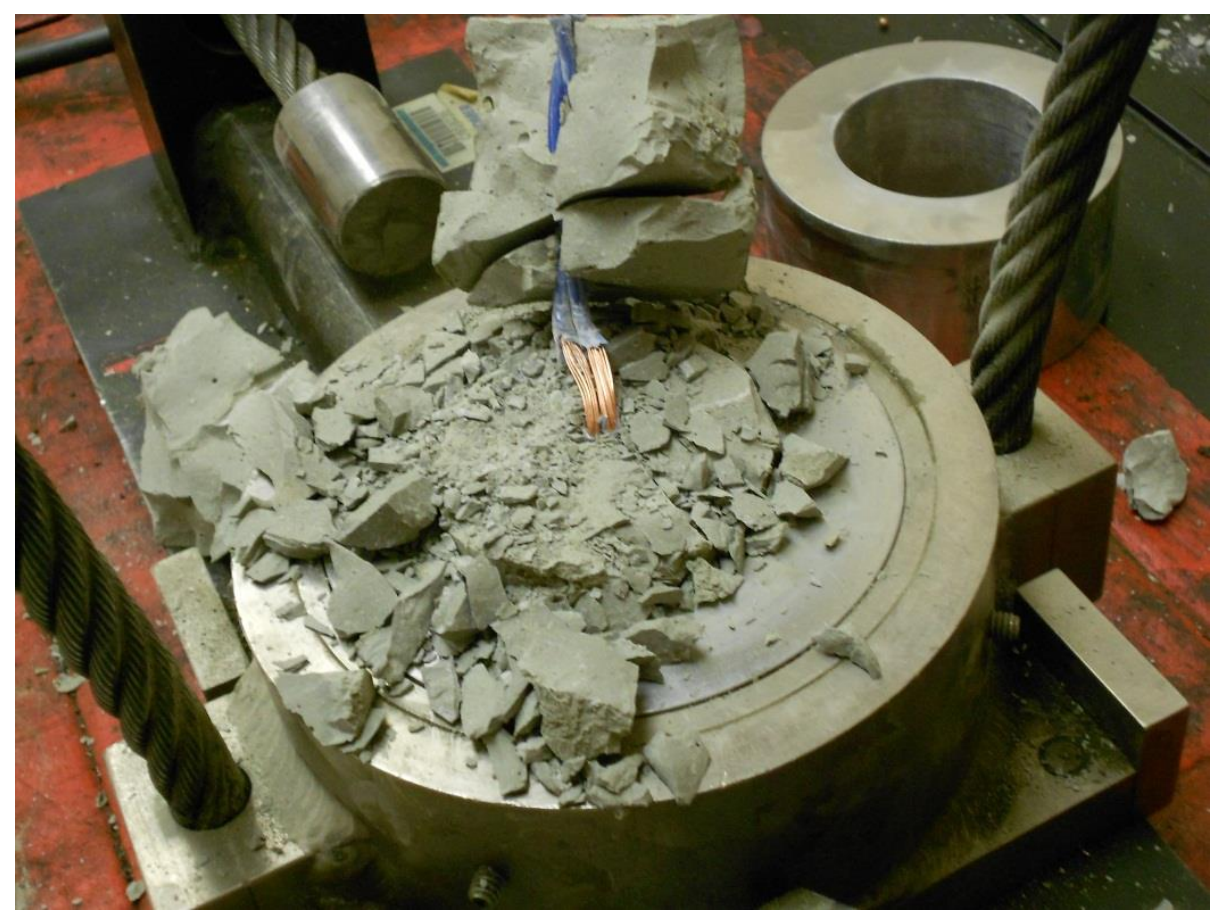

Figure 5.12: Sample F06 Post-Test. On displacement pull, exposed copper wires can make contact. 


\subsubsection{Summary of Material Evaluation}

Direct shear load was commensurate for all embedded materials. Based on the characteristics of the fractures, the parallel path, THHN insulated No. 10 copper wire performed the best. This material was chosen for embedment testing in the second evaluation, Section 5.2.

\subsection{Evaluation of Conductor Configuration}

As a follow-up to the first round of samples, a second group was prepared with six samples each of configurations of two, three, and four embedded THHN insulated No. 10 AWG copper wires following the same methods of Section 5.1.1. The objective of this test was to characterize the effect of placing additional wires into the grout. The first characteristic of interest was any effect on the direct shear force, namely any reduction therein during failure which would represent a weakening of the grout. The second characteristic relates to the likelihood of the conductors making contact should there be movement of the ground strata. The latter concept was an outgrowth of the material evaluation sample tests in which, when displacement was increased after the initial sample failure, stripping of the insulation was observed.

The direct shear load test was performed in the same manner as the phase one tests, with the value recorded. Then, the hydraulic ram was moved until the top and bottom platens were separated by one inch. The sample was observed to characterize the position and condition of the embedded wires post grout failure. All of these samples were prepared with the embedments equidistantly circumscribed about a circle of one inch radius, a value chosen for its correspondence to the O.D. of the anticipated grout delivery tube of Section 3.4.1. These configurations are shown in Figure 5.13.
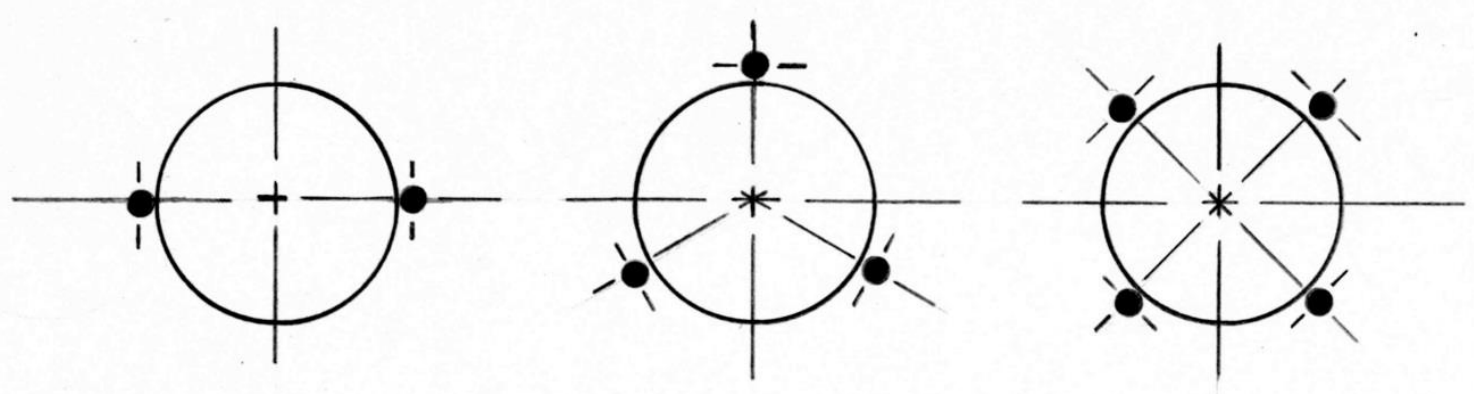

Figure 5.13: Two-, three-, and four-wire configurations. 
Figure 5.14 depicts one each of the two, three, and four wire configuration samples after pouring, with cardboard "position frames" used to maintain the proper spacing during curing (the bottom positions were maintained by attachment of the wires to the bottoms of the molds).

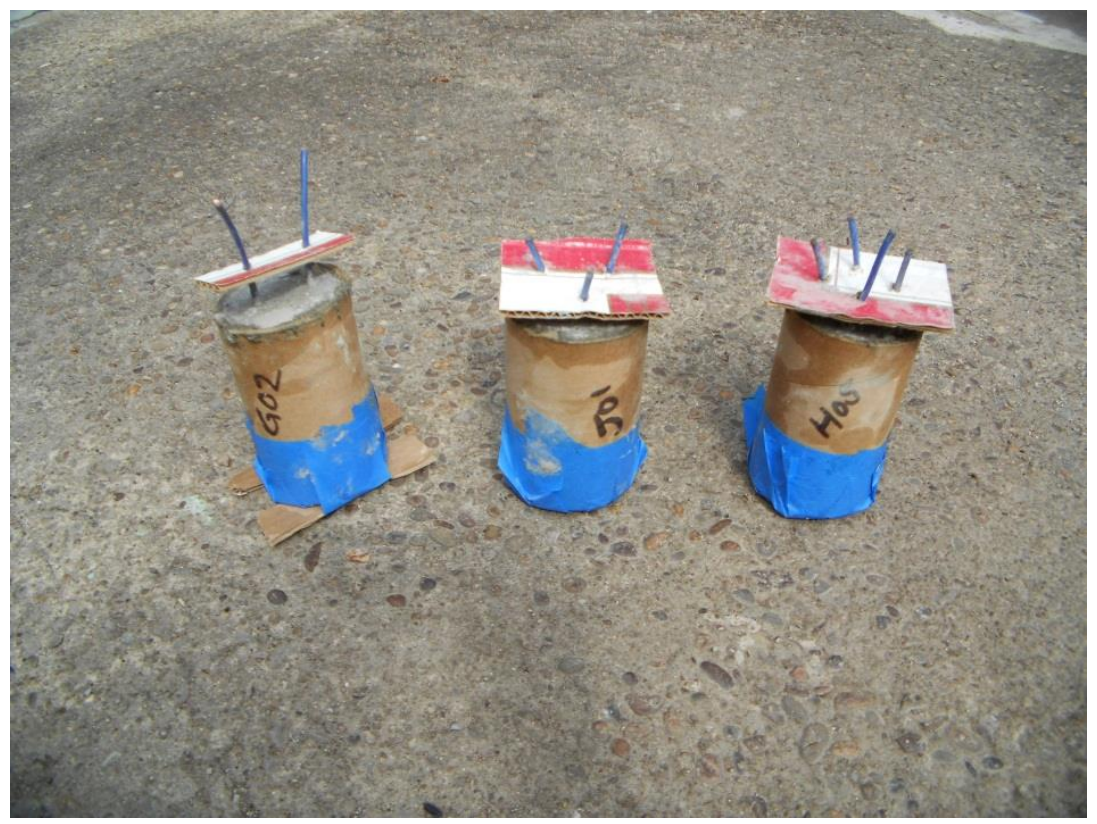

Figure 5.14: Two-, Three-, and Four-Wire configurations with stabilizers to maintain separation radius.

For the shear load and displacement test, the wires were oriented in the plane of the direction of the load, so as to create the worst case scenario (i.e. the wires were aligned with their nearest neighbors). For the parallel, triangular, and square orientations, these distances were 1.00 inch, 0.86 inches, and 0.71 inches, respectively. Results are recorded in Appendix A, Table A-2.

\subsubsection{THHN Insulated No. 10 AWG Copper, Parallel Configuration}

This group of six samples was characteristically identical to those reviewed in Section 5.1.3.5, except that they were poured at a later date relative to the first group (March 1, 2012). The mean, minimum, and maximum direct shear loads, in tons, were $0.28,0.23$, and 0.35 , respectively. These values are comparable to those of the Section 5.1.3.5 tests where the minimum, maximum, and mean direct shear loads, in tons, were $0.28,0.25$, and 0.32 , respectively. In all cases, the break was at the plane of shear load and in a single case there was also a wedge shape breakout that formed upward from the plane of shear load. Wires remained intact, but stripped, in all tests and no wires were found to be in contact after the one inch displacement. The nearest distance, pre-test, between embedments was one inch, the assumed diameter of the grout delivery tube. Figure 5.15 shows an example resulting from this group of tests. 


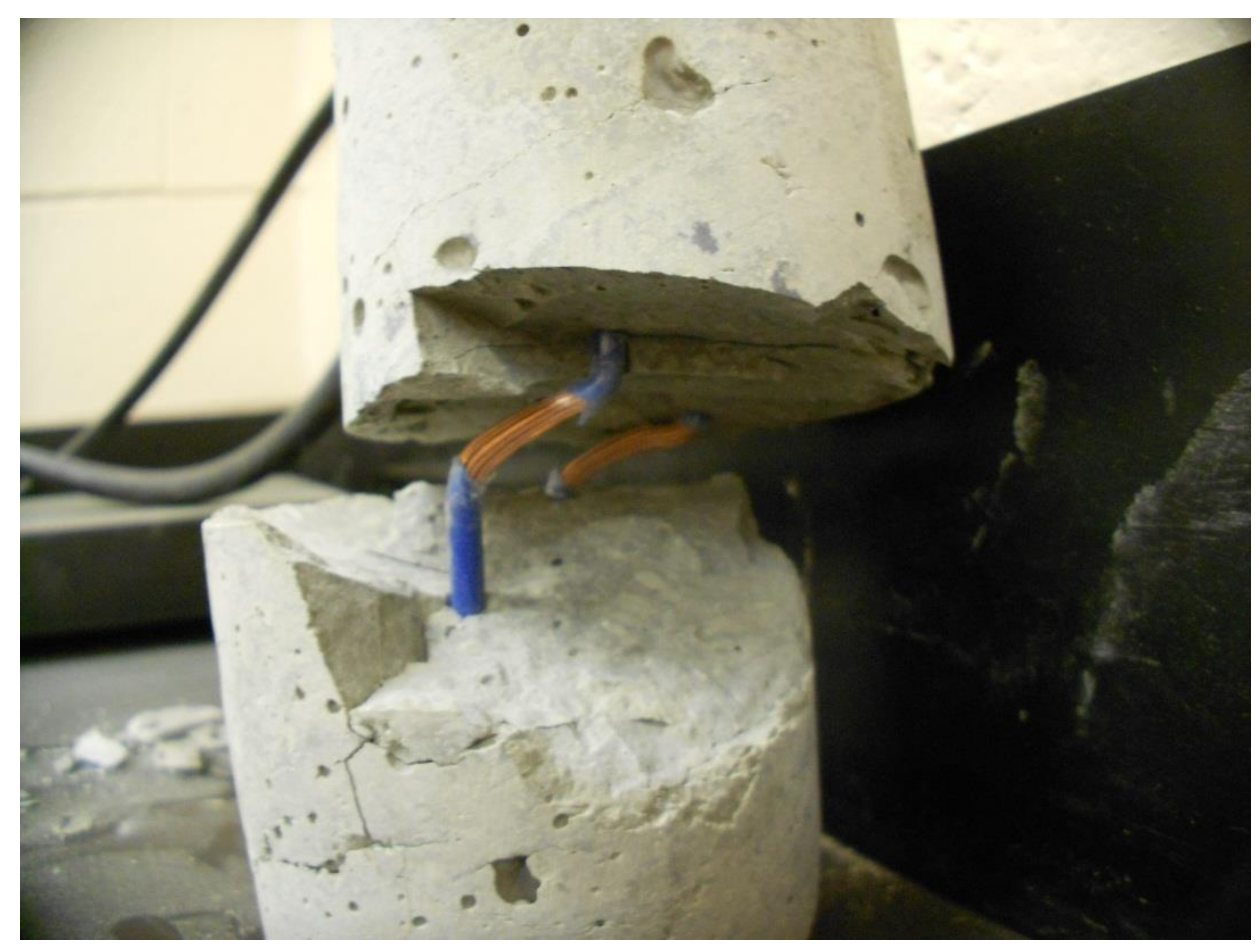

Figure 5.15: Sample G04 Post-test. Wires stripped but are not in contact on displacement.

\subsubsection{THHN Insulated No. 10 AWG Copper, Triangular Configuration}

Oriented along the axis of one edge of the triangular configuration, the nearest distance between embedments is 0.86 inches. The mean, minimum, and maximum direct shear loads, in tons, were $0.29,0.27$, and 0.34 , respectively. This configuration was the middle group in terms of the shear load on breakage. Again, the sample sizes used are not sufficient to make a statistical determination about the shear loads for these configurations. It is possible to say that the tests show that the various arrangements are commensurate. Like the parallel configuration, this group had one sample (J03) which not only failed along the plane of shear load but also had a wedge shape breakout extending upwards along the embedments. No strands were broken in any of the wires, and none of the wires were in contact after one inch of displacement. Figure 5.16 shows a typical post-test sample. 


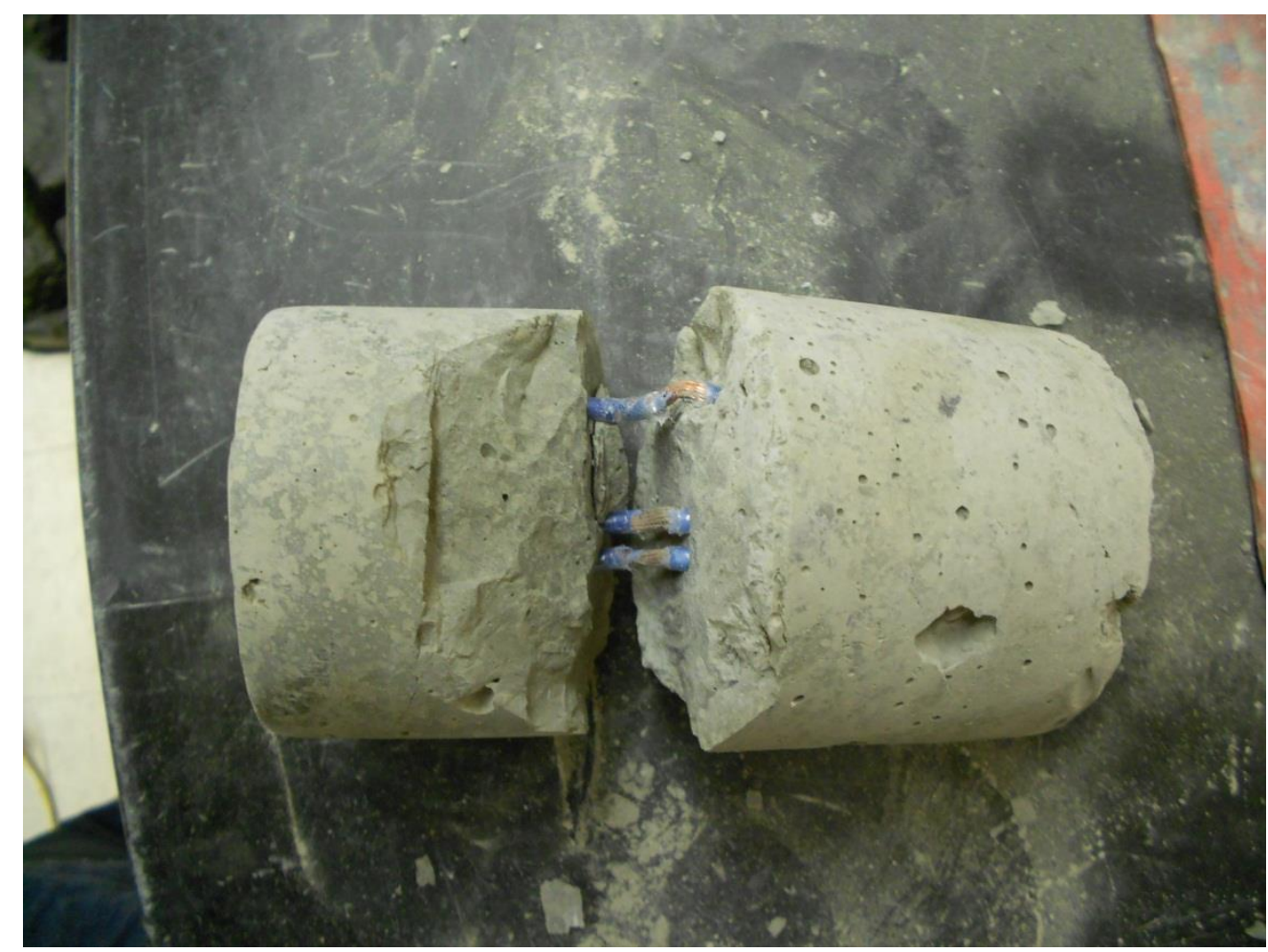

Figure 5.16: Sample J03 Post-test. Note also breakout wedge on left (top of sample).

\subsubsection{THHN Insulated No. 10 AWG Copper, Square Configuration}

Referring to Figure 5.13, the square configuration provides a nearest distance, on axis, of 0.71 inches between embedments. The mean, minimum, and maximum direct shear loads, in tons, were $0.33,0.26$, and 0.44 , respectively, and represent the largest values of the three configurations tested. It should be noted that the sample size of six, used for each configuration, is not large enough to make a statistically definitive statement about a superior influence of the square embedment pattern, despite the fact that square configurations, in many arenas, have revealed agreeable properties due to symmettry.

Figure 5.17 shows a typical post-test sample, with the stripping and displacement of the embedments. Of the three configurations tested, a single sample from this square configuration group (H04) revealed two wires making contact after the one inch displacement was completed. This sample is shown in Figure 5.18. Note that, on removal from the platens, some rotation occurred so that the wires were no longer in contact; however, the proximity remains evident in the image. For another sample (H05) debris which resulted from the shear fracture blocked the ability of wires to make contact. Consistent with the other configurations, no strands were broken in the wires and the insulation was stripped on displacement. 


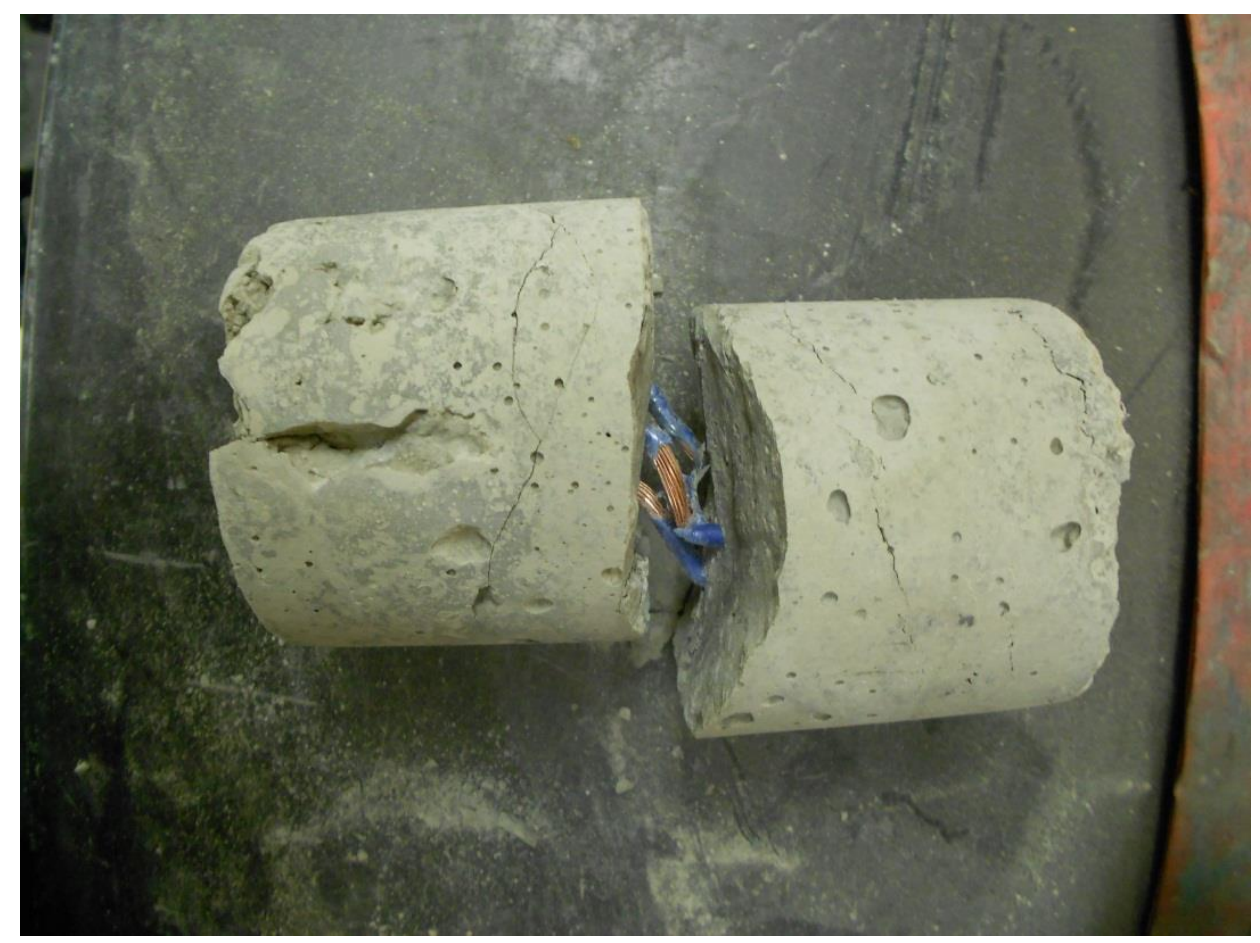

Figure 5.17: Sample H02 Post-test. Typical result for the square configuration.

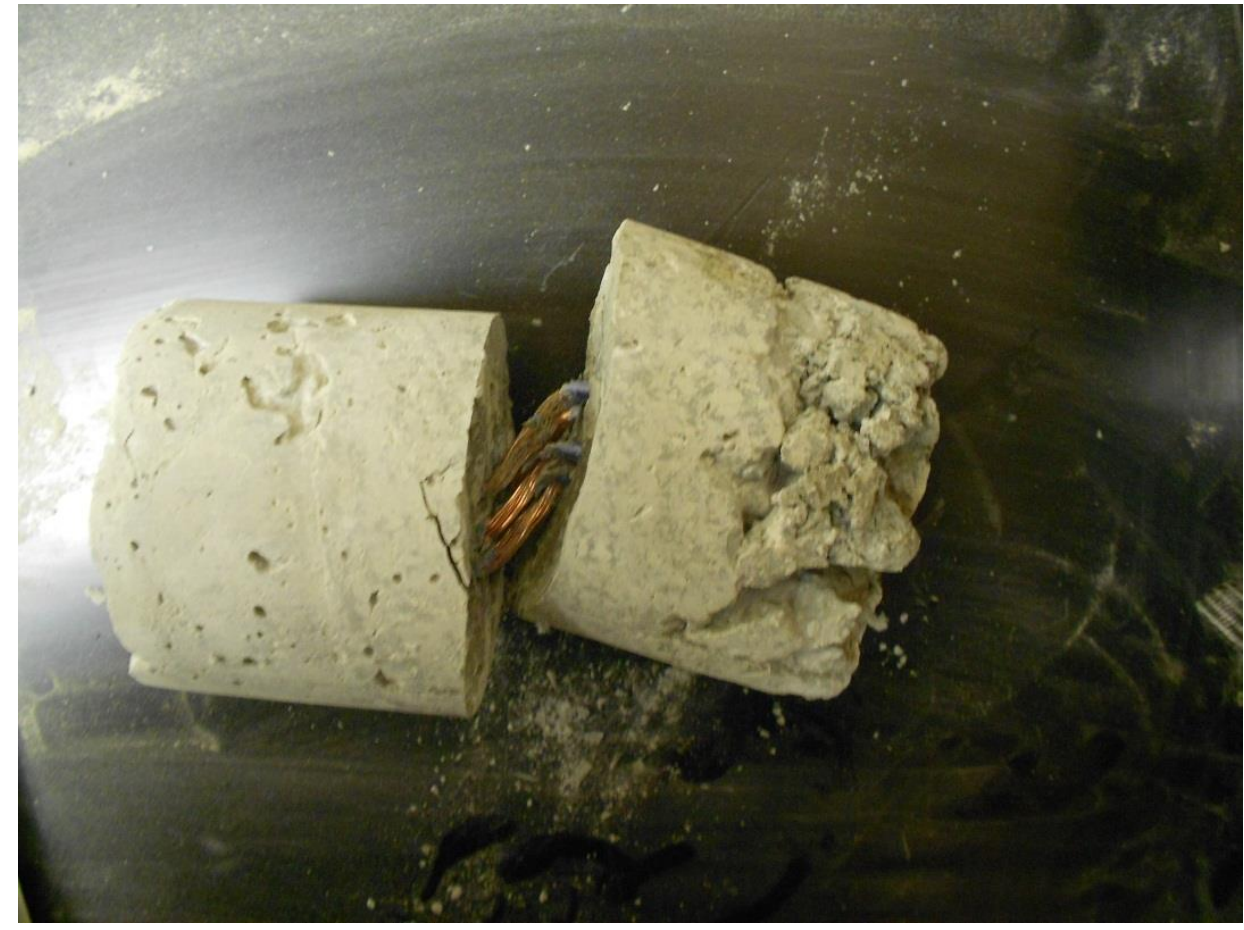

Figure 5.18: Sample H04 Post-test. Two wires were found to be in contact (note that some separation resulted on removing samples from platens). 


\subsubsection{Summary of Configuration Test Results}

Values of the direct shear load at failure were commensurate for the three types of configurations tested, and were in ranges typical for the tests of Section 5.1, indicating that the number of embedments had minimal effect on grout breaking strength. For all samples (total = 18), the wires remained intact, with no broken strands, after post-failure displacement of one inch. In only one case, with a square configuration, were two of the embedments in contact. In all cases, the wire was stripped from the insulation. This may be due to the short sample size of five inches where it is likely that the force of adhesion between the grout and the insulation exceeds the force necessary to strip the insulation from the unrestrained conductors. A field verification would be necessary to determine if broken strands would occur or if elongation of the copper conductors would be more likely.

\subsection{Evaluation of Grout Pigmentation}

In Section 3.4.2, the difficulty in identifying grouted exploration boreholes from underground was described and the concept of color diagnosticity was introduced. Based on previous research, and the geological color of coal mines, it was suggested that blue or green pigments, added to the grout, would be easiest to see. This hypothesis was tested in a laboratory setting.

\subsubsection{Description of Pigmentation Experiment}

This evaluation was performed using a simple set-up. Three grout cylinders - plain (unpigmented), blue, and green-were broken in shear using the direct shear device. Each halfcylinder was placed, sheared side outward, in a cardboard frame. Two frames were used. One was outfitted with a black background and the other with a white background. The former was to simulate cutting through coal with the grouted borehole therein and the latter was to simulate the same area after rock dusting. A coating of powdered talc was placed on each of the samples in the frame for the rock dusting simulation. These models are shown in Figures 5.19-5.22. 


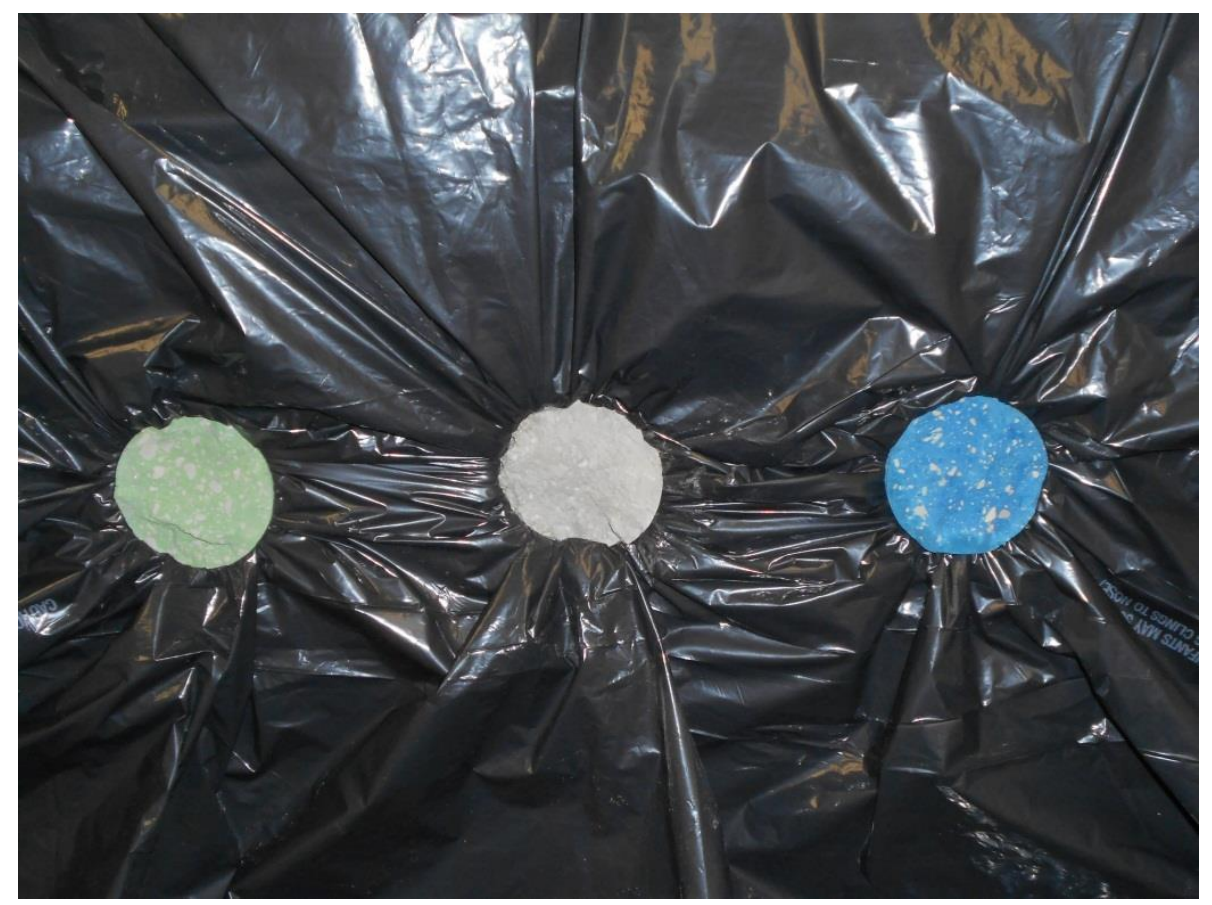

Figure 5.19: Pigmented grout samples in simulated coal face.

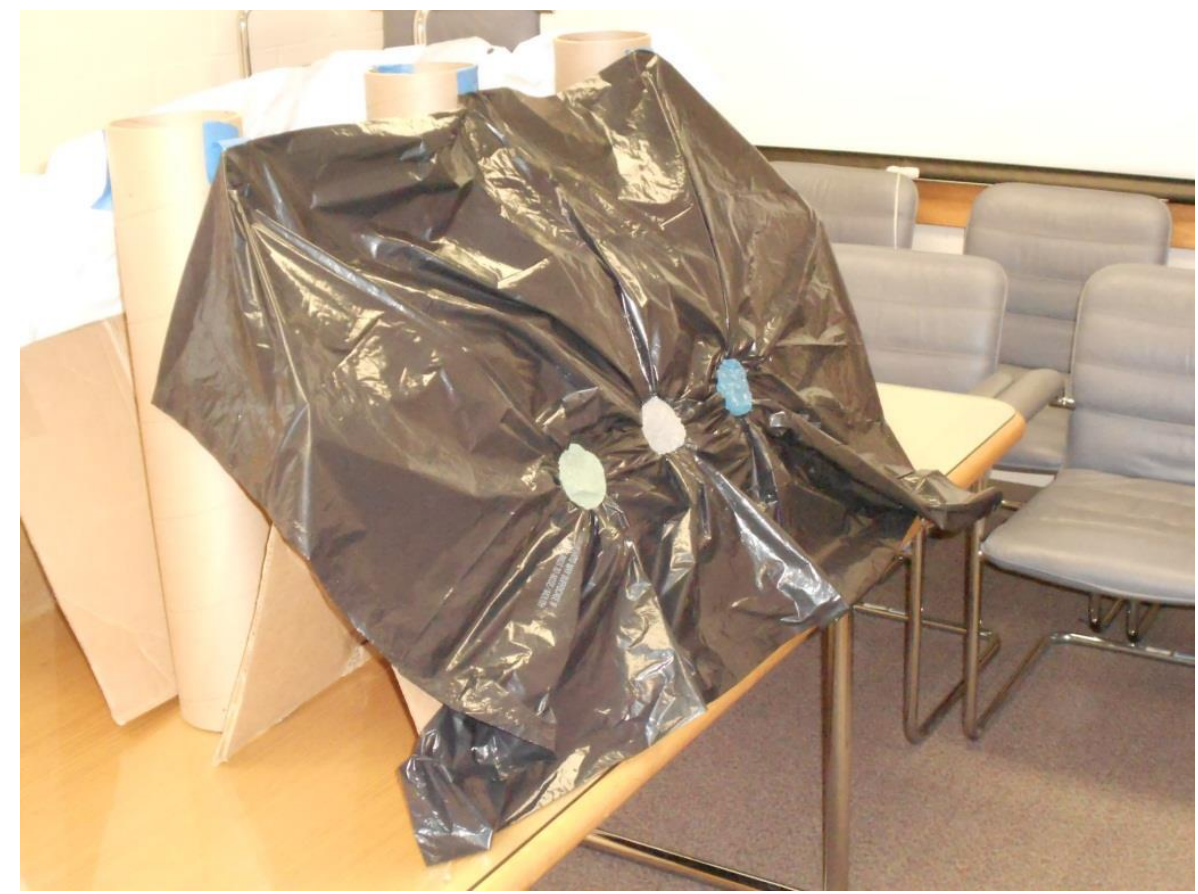

Figure 5.20: Model with dark background to simulate coal. 


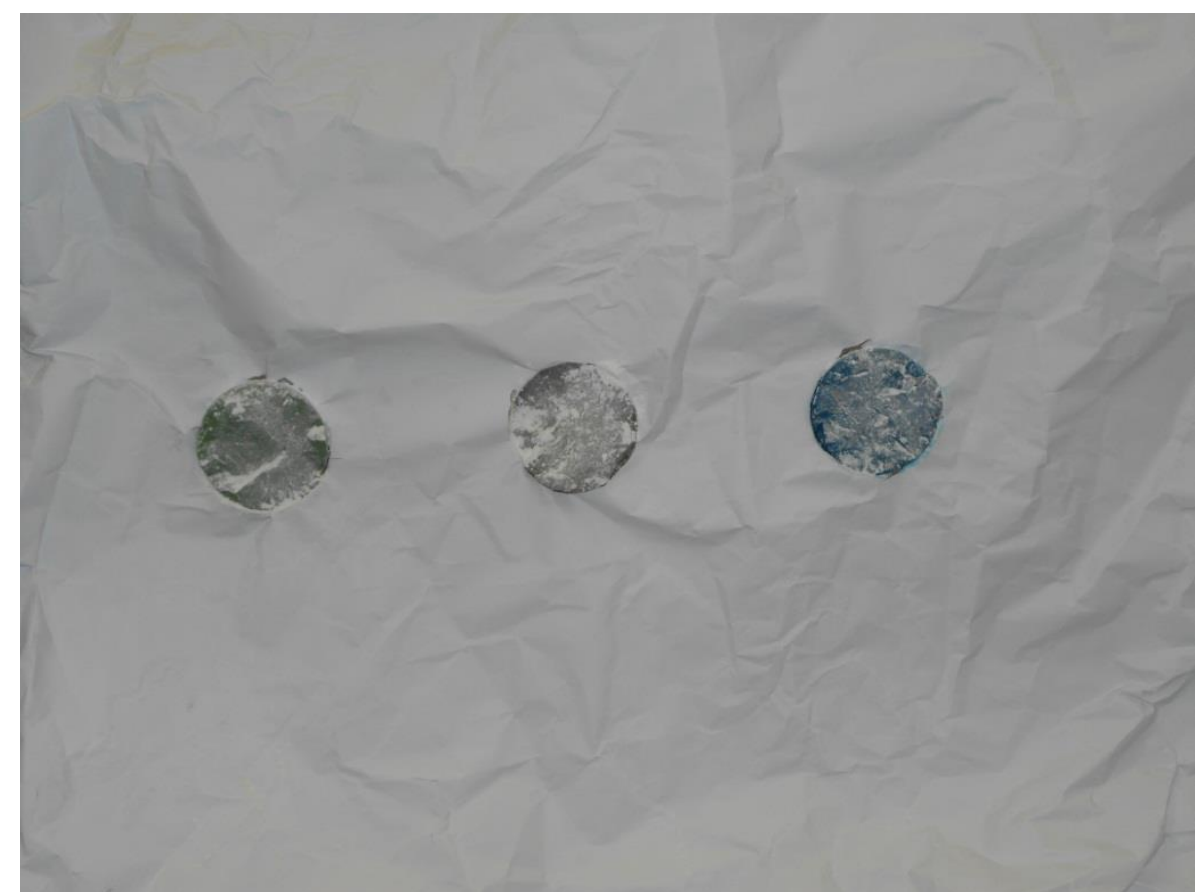

Figure 5.21: Pigmented grout samples in simulated coal face with rock dust or light-colored rock.

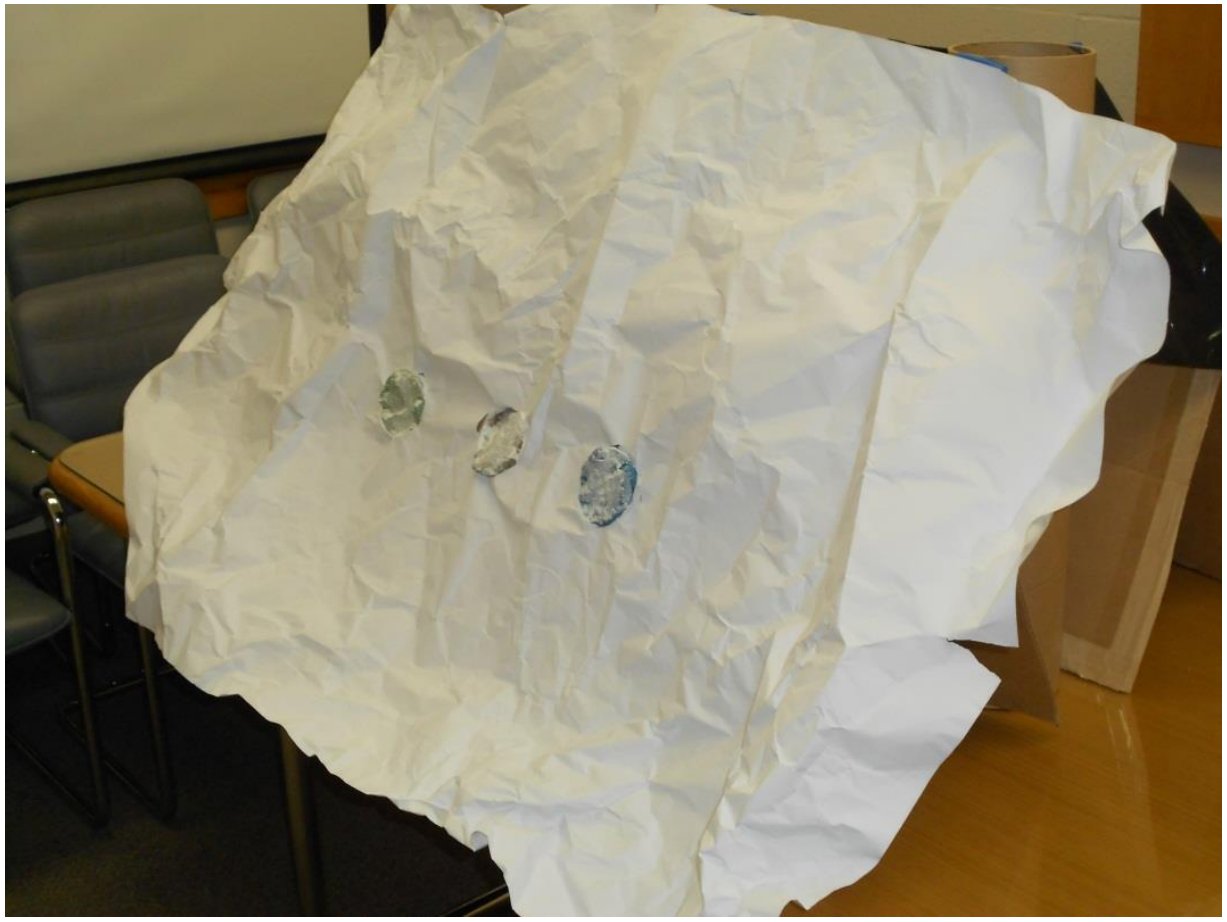

Figure 5.22: Model with light background to simulate coal with rock dust or light-colored rock. 
These models were placed in a darkened room, facing away from each other so that each had to be viewed independently. Assistance was solicited from students and staff, who were provided with a copy of the form presented in Appendix B. Each was asked to independently enter the darkened room with a flashlight and view each model, then answer the same two questions about each. First, "Which color did you notice first?" Second, "If you knew you were looking for it, which color do you think would be easiest to see?" The objective of this study was to provide an alignment with the general concepts of the research studies presented in Section 3.4.2 and to make a recommendation for the color of pigment that should be used for the first several dozen feet of borehole communication device.

\subsubsection{Results of Pigmentation Experiment}

There were 37 participants, comprised of undergraduate students, graduate students, and staff. Of the responses, three were removed from the sample because the participants did not correctly follow the instructions, leaving a sample size of 34. The raw data from this experiment appears in Appendix C. Summary data is shown in Table 5.1.

Of particular relevance is that all of the respondents were either students or staff in mining engineering. Most of the volunteers have, at minimum, visited underground coal mines and the majority of them have been employed in underground coal mines. Thus, the concept underlying the experiment was familiar to all participants.

Table 5.1: Count data for borehole grout pigment experiment.

\section{Dark Background}

Color Noticed First

Color Easiest to See if Known

\section{Light Background}

Color Noticed First

Color Easiest to See if Known

\section{$\underline{\text { Plain }}$}

4

2

6

3
Green

11

7

(1)

$\begin{array}{ll}2 & 26 \\ 4 & 27\end{array}$

From this table, grout with blue pigment was preferred for both dark (simulating coal) and light (simulating rockdust) backgrounds. The first question, as to which color was noticed first, was asked to assess alignment with the NIOSH study. The results of the borehole grout pigment experiment do not agree with the results of the NIOSH study. Suggested explanations for this are offered. The NIOSH study looked primarily at projected light whereas the grout pigment studied used only reflected light. The wavelength of the shades of green light in the NIOSH study and the grout pigment study were not commensurate. The NIOSH study looked at crisis (mine rescue) situations whereas searching for a grouted borehole is relatively mundane.

Blue was preferred to green at nearly a two-to-one ratio for color first noticed on the dark background. More important is the preference for blue when asking the question as to which 
would be the easiest to see if one knew they were looking for it. This addresses the concept of color diagnosticity, that certain colors are associated with certain objects and, thereby, make them more readily recognizable. On the light colored background, representing a rock-dusted entry, the upshot of this study is that the pigment color of the grout should be blue and that individuals looking for exploration boreholes outfitted with communication links must be informed that the grout will be this color.

Further analysis of the experimental data generates the transition probabilities of Table 5.2. From these, it can be seen that, in general, the first color noticed was also the color that was identified as easiest to see if known, $70.5 \%$ and $82.3 \%$ for dark and light backgrounds, respectively. Slightly over half, 55.8\%, of the respondents chose the same color for both light and dark backgrounds, as that which was first noticed and also that which would be easiest to see.

Several respondents provided verbal feedback indicating that partially colorblind individuals would be more likely to see the blue-pigmented grout. Some of the study participants said that they belonged to this type of cohort group and were concerned that it might influence the experiment. There is no reason to believe that participant colorblindedness would cause inaccurate results, as the objective is the same regardless of the participants' ability to distinguish the actual colors - only the choice of colors was relevant. To protect the privacy of the individuals who volunteered to help with this experiment, this information was not quantitatively gathered nor analyzed.

From this experiment a blue pigment is recommended for the lower section of the drillhole communication link, to aid with its visibility in the underground workings.

\subsection{Summary}

In consideration of the data obtained from the three rounds of laboratory tests, three general recommendations are proposed. First, the conductor material which appears to be the most robust is No. 10 AWG copper wire with THHN insulation. Second, the number of conductors embedded in the grout does not appear to have an effect on strength of the assembly, so four conductors are being recommended for the embedment, although reliability theory suggests that half of these should be reserved for spares. Third, when pouring the grout into the borehole, a blue pigment should be added to the bottom section, about forty feet, to aid in identification of the penetration into the developed entry. 
Table 5.2: Transition probabilities between categorical variables.

Dark Background Color Easiest to See if Known

Color Noticed First

Plain Green Blue

\begin{tabular}{rlll|l} 
Plain & 0.029 & 0.029 & 0.059 & 0.118 \\
Green & 0.029 & 0.147 & 0.147 & 0.324 \\
Blue & 0.000 & 0.029 & 0.529 & 0.559 \\
\hline & 0.059 & 0.206 & 0.735 & 1.000
\end{tabular}

$\underline{\text { Light Background }}$

Color Noticed First

\begin{tabular}{rlll|l}
\multicolumn{5}{c}{ Color Easiest to See if Known } \\
& $\underline{\text { Plain }}$ & $\underline{\text { Green }}$ & $\underline{\text { Blue }}$ & \\
Plain & 0.088 & 0.029 & 0.059 & 0.176 \\
Green & 0.000 & 0.029 & 0.029 & 0.059 \\
Blue & 0.000 & 0.059 & 0.706 & 0.765 \\
\cline { 2 - 4 } & 0.088 & 0.118 & 0.794 & 1.000
\end{tabular}

$\underline{\text { Color Noticed First }}$

\begin{tabular}{|c|c|c|c|c|}
\hline & & t Backgr & & \\
\hline & Plain & Green & Blue & \\
\hline Plain & 0.029 & 0.000 & 0.088 & 0.118 \\
\hline Green & 0.118 & 0.029 & 0.176 & 0.324 \\
\hline Blue & 0.029 & 0.029 & 0.500 & 0.559 \\
\hline & 0.176 & 0.059 & 0.765 & 1.000 \\
\hline
\end{tabular}

Color Easiest to See if Known

Dark Background

\begin{tabular}{rccc|c} 
& \multicolumn{3}{c}{$\begin{array}{c}\text { Light Background } \\
\text { Green }\end{array}$} & $\underline{\text { Blue }}$ \\
Plain & 0.029 & 0.029 & 0.000 & 0.059 \\
Green & 0.029 & 0.029 & 0.147 & 0.206 \\
Blue & 0.029 & 0.059 & 0.647 & 0.735 \\
\cline { 2 - 4 } & 0.088 & 0.118 & 0.794 & 1.000
\end{tabular}




\section{Chapter 6 Introduction of Potential Hazards}

Based on the previously presented design criteria, analyses, and laboratory experiments, a device for outfitting an exploration borehole with a communication link can be achieved. Prior to any proof-of-concept field test, the issue of lightning strikes as a potential hazard must be addressed. A thorough analysis is beyond the scope of the research included herein and is left as future work. However, this chapter provides a start for such research by identifying some of the relevant concerns regarding lightning as applied to the borehole communication link.

Applicable mining regulations are also summarized to illustrate that their scope is not sufficient to ensure safety of this unique device, although the probability of a direct lightning strike to such a device would be less frequent than once every 10,000 years.

\subsection{Lightning and Underground Workings}

Returning to the events at Sago Mine, non-conclusive evidence suggests the probability that the explosion that occurred behind the seals could have been triggered by an unusually large positive lightning strike ${ }^{6}$. An analysis prepared by Sandia National Laboratories as part of the official MSHA investigation reveals the theoretical possibility of such a lightning strike inducing a sufficient voltage on an abandoned pump electrical cable in the sealed area. If the inducing field was parallel to the cable segments, an induced voltage could have been generated and, on arcing to ground, could have provided sufficient energy to cause ignition of the methane-air mixture behind the seals. The report states:

The conclusions of this report are that lightning of sufficient magnitude and proximity to the sealed area would create high voltage on the pump cable to create an electrical arc. The simultaneity in time of recorded lightning strokes and the explosion occurring is very strong evidence of cause and effect. Furthermore, eyewitness accounts of simultaneous lightning and thunder at the time of the explosion, plus the analysis of credible hypothetical scenarios which cannot be confirmed by lightning detection networks, lend credibility to the idea that lightning-induced electrical arcing was not only plausible, but highly likely (Higgins and Morris, 2006, p. 61).

Important here is that the effect is suggested to be due to indirect coupling through the earth. Direct coupling (that is, through some path to the mine) was analyzed as insufficient to generate voltages capable of causing arcs with the required heat of ignition for the methane-air mixture for the situation at Sago. However, direct coupling as would occur with the borehole communication link is of larger concern to the safety of underground workings. It has been noted that the voltage and current characteristics of such an direct path at Sago would be "... sufficient to cause electrical shocks to personnel contacting these metallic penetrations, even miles back into the mine" (Higgins and Morris, 2006, pp. 59-60). This finding needs to be

\footnotetext{
${ }^{6}$ Positive lightning, less common but more severe in intensity than negative lightning, comprises about $10 \%$ of landbased cloud-to-ground lightning in North America.
} 
remembered with respect to the upcoming discussion of the effects of lightning on underground workings.

Since it is relevant not only to the design of a communication installation, but also because it was a suggested contributing factor at Sago, some characteristics of lightning will be reviewed. Section 6.1.1 concerns the behavior of lightning in general terms. The second section, Section 6.1.2 describes the phenomenon of side flashing which is particularly applicable when considering buried metallic objects. In Section 6.1.3 documented cases of lightning effects to underground workings are used to illustrate hazards associated with coupled energy.

\subsubsection{Behavior of Lightning}

As a thundercloud forms, positive charges migrate to its upper extremes and negative charges to its lower extremes forming, essentially, a dipole (for more, see Rakov and Uman, 2003 and Workman, 1967). Positively charged "pockets" form in the air below the cloud as a result of the dipole, and these "pockets" attract the negative charges in the lower extremities of the cloud. A leader stroke, often somewhat luminous, emerges from the lower boundary of the cloud. This leader stroke then forms into a stepped leader, extending in piecewise linear fashion towards the ground, with connected segments approximately 60 feet in length. Golde (1975) describes what happens next, "When the faint lightning leader channel reaches the ground, intense luminosity is seen to travel upwards along its path towards the cloud and along its branches. This is termed the return stroke. In effect, this constitutes an electric short circuit between the negative charge deposited along the leader and the electrostatically induced positive charge in the ground" (p. 11). The resulting waveform is of the shape shown in Figure 6.1.

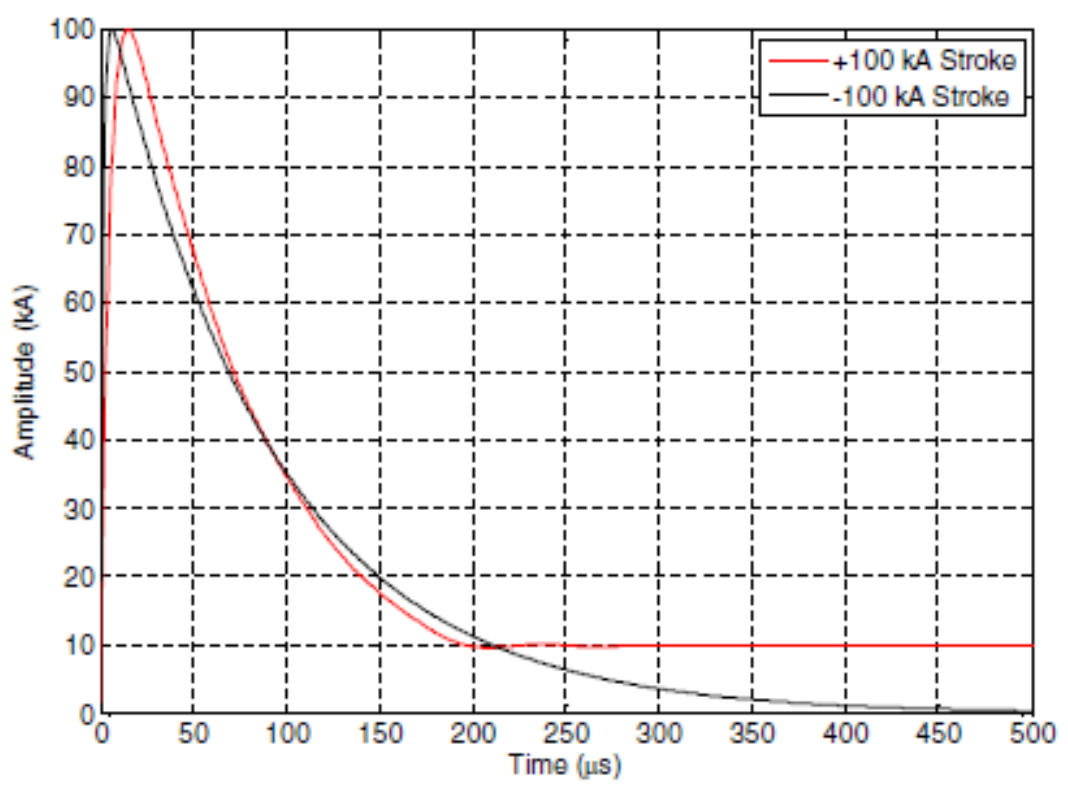

Figure 6.1: Basic Positive and Negative Lightning Waveforms (Higgins and Morris, 2006, p. 49). 
This may not complete the cycle. Once the path has been established, a dart leader (a single stroke without branching) may extend towards the ground to be met by a second return stroke. This can occur multiple times and usually, but not always, involves the same physical location on the ground.

Over ninety percent of lightning strokes are characterized as negative and follow the development thus described (Rakov and Uman, 2003). However, positive lightning strokes can also occur when thunderclouds have positive charges at their lower boundaries, as may occur at the end of a storm (Golde, 1975, p. 12) or in the winter (Sacks and Novak, 2008, p. 419). Positive strikes are usually more severe. Such a positive strike was suggested to be a contributing factor at the Sago Mine (Higgins and Morris, 2006; McAteer et al., 2007).

An important observation is that the modeling of lightning phenomena is complex since lightning is a transient electromagnetic interference with a large frequency spectrum. The induction of voltages on lines and cables from lightning electromagnetic pulse, for example, requires three specific models: (1) a model for current propagation in the discharge; (2) a model for the electromagnetic field propagation over a real soil with finite conductivity; and (3) a coupling model (Tesche et al., 1997, p. 15). As such, the use of reduced models to investigate various responses of a device, such as the borehole communication link, to lightning strikes must be weighed cautiously if physical implementation and personnel safety is to be based on the results of studies employing these reduced models.

\subsubsection{Side Flashing}

One of the characteristics of lightning is its ability to side flash, sometimes through mediums of fairly high resistivity as would be the grout used in the borehole communication link. Figure 6.2 illustrates an example from Golde (1975), credited to Müller-Hillebrand (1957), in which a tree 230 feet distant from a residential structure received a lightning strike. A side flash occurred underground between the roots of the tree to a metal fence located 66 feet from the house. From there, the side flash continued on to the electrical service panel of the house resulting in damage. A visible trench was left in the yard, marking the path taken by the side flash.

The relevant factor from this example is that the side flashing occurred through the earth to metal structures. A lightning strike that occurred near Sago similarly damaged a tree that was located 197 feet away and damaged an underground telephone cable located between the tree and the mine (Higgins and Morris, 2006, p. 18). In the case of the drillhole communication link, such significant underground metal structures will not be incorporated in the design. However, it could be argued that placing a device containing vertically embedded conductors in the vicinity of buried, horizontally oriented, utility lines would be prudent as any side flashing from aboveground conductors (e.g. wet trees with large underground root systems) may be attracted by the utility lines. While this strategy has been utilized in some cases to possibly provide lightning protection, locating a drillhole intended for communication nearby underground utility lines may not outweigh the concerns associated with the probability of additional drilling in the event a rescue capsule is desired near the communication link. Also, side flashing tends to be 
relatively shallow, where ground can be saturated with rainwater, until it directly couples to a metallic penetration. This was briefly mentioned in Section 3.2 regarding the possible locations of borehole communication links during the mine pre-planning phase.

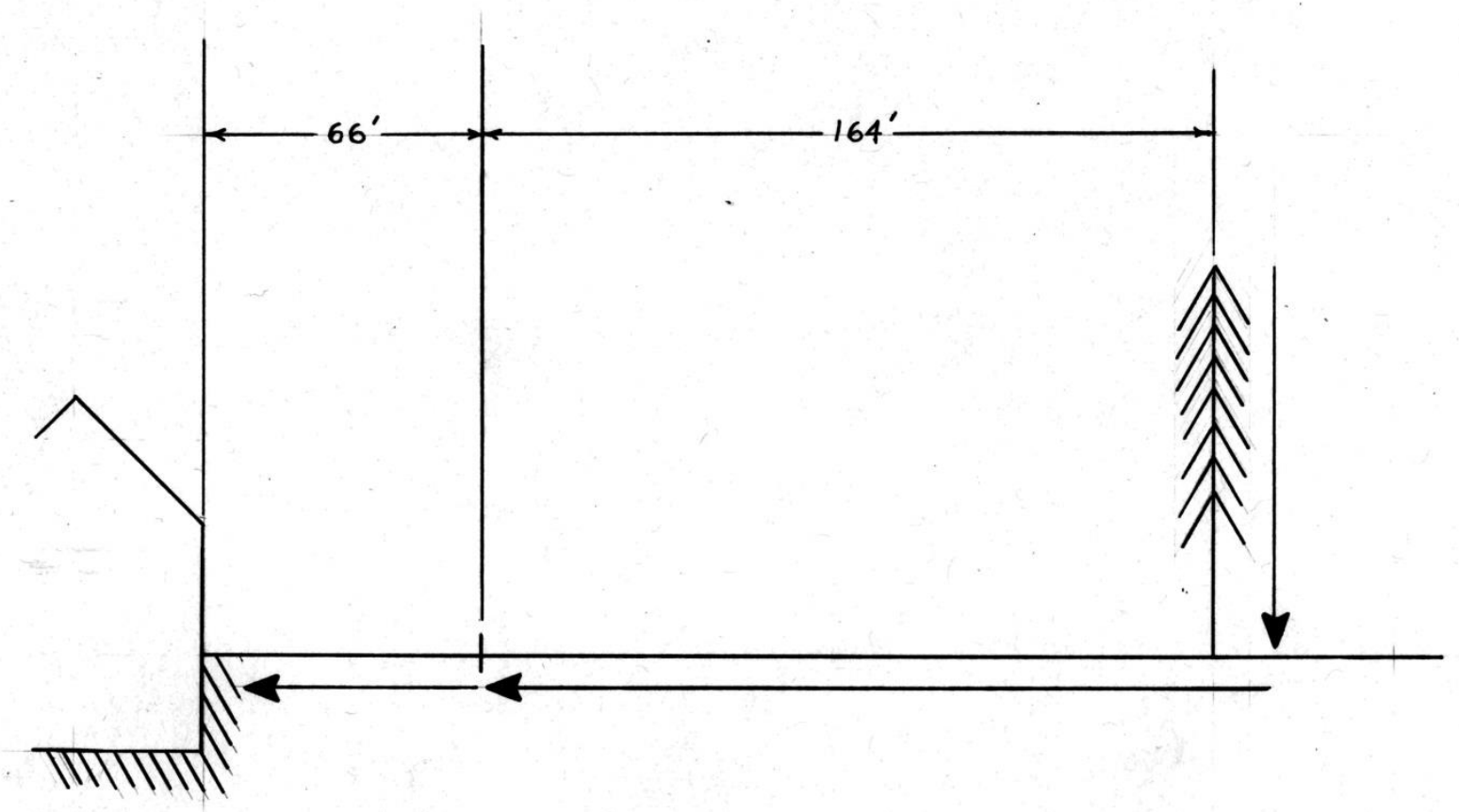

Figure 6.2: Example of side flashing to residential structure (scale approximate). Adapted from illustration in Golde (1975) illustrating phenomenon documented by Müller-Hillebrand (1957). Lightning current follows the path marked by large arrows.

\subsubsection{Examples of Lightning Effects on Underground Workings}

Given the advances in lightning protection systems and current safety precautions, both as applied to underground coal mines, contemporary literature on witnessed lightning events in underground mines is sparse. That is, the miners were evacuated during the event, the protective systems functioned to prevent the event, or the event was so catastrophic that no underground witnesses survived. Thus, to visualize the effect of lightning in underground workings, it is necessary to return to earlier literature on the subject.

The premature firing of detonators due to the incidence of lightning strikes is, perhaps, the most documented phenomenon. Many preventative measures have significantly reduced this risk, notwithstanding the fact that there are less explosives currently used in underground bituminous coal mines than in the past. These precautions can be divided into two general categories. The first encompasses material transport and handling practices, including such measures as tying the lead wires together and taking into the mine only those explosives needed 
for the job. The second involves grounding and bonding practices to ensure that there are no gaps across which a lightning-induced voltage can jump to cause an ignition. This latter category is relevant to the case of methane-air explosions in coal mines and may have been a factor at Sago (Higgins and Morris, 2006).

Two lightning-related events are next presented for the insight they provide regarding the propagation of coupled lightning energy in underground workings.

One documented incident presumably involving ignition of methane in an underground coal mine initiated by a lightning strike occurred in Victoria, Canada in 1938. During an idle period, employees working outside the mine noticed a lightning strike and cloud of smoke in the vicinity of an intake shaft located some 4,000 feet (by ventilation air travel) from the main portal. Overburden depth was 600 feet. Employees working close to the main portal were affected by the lightning and these events prompted an investigation which revealed that an explosion had occurred inby. The Chief Coal Mine Inspector also reported the following:

At the time three men working at different points in No. 3 mine reported to their fireboss that they had seen flashes of light running along the rails and making a noise like firecrackers; one man on an incline stated that he saw a light traveling up one rail for a distance of 250 feet towards him and appeared to die out 15 feet past him. None of these men experienced anything in the nature of an electric shock, but another man who was working on a 3-inch pipeline did suffer a shock. (I may say that there is no electrical equipment, with the exception of telephone and signal bells, underground in the Colliery.) (Harrington et al., 1948)

Methane levels in the return were regularly reported to be between 1.00 and 1.25 percent, although the working faces were generally reduced. The illustrative point of this incident is the long-distance conduction of lighting energy via the (low resistivity) rails on the haulage. The description did not mention any metallic path via the intake shaft but given the intensity of the occurrence and the typical equipment located at such shafts this is probable and thus indicates that the likely mechanism was direct coupling.

Another incident, involving the construction of a water tunnel, illustrates just how elusive it can be to protect underground workers from the effects of lightning strikes. The Apalachia Tunnel was a national defense project undertaken during the Second World War, and was excavated for 44,000 feet linking a dam to a power generating station. The cross-section was 20 feet and, accessed via four adits, seven headings were simultaneously worked.

A lightning event occurred above the tunnel and 2,100 feet inby the portal a chuck-tender on the middle deck of the drilling jumbo was electrocuted-he was removing a drill steel at the time of the event. Two other workers, located above the deceased on the top deck, were knocked unconscious but were resuscitated. The Chief Engineer of the Project Planning Division, Tennessee Valley Authority describes:

It was later discovered that the stroke was felt in the heading being drilled from the other end of the section and which was about $400 \mathrm{ft}$. from the scene of the accident. 
In this heading a miner was scaling loose rock from the roof, and two scaling bars were leaning against the face. According to an eye witness, "The flash played all around between the two bars ... a and all but wrenched the scaling bar out of the safety miner's hand without him feeling any discomfort from the electrical charge." A man on the muck dump 3,000 ft. away felt a shock, as did another man 22,000 ft. farther along the tunnel line. (Leonard, 1945).

In this case, it was believed that the chuck-tender, in grabbing the drill steel, completed a circuit between the face and the jumbo, the latter having been bonded to the rails in the tunnel. Since all reasonable electrical safety precautions had been taken in the tunnel, the only practical solution to prevent such an accident would have been to remove the workers from underground before the storm.

The TVA case appears to be similar to suspected events at Sago inasmuch as it portrays a mechanism characteristic of indirect coupling. At Sago, it is believed that a positive strike on the surface induced a voltage through the overburden rock strata to an abandoned pump cable. The induced voltage may have arced to ground through the end connection of the cable, providing enough energy to cause ignition of a methane-air mixture in the sealed area containing the cable (Higgins \& Morris, 2006, pp. 60-61).

Figure 6.3 shows an underground excavation, either a tunnel or a mine entry. In soils with high resistivity, as are frequently encountered in the eastern United States, the earth currents are often concentrated at the face, creating a potential difference between the face and the earth (Golde, 1975, pp. 133-138). Objects completing this circuit can cause a discharge, as was the case with the chuck-tender at the TVA Apalachia Tunnel and presumably also at Sago. The difficulty in predicting the path, and therefore attempting preventative measures, is the unknown nature of the rock strata. While the core removed from the drillhole gives some idea of the composition of the overburden, it is not sufficient to answer questions about the resistivity of each layer of the strata in the vicinity. Discontinuities in the strata can have major effects in determining the path of the earth currents (Keller, 1967; Golde, 1975; Higgins and Morris, 2006). 


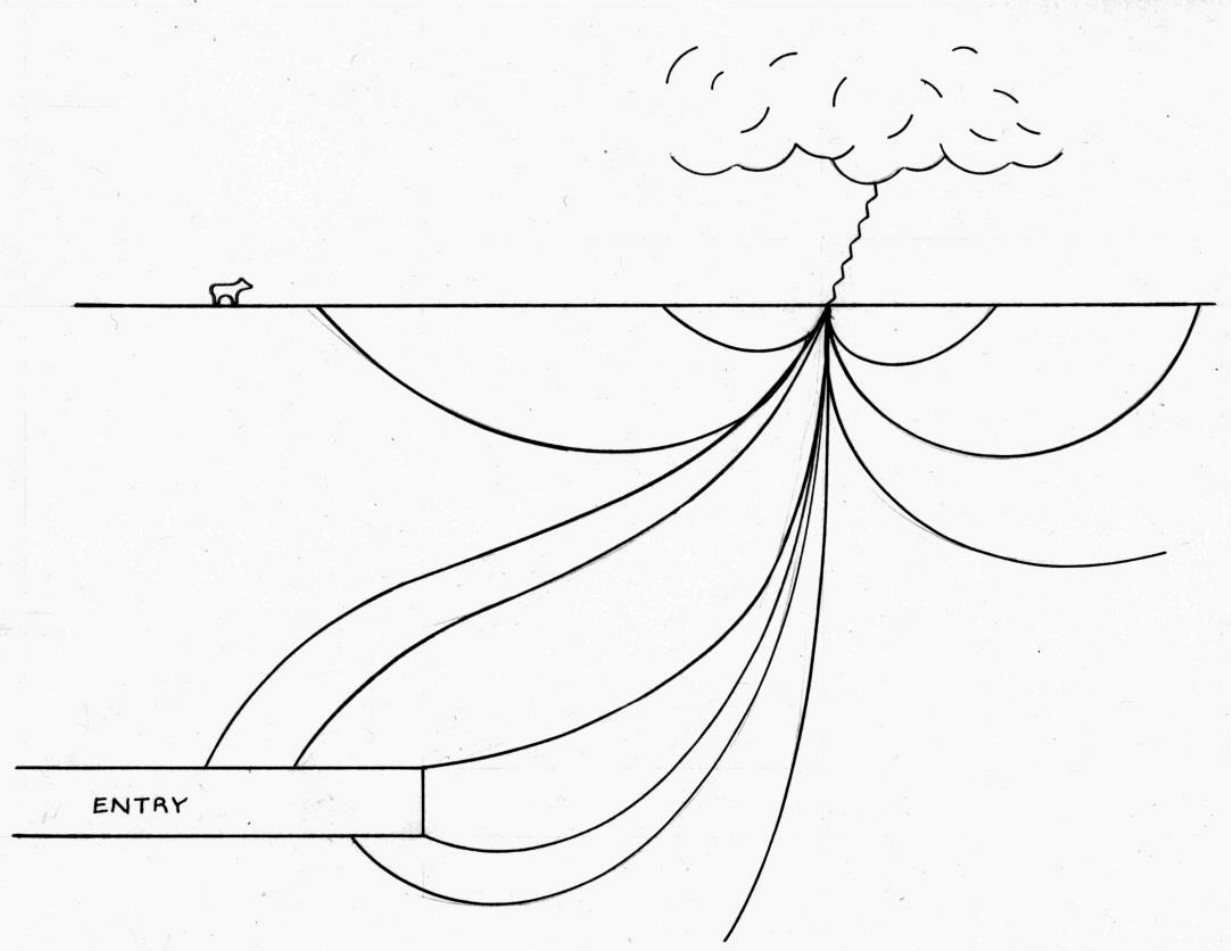

Figure 6.3: Example of ground currents surrounding a mine entry. Adapted from Golde (1975).

\subsubsection{Lightning Protection Considerations for Mine Electrical Systems}

Lightning protection for a communication link via an exploration borehole would likely differ from that for mine electrical equipment at-large. Consider first the concern of interaction effects between lightning and mine electrical systems. C. T. Pearce and R. C. Allen were engineers with Westinghouse Electric and Manufacturing Company in the 1930s. Over seventy years have passed since their oft-quoted description of lightning first appeared in Coal Age:

Lightning has much the characteristics of a prize fighter's punch. A direct stroke is like a "sock to the jaw" and can be a knockout unless the recipient is built to take it. The shock, however, goes through the system. With arresters installed, the stroke is like a glancing blow: part of the effect is "drained off," so that the peak is not as great, even though of the same steepness. (p. 59).

Later, J. A. Civilett, also of Westinghouse, described the process of lightning striking an overhead power line, "When it does, it divides into two waves and travels to both ends of a line. The fronts of these lightning waves are practically perpendicular, like a huge wall of water, 'blitzkrieging' everything in its path" (Civilett, 1942, p. 61). Without line protection, weak insulation, such as that frequently encountered in motor windings, would quickly break down, resulting in damage to the stator coils. 
With electrical equipment, especially overhead equipment, lightning protection is somewhat more straightforward. Thomas A. Edison was one of the first to attempt this type of protection using the "horn gap" principle. In implementation, two horns are set apart some distance such that, under normal operating conditions, there is no circuit. However, should a surge voltage occur, the horn gap would be sized such that the air in the gap would be ionized as the current jumped across. Heating of the air would cause the arc, thus formed, to rise until the circuit was broken. (Richart, 1942).

Since the time of Thomas Edison, whose horn gap device would not have a sufficient response time for today's circuits, there have been many advancements in surge protection. Note that the circuits employed to protect systems from lightning often provide the same protection against similar voltage wavefronts due to surges caused by switching in the high voltage systems themselves. Thus, the incentive for research into this area continues to be active, despite the fact that relatively simple protective circuits and devices can be employed in many common situations where only lightning is anticipated, such as on signal and communication wires.

One key objective, then, is to reduce the impact of the lightning strike by reducing the steepness of the voltage wavefront so that it does not break through equipment insulation in an attempt to find a path to earth ground. The second objective is to economically provide equipment insulation to handle these reduced overvoltage wavefronts (Pearce and Allen (1937); Walsh (1973), p. 133; Neugebauer (1987) p. 27-2). This advice is particularly applicable above ground, as in the case of high-voltage transmission lines, where the objective is to reduce the instantaneous waveforms to a level that can be absorbed by the lines without causing any disruptions to service nor damage to equipment and where a path to ground can be readily established. The situation is different when dealing with underground installations where voltage potential differences arcing to ground can be an ignition source for methane-air mixtures in the coal mine. However, with due consideration for bonding underground, the creation of gaps across which a high voltage potential can jump can be minimized.

First, consider the imperative to establish a solid, earth ground. If anything has been emphasized with regard to protecting mine electrical systems and personnel, grounding is the subject. Walsh (1973) has called the earth connection the most important part of the grounding system (p. 147) while as early as 1937 Pearce and Allen said, "The question is frequently asked as to what constitutes a good ground. The better the ground, the better the protection, so that the best ground is none too good" (p. 60). Similar statements have been made by Barlow (1941) and Golde (1975), and standards can be found in National Electrical Code, Article 250 (1995) and, for underground mines, 30 CFR 75 Subpart H and National Electrical Code, Standard 120 (2010). As Barlow (1941), in the earliest days of mechanized mining, said "Grounding will not eliminate all hazard, but merely lessen it." To counteract the hypothesized situation regarding an induced voltage in an abandoned pump cable in the sealed area at Sago, one would want the conductor (or cut end of the cable) in solid contact with the ground. It is perhaps too basic to suggest that a solution could have been accomplished by burying the bare end of the conductor in a mound of dirt on the mine floor so that arcing could not occur.

Various schemes are employed to lessen the effects of lightning. In mining, most are variants of the work of Civilett and Richart, based concepts of which are herein mentioned. 
When considering the proper protection of rotating equipment, Civilett (1942) cautions against using the same ground for machine frames and their protective devices as this practice would neutralize the effect of high ground resistance and could cause flashover between the frame and stator coils (p. 61). A minimum separation distance of 500 feet is recommended for circuit voltages exceeding 2000 volts. Richart (1942) suggests a low-resistance ground of less than $10 \mathrm{ohms}$ for machine frames. Now, consider the case of protecting the drillhole communication link by attempting to provide a solid earth ground. Unlike most mine power and communication systems, the grout assembly is earth ground, in contact with and having nearly the same resistivity of the surrounding earth. With uninsulated, small diameter embedded conductors, this argument likely still holds. However, if insulated conductors are embedded in the grout these parallel conductors now may defeat the assimilation of the grout assembly into its surroundings by providing a path for direct coupling to underground installations.

Assume instead that a drillhole is encased in steel instead, considered to be grounded under 30 CFR \$75.700-1 and that a ground rod (as typically used for aboveground installations) is driven into the ground at a distance of, say, ten feet from the borehole such as one scenario considered by Sacks and Novak (2005). If connected by a sufficiently large wire, then the ground rod and drillhole casing will be at the same voltage potential, meaning that a lightning strike to one would have basically the same effect as a lightning strike to the other. If there is no connecting wire (which would, of course, defeat the intended purpose) then the probability of side flash is present, creating precisely the situation that was modeled by Sacks and Novak (2005). ${ }^{7}$

What, in the case of the communication drillhole link, which is surrounded by earth, is a "good ground?" It will be reasoned that, by eliminating the steel casing, the drillhole itself is its own best ground, albeit imperfect. In Section 6.2 this will be reviewed in more detail but an extensive study must be performed to confirm this assumption.

\subsection{Evaluation of Drillhole Communication Link for Lightning Hazards}

Much attention has been given to the interaction of lightning strikes with underground coal mines since the incident at Sago where lightning was suspected as a contributing factor (Gates et al., 2007; McAteer et al. 2009). When one suggests the possibility that a drillhole could provide a means for delivering the energy of a lightning strike to an underground coal mine, it is important to understand the characteristics of lightning strikes, the materials employed in the drillhole assembly, and the probabilities associated with the intersection of the relevant factors. Lightning characteristics were reviewed in Section 6.1. Based on probabilities, it can be shown that the installation of the drillhole communication assembly will be no worse than the situation encountered if the device was not present. That is, the drillhole communication conduit will not "attract" lightning; conversely, it cannot be designed to "repel" lightning. However, in

\footnotetext{
${ }^{7}$ Note also that the Sandia National Labs report dismisses the possibility of a corona-initiated discharge and suggest instead that coupling is the mechanism for transfer of lightning energy (Higgins and Morris, 2006 , p. 11).
} 
the negligibly likely event of a direct lightning strike, analyzed in Section 6.2.1, direct coupling of the lightning energy to underground workings may be possible.

\subsubsection{Probability of Lightning Directly Striking Drillhole}

Although the cases of section 6.1.3 are historical in nature, they are timeless in their illustration of events that may be considered "rare occurrences" or "Acts of God." However, ". . . it would be very unlikely for unlikely events not to occur," yet, "The moral, again, is that some unlikely event is likely to occur, whereas it's much less likely that a particular one will." (Paulos, 1988, p. 37). In other words, it would be no more likely for lightning to strike a drillhole containing a communication link than it would be to strike any other location located on the surrounding flat ground. While dissecting a recent probability study on this subject, first consider Figure 6.4. Sacks and Novak (2008) have attempted to estimate the probability of a negative stroke lightning-induced ignition of methane in underground mines. They caution that their analysis is limited, as it does not incorporate ground resistivity nor a definition of the ignition mechanism, which are two important governing factors. As will be discussed, while the electrogeometric model employed is not intended for underground structures, using it as a predecessor for development of area calculations does not influence the probability analyses which are based on the geometric distribution of the drillholes themselves.

The electrogeometric model from IEEE Standard 1410-2004, and used by Sacks and Novak for their simulation study, was designed for high voltage transmission towers and other structures of significant height. According to Sacks and Novak, "A conductive object that is taller than the surrounding area exhibits a lightning-attractive area, which is a function of its shape and height and is dependent on the current magnitude of the flash. The model assumes that a lightning stroke with a peak current within the attractive area will strike the object rather than the ground."

The electrogeometric model in IEEE Standard 1410-2004 dates back to research done by Sir Oliver Lodge in 1892 concerning implementation of a lightning rod to create a "protective zone." Thus, the point at elevation $h$ in Figure 6.4 actually is acting as a lightning rod and, therefore, should be solidly bonded to earth potential to be effective. Additionally, it should be noted that this model, Figure 6.4, is based on a single, free-standing vertical conductor and its limitations were well known in the 1970s. As a result, very few countries specify a "protective zone" in their electrical and building codes. If such a "protective zone" is to be assigned to a structure, it will often fail during a thunderstorm when the entire structure is thoroughly wetted, thus allowing the electric field concentration to be larger at some corner of the structure away from the lighting rod (Golde, 1975, pp. 32-37). The assumptions also occur in the absence of wind, which is not realistic for most thunderstorms. Wind can blow the charged "pockets" of air and cause leader strokes to enter from angles that are not conducive to protection from lighting rods. Examples are numerous, but one frequently cited is a 1939 study of lightning strikes at the Empire State Building where many of the strikes ignored the presence of lightning rods and their "protective zone" (McEachron, 1939). Conversely, for studies of high voltage transmission line towers located in relatively open fields, the IEEE model has had more promising results and this 
conventional approach to lightning protection is reliable in many surface applications (Uman and Rakov, 2002).

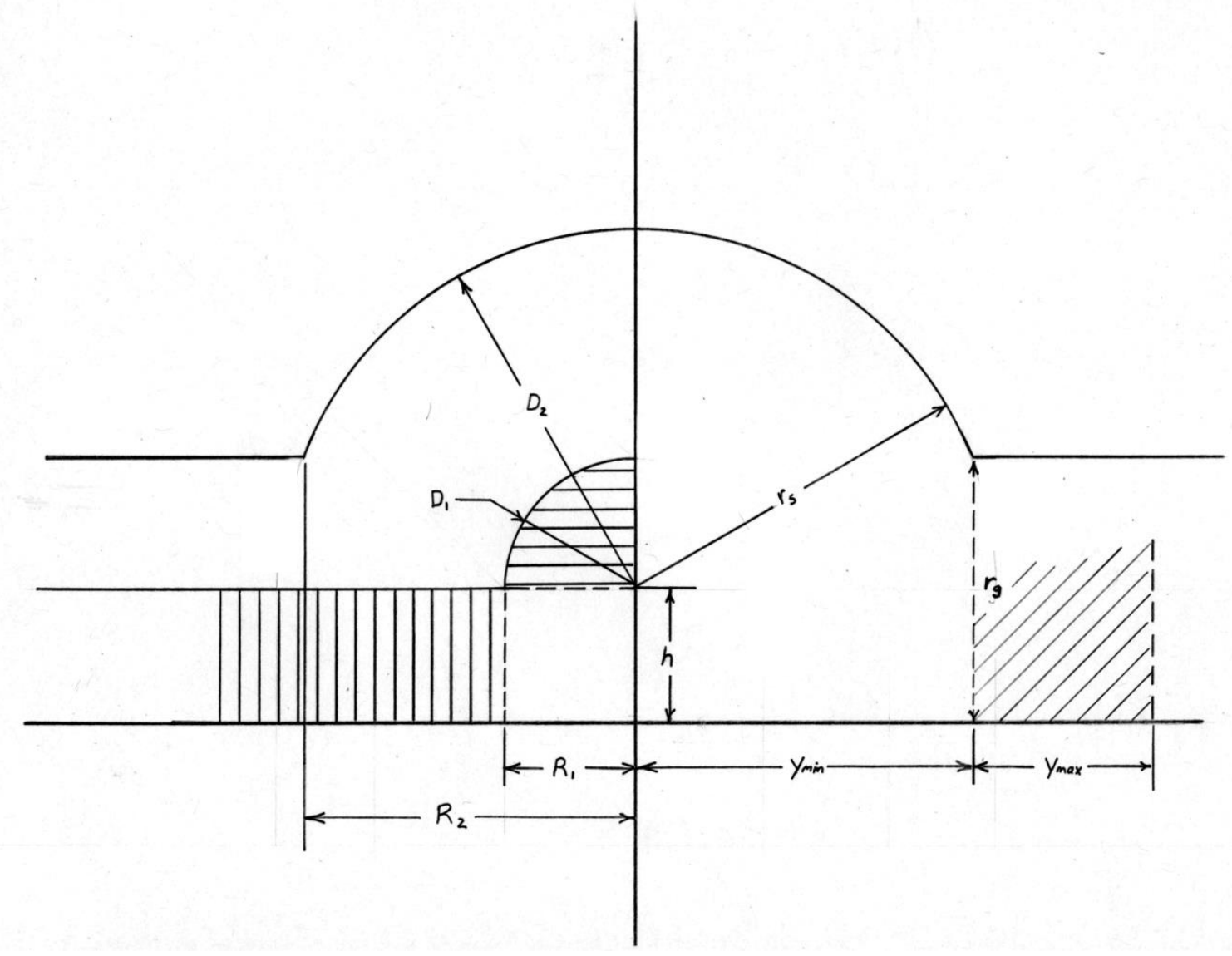

Figure 6.4: "Protective zone" for vertical lightning rod (left) adapted from Golde (1973) and "attraction zone" for high voltage utility lines (right) adapted from IEEE Standard 1410-2004.

On the left half of Figure 6.4, the "protective zone" around a lightning rod of height $h$ is given by a cylinder about the rod. In conventional nomenclature, the radius is determined by the charge on the leader channel. If the charge on the leader channel, $D_{l}$, is less than the height, then the radius is given by $R_{l}$. If the charge on the leader channel is greater than the height, given by $D_{2}$, then the radius $R_{2}$, is given by

$$
R_{2}=\sqrt{2 D_{2} h-h^{2}}
$$

In practical terms, this means that the tip of an approaching leader stroke, coming from any angle, will be attracted to earth if it penetrates the vertically hatched area in Figure 6.4 and will be attracted to the lightning rod if it penetrates the horizontally hatched area (Golde, 1975, p. 3334). In the IEEE electrogeometric model, shown on the right half of Figure 6.3, leader strokes outside the radius $r_{s}$ will be attracted to earth in the area with the cross-hatching for a distance of $y_{\min }$. The extent of $y_{\max }$ denotes the distance limit for side flashing (Sacks and Novak, 2008). The equation for the charge on the leader channel is developed from empirical data and the 
radius of the "protective zone" as a function of leader charge and lightning rod (in this case high voltage tower) height.

Sacks and Novak applied this IEEE Standard 1410-2004 model to underground borehole casings and an "attractive area" was thus calculated. This differs from previous analyses performed on structures under 60 feet in height, the height considered "ordinary" in the vernacular of lightning research (Rakov and Uman, 2003, Chapter 18). Golde articulates this point directly:

Open ground ... is almost always covered with grass, stones or low growth which ... give rise to point-discharge currents, thus facilitating the development of upward streamers. Again, the height of an ordinary structure is short compared with the total length of the last few steps of a lightning leader stroke. It may thus be concluded on the basis of present knowledge that the distance between the tip of a leader channel at the instant when an upward streamer is initiated is, as a first approximation, practically the same whether that streamer originates from open ground or from a structure of ordinary height. (pp. 25-26).

Decades of work by Rakov and Uman affirm this position as well as does literature related to the recent Sago incident. Also, consider that the IEEE Standard 1410-2004 was directed towards high voltage transmission towers which typically exceed the ordinary height.

Now, consider the equation associated with Figure 6.4 for the "attractive area,"

$$
R=\sqrt{r_{s}^{2}\left(1-\beta^{2}\right)+2 \beta r_{s} h-h^{2}}
$$

where $r_{s}$ is the striking distance (as a function of peak discharge current) and $\beta$ is an empirical factor representing the ratio of the striking distance to target divided by the striking distance to ground, usually assigned a value of 0.9. The height is given by $h$ and, in this case, will represent the height of a borehole casing.

For conservative calculations, assume the peak stroke current, $I$, is $150-\mathrm{kA}$, a high value based on field readings taken on transmission lines as early as the 1930s. Note that these early studies indicated that stroke currents exceeding 50-kA were in the $80^{\text {th }}$ percentile (Pearce and Allen, 1937). This value is 15 times the 10-kA value used by Sacks and Novak in their simulations. The striking distance as a function of peak stroke current is calculated as

$$
r_{s}=10 I^{0.65}
$$

which, for a peak current of $I=15-\mathrm{kA}$ is $5,182 \mathrm{ft}$., or approximately 1 -mile. Thus, if the borehole casing is flush with the earth, Equation 6.3 becomes

$$
R=\sqrt{r_{s}^{2}\left(1-\beta^{2}\right)}
$$


Substituting the value for $r_{s}$ calculated earlier into Equation 6.4, and assuming the value of $\beta$ remains at 0.9 (indicating that the strike is close to the target), $R=2,259 \mathrm{ft}$., or about a half mile radius centered on the borehole.

Calculating the "attractive area,"

$$
A_{A}=\pi R^{2}
$$

then, provides for areas formed a uniform distance of approximately one-half mile around the boreholes. This is the approximate spacing assumed for exploratory drillholes. Although the electrogeometric model applies to high voltage transmission lines, the half-mile spacing generated for the probability analysis by Sacks and Novak coincides with that commonly used for exploration drillholes.

Referring to the "attractive area" concept based on the IEEE 1410-2004 equation, consider its application to structures other than those exceeding ordinary height. Sacks and Novak's suggestion is to recess the borehole casing so that it does not protrude above the ground surface but is instead buried below the surface. Applying the logic of Equation 6.2 for 25 -foot increments, results in a curve such as that of Figure 6.5.

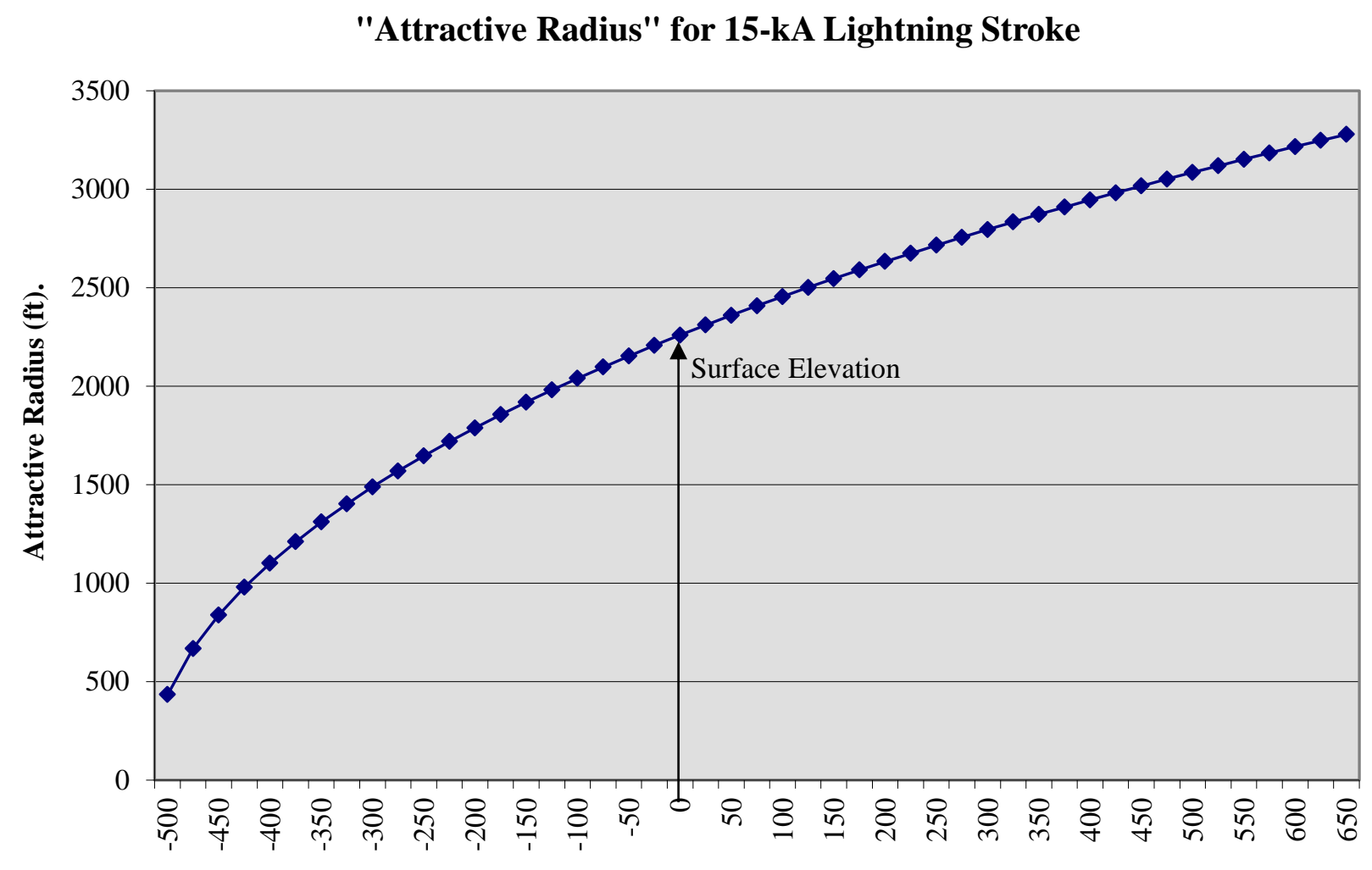

Height of Top of Borehole Casing (ft.)

Figure 6.5: "Attractive Radius" for lightning rod when analysis is performed underground. 
Using this reasoning the top of a borehole casing buried $500 \mathrm{ft}$. below the surface elevation is effectively causing an equivalent attractive radius. Clearly, this ignores the conductivity and other characteristics of the soil and overburden. Furthermore, it is highly probable that other underground and aboveground structures, such as pipelines in the former case and trees in the latter, would act as better channels for electricity than the borehole casing. Anecdotal evidence supports this (Rakov and Uman, 2003; Golde, 1975; Harrington et al., 1948; Leonard, 1945). Also, the Sacks and Novak study represents a steel-cased borehole of significant diameter. The drillhole communication link conductors considered in this research are solidly grouted in a smaller three-inch drillhole without a metallic casing.

As a final consideration, return to the aforementioned three-year study of lightning strikes to the Empire State Building. This study was conducted to better understand lightning strikes with the intention of being able to use this information for the protection of high-voltage transmission lines. Data gathered in New York was partially compared to data of lightning strikes that occurred in an, essentially, open field near General Electric's High-Voltage Engineering Laboratory at Pittsfield, Massachusetts. Additional field and lab data were also reviewed. Distillation of this and other studies were incorporated in development of IEEE 14102004 Standard. The words of McEachron (1939) are still valid:

Since the electrostatic field is along smooth curved lines, it is very evident that lightning, and sparks in general, do not follow the direction of the field. This is due to the fact that breakdown is not simultaneous over the length of the path, and the progressing streamer picks out the best path from instant to instant, resulting in the crooked path so familiar to one who studies lightning. This being so, it is not difficult to visualize why lightning does not always strike the highest object. In those cases where upward leaders determine the path, the stroke will presumably be from the highest point. However, in the case of downward leaders, the best path may not be the shortest path, and the attractiveness of one path over another may change even during the process of a multiple stroke (pp. 204205).

The summary of this observation, corroborated by Rakov and Uman, is that there is no guarantee that lightning would strike even a protective system installed with the object of "attracting" lightning away from a less desirable target, such as the drillhole communication link, nor a conventional steel encased borehole.

Thus it is asserted that, even if the simulations performed by Sacks and Novak were based on the IEEE assumptions for tall towers instead of for boreholes at lower elevations, the areas calculated using Equation 6.5 provids a radius roughly equivalent to the half-mile spacing of exploratory drillholes, so that their estimate of the probability of lightning strikes to, and in the vicinity of, boreholes can be applied.

In order to run the simulations, Sacks and Novak place an "offset electrode" of six-foot length at varying distances, $L$, from the borehole. Simulations are performed for two scenariosone with the borehole having a steel casing, and one without a steel casing. Presumably these scenarios are an attempt to simulate the phenomenon that was suggested at the Sago explosion (see Gates et al., 2007). 
Higgins and Morris (2006) used $80 \Omega \cdot \mathrm{m}$ for the soil resistivity, based upon field measured values at Sago. This is significantly less than the conservative values of 5,000, 10,000, and 20,000 $\Omega \cdot \mathrm{m}$ used by Sacks and Novak, whose worst case scenario is the case of a direct strike to a steel-cased borehole in soil of resistivity $20,000 \Omega \cdot \mathrm{m}$. In this case, the probability of a direct strike is once in just over a century (p. 422). Based on their curves, the probability of a direct strike propagating underground via a 1000-ft. steel-cased borehole through soil of resistivity $80 \Omega \cdot \mathrm{m}$ would be somewhere in the neighborhood of once in period exceeding 10,000 years. For the borehole communication link, the probability of a direct lightning strike would be, at worst, this frequent. The next section discusses the characteristics of grouted boreholes outfitted with wires, an arrangement that is, electrically, less conducive to lightning events than steel-cased installations irrespective of the probability that a lightning event actually occurs.

\subsubsection{Electrical Properties of Grout}

The grout material that has been traditionally applied in backfilling drillholes consists primarily of Portland cement. Investigation of the electrical properties of Portland cement compounds is of interest largely because of reinforced concrete which is used in many applications where electricity is present, such as in the construction of cableways or shafts, high voltage support structures, and anti-static flooring. Hansson and Hansson (1985) note that corrosion of steel in reinforced concrete, "is an electrochemical process in which the cement paste acts as the conducting electrolyte ....” (emphasis added by original authors, p. 201).

The migration of charges within Portland cement compounds has been studied by several researchers (for discussion, see three-part series by Chatterji, 1994). Germane to the drillhole communication link is the understanding that the Portland cement grout acts as electrolyte and, while not as conductive as a steel casing, it does not have the exact ground resistivity of most of the earth found east of the Mississippi River. The "slightly conductive" property of Portland cement-based substances, combined with its low expense and other factors, has led to research that seeks to decrease its resistivity for a variety of electronics applications (Wen and Chung, 2001). However, for the drillhole communication link, the desired perspective would be to increase the resistivity of the Portland cement grout at least to a value that would closely match the surrounding earth ground.

Historically, less research has addressed the electrical properties of "mature cementitious systems," those that have passed the majority of their hydration days (McCarter et al. 2000). The grout of the drillhole communication link would be classified as a mature system (> 1 year) as it is intended to be left in place for a long period of time and the curing properties are not of particular interest in this application. Furthermore, according to Hansson and Hansson, with the exception of very porous aggregate being used in very wet environmental conditions, it is the cement that carries the electrical current (p. 202). Thus, the subject of their studies, and the material of concern for the communication drillhole link, is the Portland cement.

From the perspective of uninsulated embedded wire, the grout itself is an insulator. During normal operation of the link, this is sufficient. Assume ground resistivity of $80 \Omega \cdot \mathrm{m}$, as 
determined in field measurements at Sago, (Higgins and Morris, 2006, p. 17). This value should be generally applicable in the region based on Keller (1967, p. 295). The conductivity of the ground, then, is the inverse, or $12.5 \times 10^{-3} \mathrm{mhos} / \mathrm{meter}$, compared to Type I/II Portland cement's conductivity of $14.4 \times 10^{-3}$ mhos/meter. Even allowing tolerance for error, these values are essentially the same, so that the grout in the drillhole is essentially the same material as the earth.

However, in the event of a direct lightning strike, what is the situation? First, an assumption is made that the embedded wires are likely of insufficient diameter to be of any concern for the conduction of lightning. Assume a 7 x 19 steel wire rope. At 3/32" inch each, their combined cross-sectional area is

$$
\mathrm{A}_{\text {wire }}=\pi *(3 / 32)^{2}=0.008151 \text { sq. inches }
$$

Meanwhile, the cross-sectional area of the drillhole, nominally, is

$$
\mathrm{A}_{\text {hole }}=\pi *(3 / 2)^{2}=7.065 \text { sq. inches }
$$

Thus, the percentage of area occupied by the wire is given by

$$
\%_{\text {wire }}=100 \% *\left(\mathrm{~A}_{\text {wire }} / \mathrm{A}_{\text {hole }}\right)=0.0977 \% \approx 0.1 \%
$$

For a No. $10 \mathrm{AWG}$ and No. $11 \mathrm{AWG}$, following the logic of Equations 6.6-6.8, this percentage is $0.115 \%$ and $0.091 \%$, respectively. However, insulated wire is also insulated from the grout and may introduce capacitive effects as well as providing a path for direct coupling to underground workings.

In the event of a direct lightning strike, even this small diameter would theoretically be able to withstand the associated thermal effects, with merely the possibility of side flashing occurring between the conductors so that, by the time the workings were reached, the conductors would theoretically be at the same potential relative to one another (for discussion of thermal effects, see Golde, 1975, 51-55).

While the leads may be connected to each other at the surface to further ensure that both wires remain at the same potential until such time as the communication circuit may need to be implemented, the phenomenon of side flashing between wires, combined with their separation distance at the elevation of the workings suggests that tying the wires together at the surface may be unnecessary, especially if the intention is to immediately connect into the mine phone system. As a comparison, note that 30 CFR Section 75.701-4 requires minimum A.W. G. No. 6 for ground connections. No. 6 wire has $298 \%$ more cross-section than $3 / 32$ " galvanized wire and $253 \%$ more cross-section than No. 10 AWG.

\subsection{Mining Regulations}

Some regulations have already been considered with regard to placement of drillholes and the drillhole communication link network. This section comprises those regulations, from MSHA or the State of West Virginia, that may be applicable to the drillhole communication link 
design and installation. Note that these regulations: (1) do not appear to prohibit installation of a communication link via an exploration borehole; and (2) do not address the plethora of outcomes which may result from a lightning strike at or near such an embedded surface-to-underground communication device.

According to 30 CFR 75.701-4, the capacity of ground wires, where grounding wires are used, is dictated by the size of the power wires involved. However, in the case of the communication drillhole link, there is no intention of carrying power. It is a communication path to be activated in the event of an emergency.

Under 30 CFR 75.702, "Methods other than grounding which provide no less effective protection may be permitted by the Secretary or his authorized representative." Most unused steel-cased boreholes are considered to be "grounded," despite suspicion that they behave as a conduit for lightning energy capable of methane-air ignition (Sacks and Novak, 2005; Novak and Fisher, 2001). Thus, the assumption that the grout acts as a bond to earth ground for the communications drillhole link should render it capable of being approved by MSHA. In this case, the drillhole communication link would be considered grounded under 30 CFR 75.521 considering the electrical properties of grout noted in Section 6.2.2.

The wires themselves, which would carry the communication signal, must be sized according to the maximum ampacity they are expected to carry per $30 \mathrm{CFR} 75.513,30 \mathrm{CFR}$ 75.513-1, and WV §22A-2-40. The 3/32" wire or No. 10 AWG copper is certainly capable of carrying 20 amps, much greater than any standard communication signals. Permissible mine phones usually draw no greater than 0.35 amps (Gai-Tronics, 2007) and sound-powered telephones less than this. Once these wires reach the mine, they must be insulated to the point where connection is made with the existing phone / communication system and these wires must be further insulated from any high voltage cables in the mine per 30 CFR 75.515-2 and WV $\S 22 \mathrm{~A}-2-42$.

The only regulations initially of concern are in WV §22A-2-42 (d) which requires says, in part, "Lightning arrestors shall be provided at the points where telephone circuits enter the mine" and the Code of Federal Regulations also requires this within 100 feet of the entry point. If the emergency-use drillhole communication link is considered to be a "telephone circuit," a variance from the State of West Virginia Office of Miners Health, Safety, and Training and the MSHA District Manager may be required. However, if insulated wires are used, lightning arrestors could more easily be incorporated if the link is directly connected into a larger system at the outset. This would be site specific.

Thus, although the regulations do not appear to preclude installation of a communication link via an exploration borehole, they also do not appear to fully address the hazards that may be created by such a unique assembly. 


\title{
Chapter 7 Summary, Conclusions, and Areas of Future Research
}

\begin{abstract}
Should an incident occur in which coal miners become trapped underground communication must be quickly established. While the expansion of existing communication systems, and adding redundant systems thereto, furthers this goal while also meeting legal requirements, doing so also adds cost to the mining operations which decreases overall reliability. Meanwhile, mine operators spend tens of thousands of dollars annually to drill exploration boreholes that are grouted once and abandoned once the cores are removed. These holes can be economically outfitted with conductors to provide a communication link between the surface and the underground workings, forming a latent network of connections that can either be independently activated, rapidly, in the event of an incident or selectively integrated with the mine's larger communication system.
\end{abstract}

The concept of using exploration boreholes as a potential path for surface-to-underground communications has been mentioned in the literature. However, the focus of earlier work has largely taken the orientation that such links must be connected into a comprehensive communication system that also has utility in management of daily mine operations. This perspective introduces both cost and complexity, the latter in turn reducing reliability of the overall system. Since the ultimate objective is the safety of the miners themselves, the research herein has taken the perspective that exploiting these exploration boreholes provides a costeffective alternative for establishing communication should the larger communication system become compromised.

While sensors in the exploration boreholes can provide an exact location for transcription to a mine map, a closed-form equation has also been developed to determine the probability of intersecting (planned) open workings, e.g. mains or submains, without such instrumentation. Thus, mine operators with favorable combinations of entry width and overburden, with good drill rig operators, may be able install several communication links without incurring additional costs. The surface locations of these boreholes/links would be a priori knowledge in the event of an incident and could be quickly located using classical surveying methods, even if weatherinduced disruptions preclude the use of global positioning systems.

The design of the communication link using the exploration boreholes is such that it does not substantially change the contemporary method of grouting the exploration borehole once the core is removed. The conductors are attached to a sacrificial wooden plug which is delivered to the bottom of the hole by the grout delivery pipe, and held in place by the grout as the pipe is retracted. The labor cost for this step would be insubstantial, as would be the addition of pigment to the first batch of grout mixed and placed in the borehole. An experiment indicates that the addition of blue pigment would make the grouted borehole easier to distinguish underground, even if the surrounding roof were covered with rock dust after mining. The pigment itself adds a cost of approximately $\$ 30$ per hole. 
Unlike prior research, or suggested research, into the use of boreholes for communication links, the research herein dispenses with the use of casings for the borehole itself. Instead, the embedment of the conductors makes the communication link in the borehole an integral part of its surroundings. In so doing, the workings are sealed from the surface so that water infiltration cannot happen. Additionally, the elimination of a metallic casing reduces hazards associated with lightning strikes coupling phenomena which may occur in the vicinity of the communication link. Statistically, the probability of lightning events striking the device as a specific target is rare, so that concern about such an occurrence may be overstated.

The conductor material is chosen to have enough tensile strength to resist breakage upon movement of the overburden but also be able to be cut in shear when the continuous miner cuts an entry through its location. Laboratory experiments were performed on several varieties of embedments, including wire rope, vinyl-coated wire rope, and THHN insulated copper wire. The results of these tests indicated that the insulated copper wire was most suitable for this application.

A second round of experiments was performed on two-, three-, and four-wire configurations of insulated copper wire to explore the likelihood of two bare wires making contact in the event of overburden shift. The results of this test must be approached with caution, as the five inch sample length was not sufficient to prevent degloving of the conductors and the conductors themselves experienced elongation. However, no significant differences were noted for the various configurations. Thus, it is recommended that any embedded conductors, beyond the first two that would be required for a common two-wire system, should be used as redundant paths or spares to increase the reliability of the connection.

While the latent network of communication links could be connected into a larger system, the recommendation is to maintain them as standalone links that could be activated in the event of an incident, using simple point-to-point technology such as the time-proven sound-powered telephone.

The cost of the communication links is, then, largely a function of the overburden depth and the choice of how many conductors are desired in the link itself. At current writing, a 500foot spool of THHN No. 10 AWG copper was available for around $\$ 100$. For example, then, a mine desiring a four-conductor communication link, and having 500-foot of overburden, could make each exploration borehole installation for under $\$ 500$ with minimal impact on labor.

After the aforementioned research, and based on the experiments of Section 4, the following describes the proposed design for the exploration borehole communication link device. Recall that proper surveying must be performed when choosing the location for the borehole so as to expect that, post-mining, open workings such as mains or submains will be intersected. Then, during grouting operations, four conductors of THHN insulated, No. 10 AWG copper wire would be dispatched into the hole as previously shown in Figure 3.18, attached to an anti-spin plug of the design depicted in Figure 4.1. As the grout delivery tube is retracted, the conductors would remain in place. Blue pigment should be added to the first "batch" of grout delivered to the hole to aid in recognition in the underground workings. A shortened example of this device is shown in Figure 7.1. 


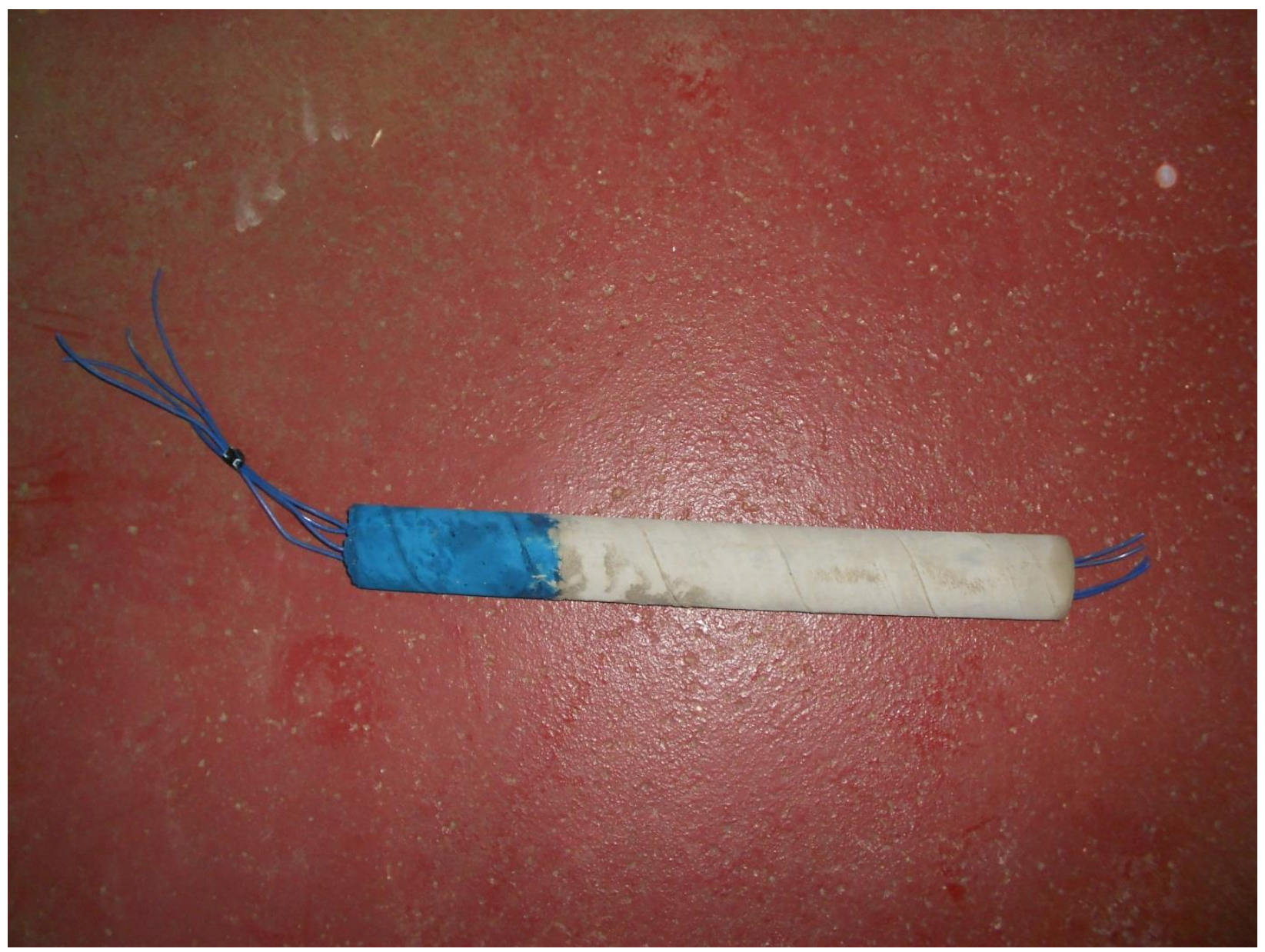

Figure 7.1: 36" Model of Borehole Communication Link with pigmented grout and four conductors.

It is fully acknowledged that a field test should be performed to test the viability of a communication link in an exploration borehole prior to implementation at any active mine site. The field test would need to encompass both the material selection and the ability to locate and then activate the link when required. In addition, an extensive study regarding the behavior of such a device in the presence of lightning is advocated despite a probability of a direct lightning strike occurring once every 10,000 years. Side flashing and indirect coupling of lightning energy to any borehole outfitted with metallic embedments could lead to an ignition of a methane-air mixture underground. This is true of any device that provides a conductive path to a mine and reinforces the position that electrical devices should be installed in intake air.

The research herein lays the groundwork for a field test of a communication link in an exploration borehole and encourages exploration of the possible effects of lightning to such a system. Two investigations are proposed. 
First, the borehole communication link design should be analyzed for its response to lightning. This would include: (1) modeling the possible scenarios using transmission line theory equations and/or other applicable modeling techniques; (2) a simulation study applying various input functions characteristic of lightning strikes, including the frequency ranges; (3) attempting a field verification with triggered lightning; (4) assessment of the likelihood of side flashing and direct coupling with small-sized conductors; (5) quantitative evaluation of the energy that would be delivered to the underground workings via the end of the conductors.

Second, pending results of the lightning hazard analysis, it is recommended to perform a proof of concept installation using several boreholes in a single mine. Note that MSHA, State, and mine approval would be required. The field test would explore following items: (1) the ability to accurately locate the borehole on the surface and underground; (2) assess the actual deviation of the drill rig for the particular mine location; (3) test the ability of the continuous miner to cut through the link and break the conductors in shear; (4) the ability to visibly locate the link in underground workings; and (5) the ability to establish communication from underground to the surface.

Exploiting exploration boreholes for emergency communication links remains an option. Should further research demonstrate that embedding conductors in the borehole grout does not create any unanticipated potential hazards from lightning strikes, the incorporation of such links into mine pre-planning is advocated. A latent network of selected boreholes, thus adapted, could provide essential communication with coal miners trapped inby a catastrophic event. 


\section{Bibliography}

Acker, W. L. III, 1974, Basic Procedures for Soil Sampling and Core Drilling, (Scranton, PA: Acker Drill Co., Inc.).

ASTM, 2010, Standard Specification for Pigments for Integrally Colored Concrete, C979/C979M-10.

ASTM, 2011, Standard Specification for Portland Cement, C150/C150M-11.

ASTM, 2008, Standard Test Method for Performing Laboratory Direct Shear Strength Tests of Rock Specimens Under Constant Normal Force, D5607-08.

ASTM, 2011, Standard Test Method for Splitting Tensile Strength of Cylindrical Concrete Specimens, C496/C496M-11.

Barlow, P. M., 1941, "Grounding Practices Must Be Responsive to Changes Introduced by Advent of Mechanized Mining," Coal Age, Vol. 46, No. 7, July, pp. 54-55, 94.

Bentley, T. L., T. Bower, R. Brazer, D. Kirkwood, and D. Steffey, "Report of Investigation, Underground Coal Mine, Inundation of Water Resulting in Entrapment of Miners, May 9, 2009, Alpha Natural Resources, Cobra Natural Resources, LLC, Mounainteer Alma A Mine, Warncliffe, Mingo County, West Virginia, ID No. 46-08730," (Arlington, VA: Mine Safety and Health Administration).

Bise, C. J., 2008, “The Integration of Mine Emergency Preparedness into Pre-Mine Planning and Development," unpublished manuscript.

Block, J. R., (ed.), 2002, All Nine Alive!, (Chicago, IL: Triumph Books).

Brady, E. P., G. R. Tinney, K. W. Wu, W. G. Denning, G. William, S.J. Michalek, R. T. Stoltz, J. F. Bowman, A. D. Carico, and H. C. Epperly, 2003, "Report of Investigation, Underground Coal Mine Nonfatal Entrapment, July 24, 2002, Quecreek \#1 Mine, ID No. 36-08746, Black Wolf Coal Company, Inc., Quecreek, Somerset County, Pennsylvania," (Arlington, VA: Mine Safety and Health Administration).

Bramão, I., F. Inácio, L. Faísca, A. Reis, and K. M. Petersson, Karl Magnus, 2011, "The Influence of Color Information on the Recognition of Color Diagnostic Objects," Journal of General Psychology, Vol. 138, No. 1, pp. 49-65.

Brooks, M., 2012, “Space Weather: Worse Than Hurricane Katrina,” New Scientist, Vol. 201, Issue 2700, pp. 31-35.

Brown, C. L., 1957, "Development of a Transistor-Type Telephone System for Mine Rescue Operations," U. S. Bureau of Mines, Report of Investigations 5318, (January). 
Chatterji, S., 1994, “Transportation of Ions Through Cement Based Materials. Part 1: Fundamental Equations and Basic Measurement Techniques," Cement and Concrete Research, Vol. 24, No. 5, pp. 907-912.

Chatterji, S., 1994, "Transportation of Ions Through Cement Based Materials. Part 2: Adaptation of the Fundamental Equations and Relevant Comments," Cement and Concrete Research, Vol. 24, No. 6, pp. 1010-1014.

Chatterji, S., 1994, "Transportation of Ions Through Cement Based Materials. Part 3: Experimental Evidence for the Basic Equations and Some Important Deductions," Cement and Concrete Research, Vol. 24, No. 7, pp. 1229-1236.

Civilett, J. A., 1942, "Lightning Damage Prevented by Using Proper Apparatus," Coal Age, Vol. 47, No. 11, (November), pp. 61-63.

Codified Federal Regulations, Title 30, Mineral Resources, Section 75, Underground Mining.

Conti, R. S., 2001., "Emerging Technologies: Aiding Responders in Mine Emergencies and During the Escape from Smoke-Filled Passageways," Proceedings of Northwest Mining Association's 107 ${ }^{\text {th }}$ Annual Meeting, (Spokane, WA, December 3-7): 1-14.

Davis, C., Portland Cement, 1948, (London: Concrete Publications Limited).

Dobroski, H., and J. Durkin, 1980, “An Overview of Bureau of Mines Communications Research," 1980, Proceedings of Fifth Annual WVU Conference on Coal Mine Electrotechnology, (Morgantown, WV, July 30-August 1): 24-1-15.

Dowding, C. H., M. B. Su, and K. O’Connor, 1986, “Choosing Coaxial Cable for TDR Monitoring."

Dynalec Corporation, 1986, “Sound-powered Telephone Systems," (Sodus, New York), 12 pp.

Edwards, R. W., 1955, "Improved Safety and Operating Efficiency with Sound-Powered Phones," Mining Engineering, Vol. 7, (December), pp. 1116-1118.

Femco Division, Gulton Industries, Inc., 1982, "Maintenance Manual for Permissible Loudspeaking Telephone 821301/202, AM702121” Publication 821301-02.1, (September).

Femco Division, Gulton Industries, Inc., 1983, "Maintenance Manual for Permissible Loudspeaking Telephone 821301/302, AM70212,” Publication 821301-02.7, (May).

Femco Division, Gulton Industries, Inc., 1983, "Maintenance Manual for Permissible Talkback Loudspeaking Telephone 821301/303, AM7022," Publication 821301-02.8, (June). 
Fiscor, S., 2011, "Miners Quickly Adopt New Communication Systems," Coal Age, Vol. 116, No. 1 (January): 30-36.

Forbes, J. J., F. E.Griffith, F. E.Cash, and M. S. Petersen, 1946, “Mine Rescue Life-Line Telephone Assemblies," U. S. Bureau of Mines, Report of Investigations 3875, (March).

Foster-Miller, Inc., 1983, “Development of Guidelines for Rescue Chambers, Vol. 1,” U. S. Bureau of Mines, Mining Research Contract Report, (October).

GAI-Tronics, A Hubbell Company, 2007, "Loudspeaking Telephone," Product Publication No. F930218B, (May).

GAI-Tronics, A Hubbell Company, n.d., "Mine Dial/Page Telephone," Product Publication No. 060601.

GAI-Tronics, A Hubbell Company, 2006, "Loudspeaking Telephone," Product Publication No. 42004-195E, (Mohnton, PA: GAI-Tronics Corporation, October).

Gary, Dale E., Lanzerotti, Louis J., Nita, Gelu M., and Thomson, David J., "Effects of Solar Radio Bursts on Wireless Systems," pp. 203-213 in Daglis, Ioannis A., ed. Effects of Space Weather on Technology Infrastructure, (Dordrecht: Kluwer Academic Publishers, 2003).

Gates, R. A., R. L. Phillips, J. E. Urosek, C. R. Stephan, R. T. Stoltz, D. J. Swentosky, G. W. Harris, J. R. O’Donnell, Jr., and R. A. Dresch, 2007, “Report of Investigation, Fatal Underground Coal Mine Explosion, January 2, 2006, Sago Mine, Wolf Run Mining Company, Tallmansville, Upshur County, West Virginia," (Arlington, VA: Mine Safety and Health Administration).

Golde, R. H., 1975, Lightning Protection, (New York: Chemical Publishing Company).

Jansky, J. H., 2009, "Mine Rescue Team Communication Systems," Joseph A. Holmes Safety Association Bulletin, (January/February), pp. 14-18.

Hansson, I. L. H., and C. M. Hansson, 1985, "Ion-Conduction in Cement-Based Materials," Cement and Concrete Research, Vol. 15, pp. 201-212.

Harrington, D., D. J. Parker, and L. H. Harrison, 1948, "Protection Against Lightning at Surface and Underground Mining Plants," U. S. Bureau of Mines, Information Circular 7447, (April).

Higgins, M. B. and M. E. Morris, 2006, "Measurement and Modeling of Transfer Functions for Lightning Coupling into the Sago Mine," (Albuquerque, New Mexico: Sandia National Laboratories, Report SAND2006-7976). 
Huntley, D. W., R. J. Painter, J. K. Oakes, D. R. Cavanaugh, and W. G. Denning, "Report of Investigation, Underground Coal Mine Fire, Wilberg Mine - I. D. No. 42-00080, Emery Mining Corporation, Orangeville, Emery County, Utah, December 19, 1984," (Arlington, VA: Mine Safety and Health Administration, 1985).

Hurley, T., 2006, “Minesite Avalanche-Some Lessons Learned,” Mining Engineering, (April), pp. 24-26.

Irion, R., 2011, “Something New Under the Sun,” Smithsonian, Vol. 42, No. 1, (April), pp. 4653.

Joy Mining Machinery, 2009, 14CM Series Continuous Miner Product Line, Bulletin No. CM790109.

Keller, G. V., 1967, "Supplementary Guide to the Literature on Electrical Properties of Rocks and Minerals" in Parkhomenko, E. I., Electrical Properties of Rocks, (New York, NY: Plenum Press).

Landua, H. L., 1977, “Coring Techniques and Applications,” in L. W. LeRoy and D. O. LeRoy, Subsurface Geology, $4^{\text {th }}$ Ed., (Golden, CO: Colorado School of Mines).

Leonard, G. K., 1945, "Lightning Strikes on the Job-In Apalachia Tunnel," Civil Engineering Vol. 15, No. 12, (December), pp. 545-547.

Manual on Drilling, Sampling, and Analysis of Coal,1992, ASTM Manual Series MNL 11, (Ann Arbor, MI: ASTM).

McAteer, J. D., T. N. Bethell, C. Monforton, J. W. Pavlovich, D. Roberts, Deborah, and B. Spence, 2009, "The Sago Mine Disaster: A Preliminary Report to Governor Joe Manchin III," (Buckhannon, WV: J. Davitt McAteer \& Associates, July).

McCarter, W. J., G. Starrs, and T. M. Chrisp, 2000, "Electrical Conductivity, Diffusion, and Permeability of Portland Cement-Based Mortars," Cement and Concrete Research, Vol. 30, pp. 1395-1400.

McEachron, K. B., 1939, "Lightning to the Empire State Building," Journal of the Franklin Institute, Vol. 227, pp. 149-217.

Miller, T. L., W. S. Vilcheck and R. L. Reynolds, 1980, "The Application of Fiber Optics to Coal Mine Telephone Pager Systems," Mine Electrical Systems Division, 1980, Proceedings of Fifth Annual WVU Conference on Coal Mine Electrotechnology, (Morgantown, WV, July 30August 1): 29-1-7.

Mine Improvement and Emergency Response Act of 2006 (MINER Act), 2006, PL 109-236 (S 2803), (15 June). 
Molinda, G., C. Mark, and D. Dolinar, 2000, “Assessing Coal Mine Roof Stability Through Roof Fall Analysis,” pp. 53-72. In: New Technology for Coal Mine Roof Support, NIOSH Information Circular 9453 (October).

MSHA, 2009, “Questions and Answers on MSHA's Program Policy Letter (PPL) (P09-V-01) on Compliance with Post-Accident Two-Way Communications and Electronic Tracking Requirements of the Mine Improvement and New Emergency Response Act (MINER Act), (29 April), 5 pp.

Murphy, J. N. and H. E. Parkinson, 1978, "Underground Mine Communications," Proceedings of the IEEE, Vol. 66, No. 1, (January).

Nagai, J. and K. Yokosawa, 2003, "What Regulates the Surface Color Effect in Object Recognition: Color Diagnosticity or Category?," Technical Report on Attention and Cognition, No. 28.

Neeugebauer, W., 1987, "Lightning and Surge Protection," in Standard Handboodk for Electrical Engineers $12^{\text {th }}$ Ed., Donald G. Fink and H. Wayne Beaty, eds., (New York: McGraw-Hill).

National Electrical Code, 1996, 1995, (Quincy, MA: National Fire Protection Association).

Novak, T., and Fisher, T. J., 2001, "Lightning Propogation Through the Earth and Its Potential for Methane Ignitions in Abandoned Areas of Underground Coal Mines," IEEE Transactions on Industry Applications, Vol. 37, No. 6, (November / December), pp. 1555-1562.

Parkinson, H., "Communication Systems Research at Bruceton Mine," 1972, Proceedings of First Annual WVU Conference on Coal Mine Electrotechnology, (Morgantown, WV, August 24): VI-1-10.

Paulos, J. A., Innumeracy, 1988, (New York, NY: Hill and Wang).

Pearce, C. T. and R. C. Allen, 1937, "Lightning Dangers to Coal Mine Distribution Systems Minimized by Protective Devices," Coal Age, Vol. 42, No. 9, (September), pp. 59-60, and No. 10 (October), pp. 55-58.

Portland Cement Association, 1951, "Mineral Pigments for Use in Coloring Concrete," (Skokie, IL: Portland Cement Association), 2 pp.

Rakov, V. A., and M. A. Uman, 2003, Lightning, Physics and Effects, (Cambridge, UK: Cambridge University Press).

Rao, N., 1994, Elements of Engineering Electromagnetics, $4^{\text {th }}$ Ed., (Englewood Cliffs, NJ: Prentice-Hall).

Richart, F. W., 1942, "How Lightning and Surges Can Be Rendered Innocuous by Two Sets of Arresters Working in Tune," Coal Age, Vol. 47, No. 5, (May), pp. 51, 54-55. 
Rodger, C. J., P. T. Verronen, M. A. Clilverd, A. Seppälä, and E. Turunen, 2008, “Atmospheric Impact of the Carrington Event Solar Protons," Journal of Geophysical Research, Vol. 113, pp. $1-13$.

Ross, S. M., 2000, Introduction to Probability Models, $7^{\text {th }}$ Edition, (San Diego, CA: Academic Press).

Sacks, H. K., 1978, “Electromagnetic Technique for Locating Boreholes,” U. S. Bureau of Mines, Information Circular 8302.

Sacks, H. K., and T. Novak, 2005, "Corona-Discharge-Initiated Mine Explosions," IEEE Transactions on Industry Applications, Vol.41, No. 5, (September / October), pp. 1316-1361.

Sacks, H. K., and T. Novak, 2008, "A Method for Estimating the Probability of Lightning Causing a Methane Ignition in an Underground Mine," IEEE Transactions on Industry Applications, Vol. 44, No. 2, (March / April), pp. 418-423.

Sadiku, M. N. O., 1989, Elements of Electromagnetics, (Fort Worth, TX: Saunders College Publishing).

Santa Cruz Sentinel, 1907, “S. P. to Replace Iron Lines with Copper,” (23 April), p. 5.

Smith, W. F., 1990, Principles of Materials Science and Engineering, $2^{\text {nd }}$ Ed., (New York, NY: McGraw-Hill, Inc.).

Standard for Fire Prevention and Control in Coal Mines, 2010 Edition, NFPA Standard 120, 2011, (Quincy, MA: National Fire Protection Association).

Staff, U. S. Bureau of Mines, 1984, "Underground Mine Communications, Control and Monitoring,” U. S. Bureau of Mines, Information Circular 8955.

Stricklin, K., and M. Skiles, 2009, Program Policy Letter No. P09-V-01, “Guidance for Compliance with Post-Accident Two-Way Communications and Electronic Tracking Requirements of the Mine Improvement and New Emergency Response Act (MINER Act)," (16 January), 10 pages.

Structural Behavior Engineering Laboratories, Inc., n.d., Operating Instructions, Model RM101 Direct Shear Machine, (Phoenix, AZ).

Supplemental Mine Improvement and New Emergency Response Act of 2007 (S-MINER Act), 2007, H.R. 2768, $110^{\text {th }}$ Congress.

Tanaka, J. W. and L. M. Presnell, 1999, “Color Diagnosticity in Object Recognition,” Perception and Psychophysics, Vol. 61, No. 6, pp. 1140-1153. 
Tesche, F. M., M. V. Ianoz, and T. Karlsson, 1997, EMC Analysis Methods and Computational Models, (New York, NY: John Wiley \& Sons, Inc.).

Uman, M. A., and V. A. Rakov, 2002, “A Critical Review of Nonconventional Approaches to Lightning Protection," American Meteorological Society, Vol. 83, No. 12, (December), pp. 1809-1820.

Walsh, G. W., 1973, “A Review of Lightning Protection and Grounding Practices,” IEEE Transactions on Industry Applications, Vol. 1A-9, No. 2, (March / April), pp. 133-148.

Ward, Jr., K., 2010a, "Miner Safety Equipment; Four Years After Sago, Few Mines Have Texting Device," Charleston [West Virginia] Gazette, (21 March), p. 1A.

Ward, Jr., K., 2010b, “Mine Safety; Joe Main: I'm Not Happy; More Work Needed on Mine Communications, MSHA's Chief Asserts," Charleston [West Virginia] Gazette, (26 March), p. $1 \mathrm{C}$.

Warner, J., 2004, Practical Handbook of Grouting, (Hoboken, NJ: John Wiley \& Sons).

Wen, S., and D. D. L. Chung, 2001, “Cement-Based Controlled Electrical Resistivity Materials," Journal of Electronic Materials, Vol. 30, No. 11, pp. 1448-1451.

West Virginia, State of, 2008, Underground Mining Laws, Rules and Regulations, 2008 Field Reference Edition, (Charleston, WV: Office of Miners' Health, Safety \& Training).

Workman, E. J., 1967, “The Production of Thunderstorm Electricity," Journal of the Franklin Institute, Vol. 283, pp. 540-557.

Wurm, L. H., G. E. Legge, L. M. Isenberg, and A. Luebker, 1993, “Color Improves Object Recognition in Normal and Low Vision," Experimental Psychology: Perception and Performance, Vol. 19, No.4, pp. 899-911. 


\section{Appendix A: Data Tables from Shear Load Tests}

Table A-1: Experimental Data from Shear Testing for Material Selection

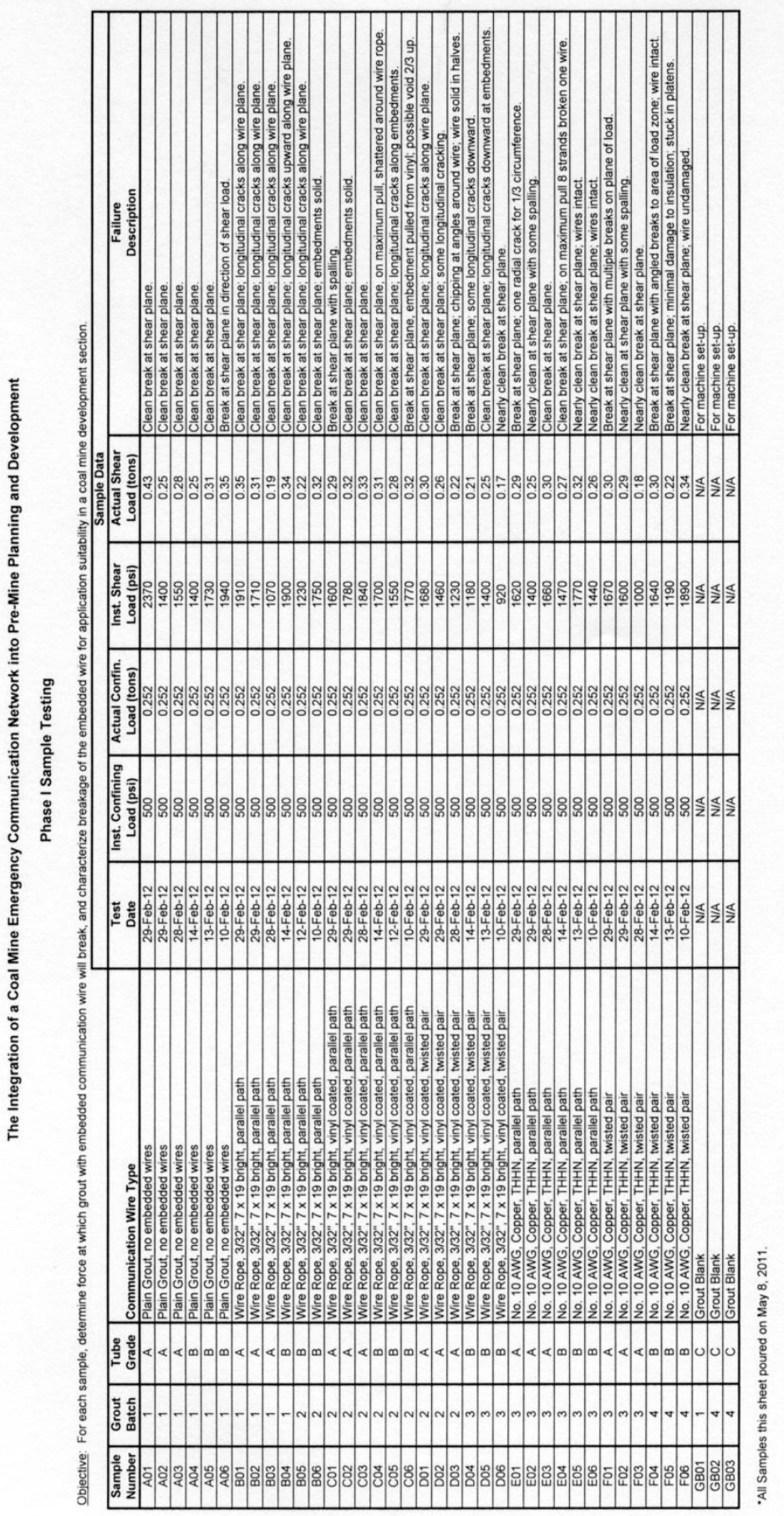


Table A-2: : Experimental Data from Shear Testing for Configuration Evaluation

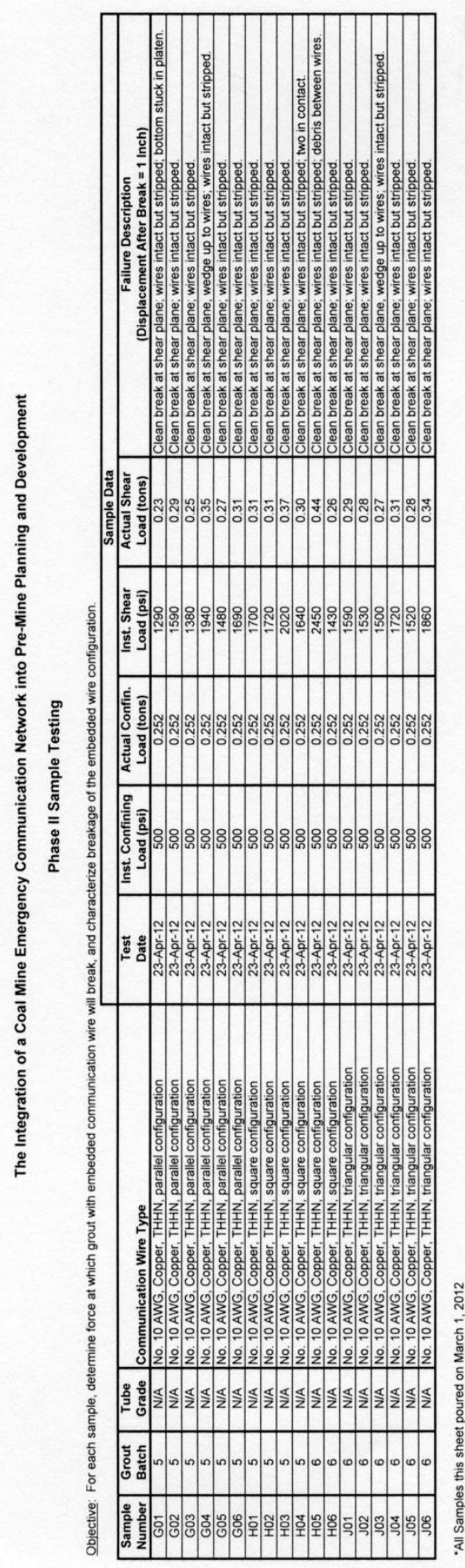




\section{Appendix B: Instructions for Borehole Grout Pigment Experiment}

\section{Description}

After core samples are taken, exploration boreholes are filled with grout. Mine development then proceeds underground. When a continuous miner cuts through a grouted borehole, it is usually evident. However, after the entries have progressed, the location of these boreholes becomes less obvious.

This experiment investigates the possibility of adding pigment to the grout in order to increase recognition of the borehole locations from underground entries.

There are two models in a darkened room. Both represent the roof of a coal mine-one is black to simulate coal, or dark, top. The other is white to simulate a rock-dusted, or light, top.

\section{$\underline{\text { Instructions }}$}

1) Walk into the darkened room with the flashlight and shine on the first (right side) model and answer the following two questions:

Which color did you notice first?

If you knew you were looking for it, which color do you think would be easiest to see?

2) Move to the second model (left side) with the flashlight and shine on the second model and answer the same two questions:

Which color did you notice first?

If you knew you were looking for it, which color do you think would be easiest to see?

\section{Debriefing}

Please do not discuss your evaluation nor the experimental set-up with anyone until after the experiment has been completed (4:00 p.m. today).

Data will be aggregated and summarized. This data will then be posted in MRB 233 so that you may see the results of the experiment. If you have any questions or comments about the experiment, please share them.

Thank you. 


\section{Appendix C: Grout Pigment Experiment Data}

Table C-1: Raw Data Collected for Borehole Grout Pigment Experiment

\section{Samples Included in Analysis}

\begin{tabular}{ccc} 
Respondent & \multicolumn{2}{c}{ Dark Background } \\
\cline { 1 - 3 } & First (1) & Easiest (2) \\
\cline { 2 - 3 } 2 & Blue & Green \\
3 & Plain & Green \\
4 & Blue & Blue \\
5 & Plain & Plain \\
6 & Blue & Blue \\
7 & Green & Blue \\
8 & Blue & Blue \\
9 & Green & Blue \\
10 & Blue & Blue \\
11 & Green & Plain \\
12 & Blue & Blue \\
13 & Green & Green \\
14 & Green & Blue \\
15 & Blue & Blue \\
16 & Plain & Blue \\
17 & Blue & Blue \\
18 & Blue & Blue \\
19 & Blue & Blue \\
20 & Blue & Blue \\
21 & Blue & Blue \\
22 & Blue & Blue \\
23 & Green & Green \\
24 & Blue & Blue \\
25 & Green & Green \\
26 & Green & Blue \\
27 & Blue & Blue \\
28 & Blue & Blue \\
30 & Green & Blue \\
31 & Plain & Blue \\
33 & Blue & Blue \\
34 & Blue & Blue \\
36 & Green & Green \\
37 & Green & Green \\
& Blue & Blue
\end{tabular}

\section{Light Background}

\begin{tabular}{cc} 
First (3) & Easiest (4) \\
\hline Blue & Green \\
Blue & Blue \\
Blue & Blue \\
Plain & Green \\
Blue & Blue \\
Blue & Blue \\
Blue & Blue \\
Green & Green \\
Blue & Blue \\
Plain & Plain \\
Plain & Blue \\
Plain & Plain \\
Plain & Plain \\
Blue & Blue \\
Blue & Blue \\
Blue & Blue \\
Blue & Blue \\
Blue & Blue \\
Blue & Blue \\
Blue & Blue \\
Blue & Blue \\
Plain & Blue \\
Blue & Blue \\
Blue & Blue \\
Blue & Blue \\
Green & Blue \\
Blue & Blue \\
Blue & Blue \\
Blue & Green \\
Blue & Blue \\
Blue & Blue \\
Blue & Blue \\
Blue & Blue \\
Blue & Blue
\end{tabular}

Samples Removed from Analysis

$\begin{array}{lcccc}29 & \text { Black } & \text { Green } & \text { White } & \text { Blue } \\ 32 & \text { Blue } & \text { White or Red } & \text { Blue } & \text { Red or Black } \\ 35 & \text { Blue } & \text { Blue } & & \end{array}$

Notes

$6 \quad$ (1) Identified green as "light blue." (4) Red should be an option on white.

15 (2) Distinct compared to other colors underground. (4) Easier to see with rockdust.

24 (2) There are not many natural rocks with that color shade. (4) It contrasts with white

35 (3) \& (4) They all looked the same. 
This Page Intentionally Left Blank 